\title{
Cholesterol Diet-Associated Changes in the Hippocampus - A Prelude to Alzheimer's Disease?
}

\author{
Sylwia W. Brooks
}

Follow this and additional works at: https://researchrepository.wvu.edu/etd

\section{Recommended Citation}

Brooks, Sylwia W., "Cholesterol Diet-Associated Changes in the Hippocampus - A Prelude to Alzheimer's Disease?" (2016). Graduate Theses, Dissertations, and Problem Reports. 5262.

https://researchrepository.wvu.edu/etd/5262

This Dissertation is protected by copyright and/or related rights. It has been brought to you by the The Research Repository @ WVU with permission from the rights-holder(s). You are free to use this Dissertation in any way that is permitted by the copyright and related rights legislation that applies to your use. For other uses you must obtain permission from the rights-holder(s) directly, unless additional rights are indicated by a Creative Commons license in the record and/ or on the work itself. This Dissertation has been accepted for inclusion in WVU Graduate Theses, Dissertations, and Problem Reports collection by an authorized administrator of The Research Repository @ WVU.

For more information, please contact researchrepository@mail.wvu.edu. 


\title{
Cholesterol diet-associated changes in the hippocampus - a prelude to \\ Alzheimer's disease?
}

\author{
Sylwia W. Brooks
}

Dissertation submitted to the School of Medicine at West Virginia University in partial fulfillment of the requirements for the degree of Doctor of Philosophy in Neuroscience

\author{
Bernard G. Schreurs, Ph.D., Chair \\ David P. Siderovski, Ph.D. \\ James W. Simpkins, Ph.D. \\ Gregory W. Konat, Ph.D. \\ Albert S. Berrebi, Ph.D.
}

Department of Neurobiology and Anatomy

Morgantown, West Virginia

2016

Keywords: AD, cholesterol, cholesterol-fed rabbit, estrogen receptors, ER $\alpha, E R \beta, 27-$ hydroxycholesterol, mitochondria, oxysterol, PSD-95, synapse

Copyright 2016 Sylwia W. Brooks 


\section{Abstract \\ Cholesterol diet-associated changes in the hippocampus - a prelude to Alzheimer's disease?}

\section{Sylwia W. Brooks}

High serum cholesterol levels in midlife have been associated with an increased risk of developing Alzheimer's disease $(A D)$ later in life. This thesis investigates a possible mechanism linking dietary cholesterol, which cannot pass the blood brain barrier, and AD-like hippocampal neuropathology. The first study tested the hypothesis that a high cholesterol diet increases the flux of the cholesterol metabolite 27hydroxycholesterol (27-OHC) into the hippocampus. We found that a high-cholesterol diet increased levels of $27-\mathrm{OHC}$, a biologically active circulatory breakdown product of cholesterol, in hippocampal tissue. $27-\mathrm{OHC}$ has been identified as an endogenous selective estrogen receptor modulator (SERM) that affects estrogen signaling pathways in a tissue-dependent manner. Estrogen-mediated non-reproductive functions require estrogen receptors (ERs) and include modulation of mitochondrial function and structure, as well as regulation of synaptogenesis in the brain. In the second study we hypothesized that the expression of ER's in hippocampus will change following a highcholesterol diet and that estrogen-dependent neuroprotection will be compromised. We found that the high-cholesterol diet and resulting increase of $27-\mathrm{OHC}$ in the brain were associated with changes in the expression of ER's, decreased mitochondrial content and synaptic densities as well as increased neuronal degeneration in the hippocampus. In the third study we assessed the correlations between the levels of 27-OHC and ER expression and we found that high $27-\mathrm{OHC}$ levels in the hippocampus are positively correlated with levels of ER $\beta$ and negatively correlated with expression of mitochondrial 
protein. We also found a positive correlation between PSD-95, a synaptic marker, levels and performance on a memory test, and a negative correlation between ER $\beta$ expression and mitochondrial protein levels. This suggests that $27-\mathrm{OHC}$ might be a molecule that modulates ER signaling and results in loss of estrogen-related neuroprotection. 
I dedicate this work to my grandmother Helena.

"Memory is all we are. Moments and feelings, captured in amber, strung on filaments of reason. Take a man's memories and you take all of him. Chip away a memory at a time and you destroy him as surely as if you hammered nail after nail through his skull."

— Mark Lawrence, King of Thorns 


\section{ACKNOWLEDGMENTS}

There are many people I would like to thank for their support and contributions to this project. First and foremost, I would like to thank my advisor Dr. Bernard G. Schreurs, for his patience, guidance and trust he bestowed upon me as a young scientist as well as reading and editing all my manuscripts and patiently correcting my "ponglish". His passion and never-ending scientific curiosity as well as his commitment to traditional education made him a mentor that helped me develop not only as a scientist but also as a person.

I also wish to thank my committee members Drs. Albert Berrebi and Gregory Konat that have been with me from the beginning and Drs. James Simpkins and David Siderovski for stepping in when I needed their help. I am tremendously grateful for the guidance in my graduate training and support they have offered for the last 5 years.

A special thank you to Dr. Lauren B. Burhans for countless hours she spent training me in all aspects of the lab's daily operations from behavioral setup to stereotaxic surgeries, for reading all my manuscripts and listening to all my ideas, for being a true mentor as well as an amazing friend.

Importantly none of this would be possible without the help of a group of people known as The Schreurs' Lab who collected behavioral data and the tissue for this project. Thanks to Jimena Gonzalez-Joekes for her help with histological methods development and Desheng Wang for help with all aspects of brain sectioning and various staining methods. Thanks also to Carrie Smith-Bell and Roger Bell for assisting with orders and supplies and Deidre O'Dell, the newest member of the lab, for bringing a fresh dose of enthusiasm.

I would also like to thank Dr. Ava Dykes from NIOSH for help with protein assays and EM sample preparation training, Richard Barkley from Zeiss for help with all technical aspects of working with the EM, Dr. Thomas J. Nelson for help with HPLC-MS method development and Dr. Chol Lim for showing me how to do western blotting.

Likewise I am grateful for many friendships that began in the trenches of my graduate education; I would like to thank my fellow students and faculty for their support and encouragement.

Finally, I am grateful for my loving and supportive family. I am thankful for my grandmother Helena who raised me to be the person I am today, my mother who is always supportive of my decisions, my brothers who always have my back and their kids Julia, Dawid and Kornelia whose innate curiosity is inspiring. Last but not least I would like to thank my husband Justin for his unconditional love and encouragement, his parents - Debbie and Carson, his brother Josh and his wife Sarah who always believed in me and cheered me on.

To all of you: thank you. 
Table of Contents

Dedication. .iv

Acknowledgements.

..v

Table of Contents

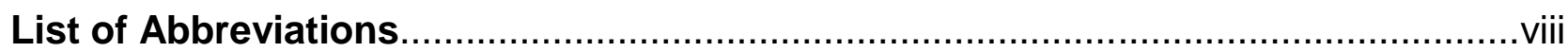

Chapter 1: Introduction

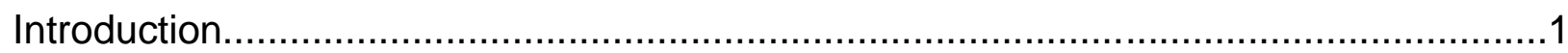

Chapter 2: Objectives and Rationale

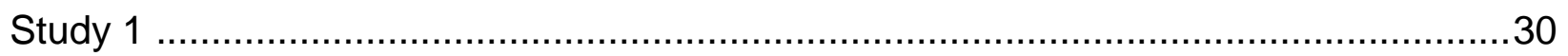

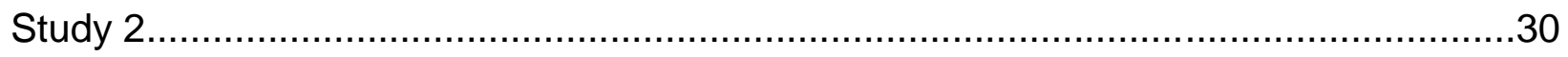

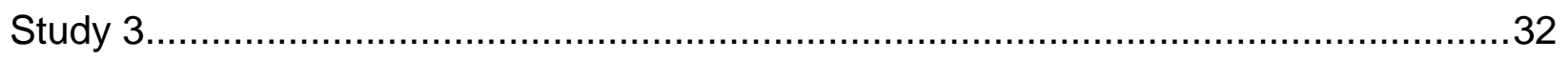

Chapter 3: Measurement of 27-hydroxycholesterol in the hippocampus

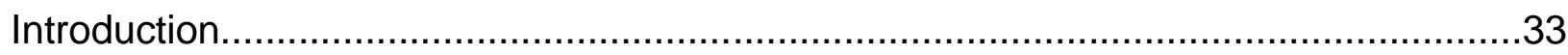

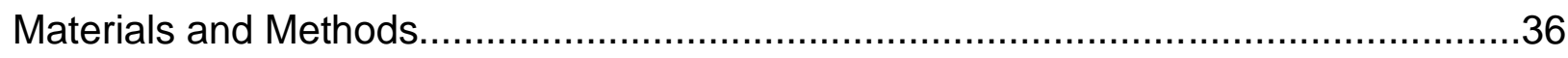

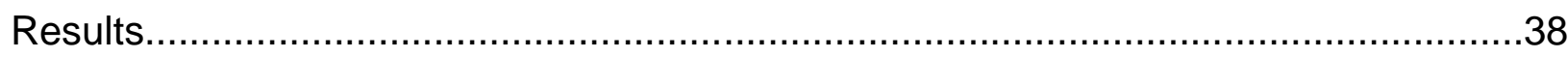

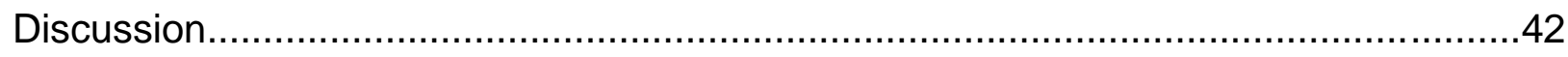

Chapter 4: 27-hydroxycholesterol effects on estrogen receptor signaling and estrogen receptor pathway downstream targets 


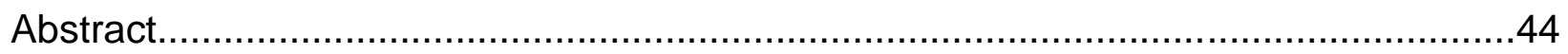

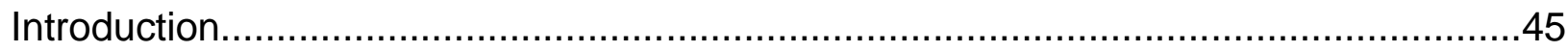

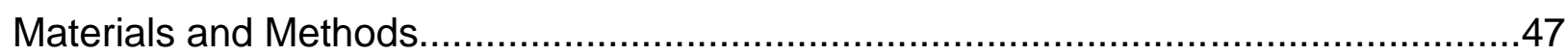

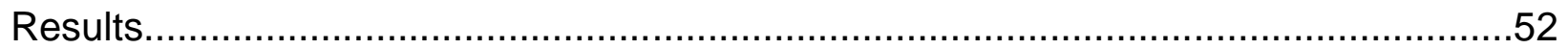

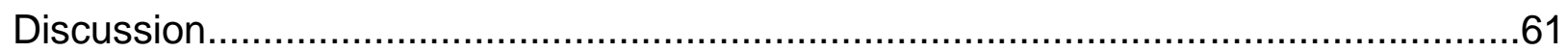

Chapter 5: Additional data supporting negative effects of high-cholesterol diet on hippocampus.

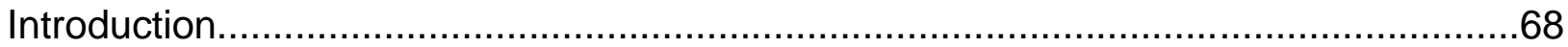

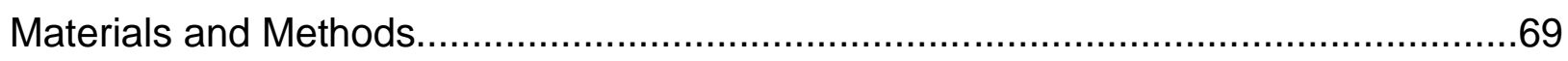

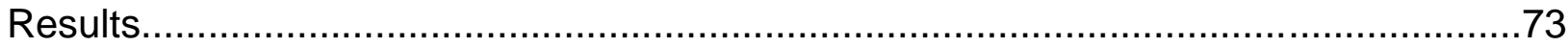

Chapter 6: General Discussion

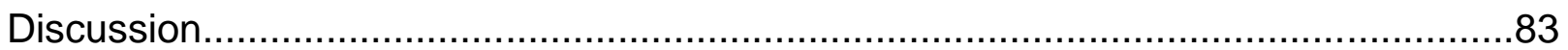




\section{List of Abbreviations}

24-OHC 24(S)-hydroxycholesterol

24-OHC 24-hydroxycholesterol

27-OHC 27-hydroxycholesterol

ABCA1 ATP-binding cassette transporter 1

ACAT1 acyl CoA:cholesterol acyltransferase 1

AD Alzheimer's disease

AKT protein kinase $B$

$\mathrm{APCl} \quad$ Atmospheric Pressure Chemical Ionization

APOE Apolipoprotein E

APP amyloid precursor protein

APPI Atmospheric Pressure Photoionization

$A \beta \quad$ amyloid-beta peptide

BACE1 $\beta$-site APP cleaving enzyme 1 ( $\beta$-secretase)

BBB blood brain barrier

CNS central nervous system 
CR conditioned response

CS conditioned stimulus

CSF cerebrospinal fluid

ER estrogen receptor

ERa estrogen receptor alpha

ER $\beta \quad$ estrogen receptor beta

ERK extracellular signal-regulated kinase

ESI Electrospray lonization

GPER1 G protein-coupled estrogen receptor 1

IDE insulin-degrading enzyme

IGF1 insulin-like growth factor 1

IGF1R insulin-like growth factor 1 receptor

LC-MS Liquid Chromatography- Mass Spectrometry

LIMK1 Lim kinase 1

LLE liquid-liquid-extraction

LRP-1 lipoprotein receptor-related protein 
LTP long-term potentiation

LXR liver-X-receptor

$\mathrm{MCl} \quad$ mild cognitive impairment

mTOR mammalian target of rapamycin

NFT neurofibrillary tangles

NM nictitating membrane

PI3K phosphoinositol-3 kinase

RROS Rush Religious Orders study

SERM selective estrogen receptor modulator

SIM selected ion monitoring

UR unconditioned response

US unconditioned stimulus 
Chapter 1: Introduction 


\section{Alzheimer's disease: An overview}

In 1906, psychiatrist Alois Alzheimer reported a case of unusual psychiatric illness in a patient and presented the pathological observations from her brain autopsy at a conference of the Southwest German Psychiatrists and Neurologists (Foley, 2010). 51-year-old Auguste Deter was a patient at the Frankfurt Asylum and presented with strange behavioral symptoms and memory loss. After her death, Alzheimer examined her brain and found amyloid plaques and neurofibrillary tangles. He published these findings in 1907 in Allgemeine Zeitschrift für Psychiatrie, and his work has been translated into English many times since (Jarvik and Greenson, 1987; Hurley and Wells, 1999; Strassnig and Ganguli, 2005). Alzheimer's patient suffered from an early onset disease, and consequently, in the decades that followed the term Alzheimer's disease (AD) was used to describe presenile dementia affecting middle-aged individuals. In 1964, Kay and colleagues reported the same neuropathological findings in elderly patients with senile dementia (Kay et al., 1964). Today two broad categories are used when classifying $A D$ : early-onset (presenile) and late-onset (senile) AD. In late-onset $A D$, the first signs of cognitive demise generally occur after age 65 , and this form accounts for approximately $95 \%$ of cases. Early onset AD involves about $5 \%$ of cases and affects individuals who develop symptoms earlier in life and who may have a family history of dementia. About $50 \%$ of these cases are associated with genetic mutations in the presenilin-1, presenilin-2 or amyloid precursor protein (APP) gene. In the remaining cases of early onset $A D$, specific mutations have not yet been described. 
As the population of Western countries ages, dementia is becoming a major epidemiological concern. Brain abnormalities found in elderly individuals are usually associated with more than one type of dementia such as vascular dementia and Alzheimer's disease combined (Schneider et al., 2007; Schneider et al., 2009; Viswanathan et al., 2009). The term dementia describes a variety of conditions where injury and/or death of neurons causes cognitive demise in a patient. AD is the most common form of dementia, and it is the sixth leading cause of death in older Americans (Minino et al., 2011). Early symptoms such as memory loss and spatial orientation problems advance to difficulties with speech and sensorimotor functions. AD can be diagnosed with absolute certainty only post mortem when microscopic examination of brain tissue reveals intracellular and extracellular amyloid deposits often in the form of senile plaques, and intracellular neurofibrillary tangles (NFT) composed of hyperphosphorylated tau protein. Since the NFTs are also found in other conditions such as Niemann Pick disease, accumulation of amyloid-beta peptide (A $\beta)$ is a major hallmark of AD. Interestingly, Alzheimer wrote: "...the plaques are not the cause of senile dementia but only an accompanying feature of senile involution of the central nervous system." (Davis and Chisholm, 1999).

The amyloid hypothesis postulates that AD begins with abnormal processing of APP (Hardy and Selkoe, 2002; Tanzi and Bertram, 2005). The physiological purpose of APP includes functioning in synaptic formation and repair (Priller et al., 2006). APP is expressed early in development and differential processing of APP by its secretases appears to regulate human embryonic stem cell proliferation and differentiation into neural precursor cells (Porayette et al., 2009). Transgenic mice lacking APP do not 
exhibit neuronal loss but present with serious memory deficits and changes in synaptic plasticity in the form of impaired long-term potentiation (LTP) (Phinney et al., 1999). Interestingly, mice overexpressing APP exhibit impaired LTP as well (Matsuyama et al., 2007) indicating the importance of APP processing homeostasis in synaptic correlates of learning and memory processes.

Over the last two decades, numerous risk factors contributing to AD development and progression have been proposed. These include diabetes mellitus, hypertension, atherosclerosis and hypercholesterolemia (Panza et al., 2010). Obese individuals with high blood pressure and high cholesterol are six times more likely to develop $A D$ (Luchsinger and Gustafson, 2009). High plasma cholesterol in midlife is associated with increased risk of AD (Notkola et al., 1998; Kivipelto et al., 2001a; Kivipelto et al., 2001b; Kivipelto et al., 2002; Solomon et al., 2009b). Consumption of a fatty diet rich in cholesterol causes atherosclerosis, dyslipidemia, blood-brain barrier dysfunction, inflammation and oxidative stress (Kalmijn et al., 1997; Grant, 1999; Luzzi et al., 2010). Oxidative stress is a phenomenon seen in many disorders, and the brain seems to be particularly vulnerable due to its high oxygen consumption. $A \beta$ has been shown to contribute to oxidative stress while reacting with transition metal ions such as $\mathrm{Cu}^{2+}$ and $\mathrm{Zn}^{2+}$ found in senile plaques (Bush and Tanzi, 2008). A connection between cholesterol and $A \beta$ aggregation in an animal model was first shown in rabbits (Sparks et al., 1994) but the mechanism connecting cholesterol to $A \beta$ pathogenesis in $A D$ has yet to be determined. 
The role of cholesterol in physiological functioning and $A D$

Cholesterol is a vital factor in the homeostasis of an organism. It is a critical component of cell membranes, a precursor to all steroid hormones as well as vitamin $\mathrm{D}$, and it is necessary for synaptogenesis, making it essential for learning and memory. Middle-aged women with high cholesterol levels performed better on memory tests than matched controls (Henderson et al., 2003); moreover, the same pattern was seen when performance on memory tests and lipid levels were correlated in a cohort of elderly individuals (West et al., 2008). Electrophysiological recordings from hippocampal neurons of rabbits fed a diet rich in cholesterol showed changes in neuronal membrane properties such as shortened duration of action potentials with decreased falling phase and reduced after-hyperpolarization phase (Wang and Schreurs, 2010) that has been correlated with enhanced learning (Disterhoft et al., 1996). In animal studies, a high cholesterol diet may enhance memory formation (Schreurs, 2003; Schreurs et al., 2007a; Schreurs et al., 2007b), but more importantly, a high cholesterol diet negatively affects a previously learned memory (Darwish et al., 2010; Schreurs et al., 2013b).

Cholesterol cannot cross the blood brain barrier (BBB) although almost $25 \%$ of the body's total unesterified cholesterol is found within the central nervous system (CNS). The majority of the brain's cholesterol is found in myelin that facilitates the transmission of electrical signals through the axons. In the CNS, cholesterol is almost entirely derived from de novo synthesis in neurons during development and glial cells in the mature brain (Dietschy and Turley, 2001). Here cholesterol synthesized by astrocytes is loaded onto apolipoprotein E (APOE), exported by ATP-binding cassette 
transporter 1 (ABCA1), and imported by neurons via lipoprotein receptors (Pfrieger, 2003). Most of the cholesterol within cells resides in the cell membrane and endocyticrecycling compartment. Free cholesterol in a cell is converted into cholesterol esters by the enzyme acyl CoA:cholesterol acyltransferase 1 (ACAT1) (Figure 1.1)

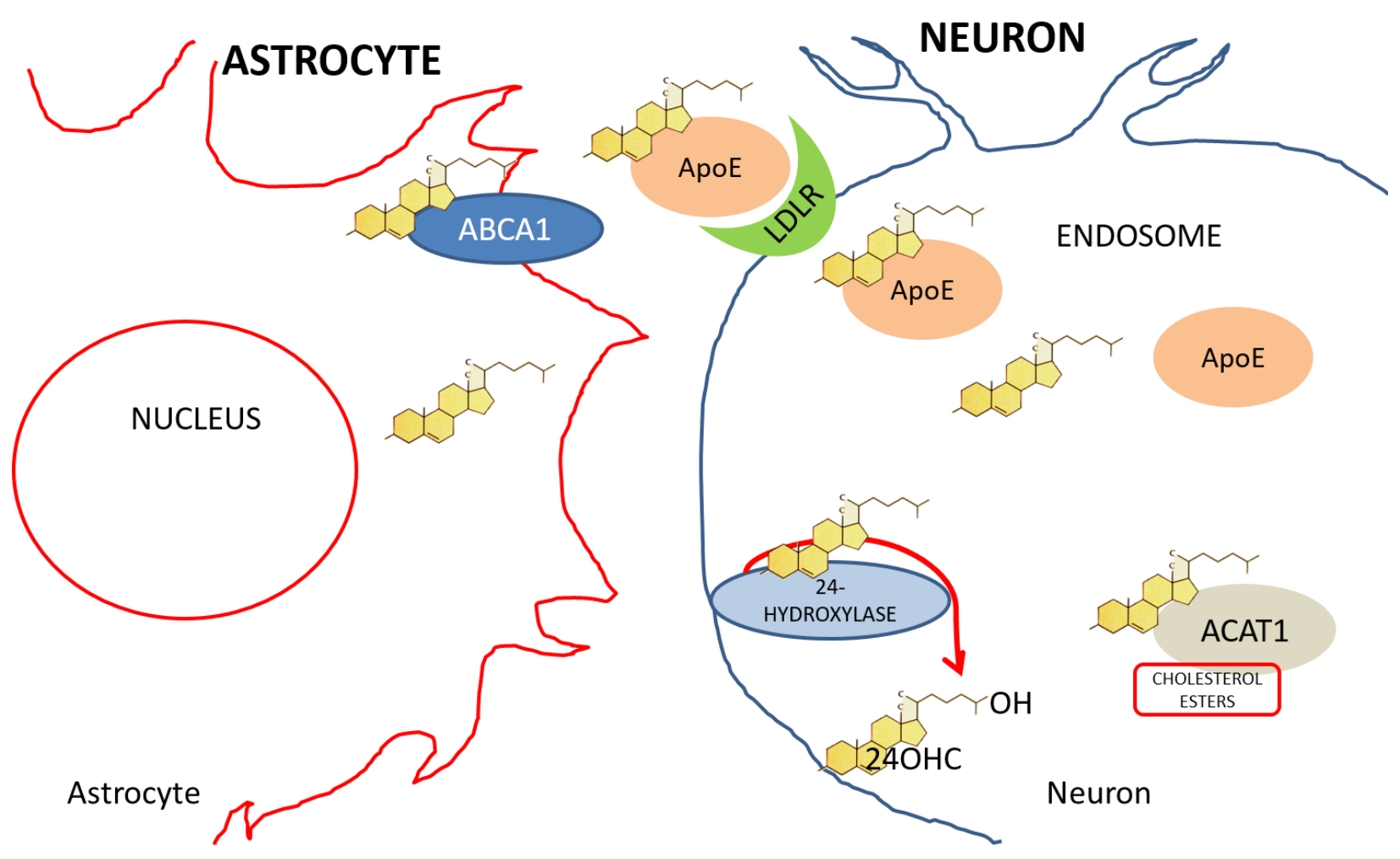

Figure 1.1 Cholesterol synthesis in the CNS. In the mature brain cholesterol is synthesized by astrocytes, exported via ATP-binding cassette transporter 1 (ABCA1), imported by neurons via lipoprotein receptors (LDLR), and either used or stored as cholesterol esters. Excess cholesterol is metabolized by 24-hydroxylase to 24hydroxycholesterol, a metabolite that can follow circulatory elimination pathways. 
Cholesterol has been implicated in $A \beta$ production and aggregation that leads to neurotoxicity as well as transcriptional control of $A \beta$ clearance, yet precise mechanisms of this connection are still elusive. $A \beta$ aggregates are responsible for neurotoxicity and many studies have explored the relationship between cholesterol and the toxic effects of $A \beta$. An in vitro study by Puglielli and collegues has shown that ACAT1 controls the ratio of cholesterol and cholesterol esters. Increasing cholesterol esters boosts $A \beta$ release in cultured cells (Puglielli et al., 2001). The same study showed that pharmacological inhibitors of ACAT developed for treatment of atherosclerosis led to a decrease in cholesterol ester levels as well as $A \beta$. Studies of cell cultures showed that high cell membrane cholesterol rendered cells vulnerable to the toxic effects of $A \beta$; and decreasing cholesterol levels seemed to have protective effects (Lin et al., 2008; Abramov et al., 2011). A study investigating the effect of $A \beta$ in the brain in young and aged rats fed either high cholesterol, high fat or a control diet showed that aged rats fed a high-cholesterol diet showed the greatest reduction in neuronal density indicating that both age and a high-cholesterol diet confer higher neuronal vulnerability to $A \beta$ injections than a high-fat or control diet (Gonzalo-Ruiz et al., 2006).

\section{Cholesterol and Amyloid Precursor Protein processing}

APP processing can result in a soluble product via a non-amyloidogenic pathway or insoluble $A \beta$-peptides via an amyloidogenic pathway. The amyloid fibrils in amyloid 
plaques are formed from 39-43 amino-acid long $A \beta$ peptides that are secreted as a result of normal metabolism of the APP. Membrane-bound APP is a substrate for sequential proteolytic cleavage by $\alpha$-secretase or $\beta$-secretase followed by $\gamma$-secretase. The non-amyloidogenic pathway involves $\alpha$-secretase followed by $\mathrm{Y}$-secretase cleavage and results in a soluble product (Figure 1.2).

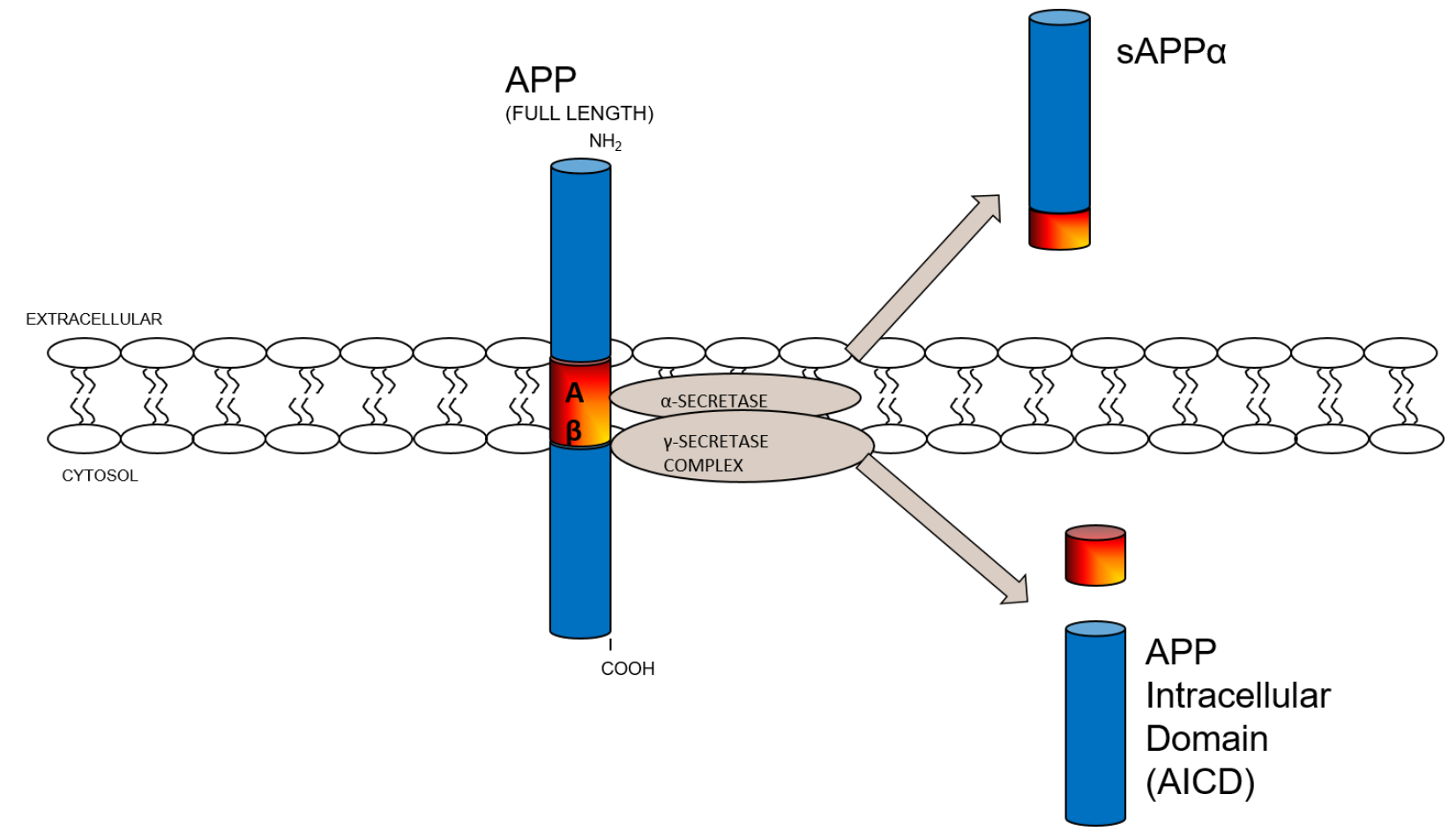

Figure 1.2 Non-amyloidogenic amyloid APP cleavage.

The identity of $\alpha$-secretase is still under investigation but several enzymes have been shown to cleave APP within the A $\beta$ domain such as tumor necrosis factor- $\alpha$ converting enzyme/A disintegrin as well as members of metalloproteinase family: 
ADAM-17, ADAM-9, and ADAM 10 (Allinson et al., 2003). Under normal conditions, A $\beta$ occurs as a soluble monomeric isoform that does not cause neuronal damage. In fact, these monomers seem to have a neuroprotective function. Synthetic monomers of A 342 supported developing neurons subjected to trophic deprivation, and protected mature neurons against excitotoxic death (Giuffrida et al., 2009). This study suggested that pathological aggregation of $A \beta 42$ might contribute to neurodegeneration by taking away the protection of $A \beta 42$ monomers as some research suggested that toxic effects of $A \beta$ emerge when the monomers aggregate into the soluble $A \beta$ oligomers and not the fibrils deposited in $A \beta$ plaques (Haass and Selkoe, 2007).

In the amyloidogenic pathway, cleavage by $\beta$-secretase, also known as $\beta$-site APP cleaving enzyme 1 (BACE1), generates a transmembrane domain C99 that in turn is cleaved by $Y$-secretase to produce short $A \beta$ peptides consisting of 39-43 amino acids (Figure 1.3). $y$-Secretase is a complex that includes presenilin-1 or presenilin-2 and three cofactors required for complex assembly and substrate recognition (Serneels et al., 2009). 


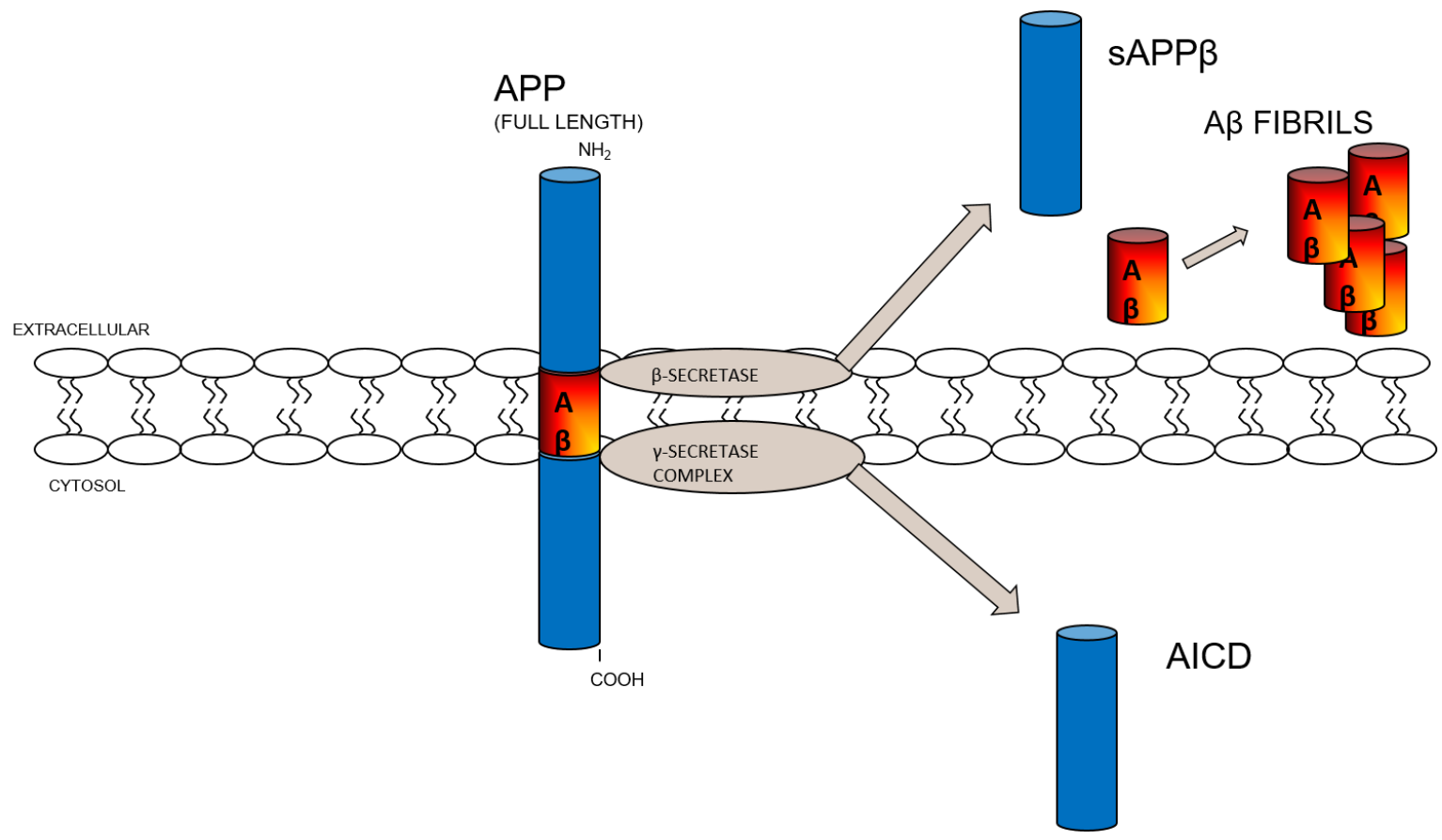

Figure 1.3 Amyloidogenic APP cleavage.

Under normal physiological conditions, the non-amyloidogenic pathway is the predominant one. Increasing cholesterol levels can shift APP processing towards the amyloidogenic pathway (Marquer et al., 2011). Depletion of cholesterol decreases this association and consequently $A \beta$ production declines (Hattori et al., 2006). Cholesterol can direct APP processing towards the amyloidogenic pathway by blocking the $\alpha$ secretase cleavage site on the protein. APP has a cholesterol-binding site that is adjacent to the $\alpha$-secretase cleavage site; hence, excess cholesterol can contribute to reduction of non-amyloidogenic APP processing by physically blocking the $\alpha$-secretase proteolytic site (Bodovitz and Klein, 1996; Kojro et al., 2001). Furthermore, C99 also contains a cholesterol-binding site, within the $A \beta 40$ domain, that favors production of 
$A \beta 42$ in an environment rich in cholesterol (Barrett et al., 2012). In a healthy system, most of secreted $A \beta$ peptides are $A \beta 40$, which are soluble and slowly convert into a $\beta$ sheet. $A \beta 42$ is normally the less abundant species with seemingly more fibrillogenic properties, hence more toxic to neurons than $A \beta 40$ (Haass and Selkoe, 2007).

\section{Cholesterol and $A \beta$ clearance}

$A \beta$ peptides are generally degraded by various proteases. Neprilysin is a zincdependent metalloprotease enzyme, expressed on the membrane of neurons that degrades a number of peptides including $A \beta$. Neprilysin levels are significantly decreased in AD patients' brains compared to age matched controls (Yasojima et al., 2001). Transgenic mice lacking neprilysin demonstrate increased $A \beta$ deposits as well as cognitive deficits (Madani et al., 2006). Another enzyme responsible for degradation of $A \beta$ : insulin-degrading enzyme (IDE) is an insulin protease that cleaves proteins with a propensity to form $\beta$-pleated protein sheets such as insulin, glucagon, atrial natriuretic factor, TGF- $\alpha$, APP intracellular domain and A $\beta$ (Mukherjee et al., 2000; Selkoe, 2001). Overexpression of this enzyme in mammalian cells reduces extracellular A $\beta 40$ and Aß42 (Vekrellis et al., 2000) and it has been shown to be upregulated in cholesterol-fed animal models where it is thought to be a response to an increased $A \beta$ load (Dasari et al., 2011).

APOE is a molecule that plays an important role in cholesterol transport and it is the strongest identified genetic risk factor for late onset AD. Three isoforms of APOE 
alleles: $\varepsilon 2$, $\varepsilon 3$, and $\varepsilon 4$ differentially modulate extracellular amyloid plaque deposition (Reiman et al., 2009; Morris et al., 2010). Humans can be heterozygous or homozygous for one of these isoforms. In the early 90's, a study linked the APOE $\varepsilon 4$ allele with increased risk and lower age of onset of AD by 7 to 15 years; while APOE $\varepsilon 2$ seemed to play a protective role against developing AD (Corder et al., 1993; Corder et al., 1994). In the years that followed, many different studies investigated APOE functions and their effects on AD pathology. APOE facilitates proteolytic degradation of $A \beta$ by neprilysin and related enzymes within the microglia (Jiang et al., 2008). APOE also enhances extracellular A $\beta$ clearance by IDE (Edland et al., 2003). These effects are dependent on the APOE isoform and APOE lipidation status: lipidated APOE stimulates $A \beta$ degradation and $\varepsilon 2$ and $\varepsilon 3$ are much more efficient in this facilitation than APOE $\varepsilon 4$ (Jiang et al., 2008). In mice expressing human APOE $\varepsilon 4$ and APP, A $\beta$ deposition is accelerated, an effect that is not seen in animals with other isoforms of APOE (Holtzman et al., 2000). Castellano and colleagues (Castellano et al., 2011) showed the differences in the way that APOE isoforms modulate $A \beta$ accumulation are due to $A \beta$ elimination, confirming the idea that the initiating pathway for $A \beta$ deposits is decreased $A \beta$ clearance rather than overproduction (Deane et al., 2005). APOE also appears to be important in maintaining BBB integrity, though isoforms $\varepsilon 2$ and $\varepsilon 3$ seem to be much more effective than the $\varepsilon 4$ isoform (Salloway et al., 2002; Zipser et al., 2007).

Furthermore, there is a significant interaction between the APOE status and gender. A meta-analysis of data on AD patients and healthy controls that looked at 40 independent studies has shown that females with APOE $\varepsilon 4$ variant are four times more 
likely to have AD than individuals with any other APOE allele (Farrer et al., 1997). Additionally, a relatively recent neuroimaging study showed that healthy older female APOE $\varepsilon 4$ carriers exhibit reduced functional brain connectivity in brain areas implicated in $A D$ pathology than women without this $A P O E$ variant or men with APOE $\varepsilon 4$ (Damoiseaux et al., 2012).

\section{Cholesterol metabolites associated with $A D$}

Although cholesterol cannot freely cross the blood-brain barrier, some of its metabolites can. The cholesterol enzyme 24-hydroxylase encoded by the gene CYP46 found exclusively in the brain, converts cholesterol to 24(S)-hydroxycholesterol (24$\mathrm{OHC})$, the metabolite that crosses the BBB, enters the plasma and follows elimination pathways. $24-\mathrm{OHC}$ therefore is a reliable marker of cholesterol metabolism in the CNS (Dietschy and Turley, 2001). Abnormal levels of this oxysterol have been linked to AD. 24-OHC is increased in the cerebrospinal fluid (CSF) of Alzheimer's patients and has been found to correlate with the levels of APOE and cholesterol in the CSF (Bjorkhem et al., 2006; Leoni and Caccia, 2011). In vitro studies showed that 24-OHC facilitates $\alpha-$ secretase activity increasing the $\alpha / \beta$ secretase activity ratio (Famer et al., 2007). 24$\mathrm{OHC}$ is also an activator of liver-X-receptor (LXR). LXR is a nuclear receptor that regulates $A B C A 1$ gene transcription. $24-\mathrm{OHC}$ binds to $\mathrm{LXR}$ causing an increase in $A B C A 1$, which in turn increases lipidation of APOE and the flux of cholesterol from astrocytes to neurons (Repa et al., 2000). ABCA1 levels are significantly elevated in hippocampus and cortex of cholesterol-fed rabbits (Schreurs and Sparks, 2015). 
On the other hand, 27-hydroxycholesterol (27-OHC), the metabolite of cholesterol in the periphery, can flux into the CNS (Heverin et al., 2005). Plasma levels of $27-\mathrm{OHC}$ correlate with the total cholesterol in the circulation. The flux of $27-\mathrm{OHC}$ from the circulation into the brain is thought to be a link between hypercholesterolemia and AD (Bjorkhem et al., 2009). A possible mechanism linking 27-OHC and AD might involve estrogen receptors given that $27-\mathrm{OHC}$ acts as a selective estrogen receptor modulator (SERM) (DuSell and McDonnell, 2008; DuSell et al., 2008). Molecules identified as SERMs are able to act as ligands for both types of estrogen receptors (ER) ( $\alpha$ and $\beta$ ) in a tissue-dependent agonistic or antagonistic manner. Estrogen receptor signaling plays an important role in the modulation of synaptic plasticity and improves hippocampal memory consolidation (Fernandez et al., 2008; Liu et al., 2008).

\section{Estrogen signaling and links to $A D$}

Epidemiological studies have shown that the risk of developing $A D$ in women increases significantly after menopause (Henderson, 2009; Henderson, 2010). Examination of female AD brains showed low levels of estrogen and reduced expression of aromatase expression - an enzyme catabolizing endogenous estrogen production (Yue et al., 2005) and several studies reported beneficial effects of estrogen and progestin treatment in AD (Resnick et al., 2006). Multiple epidemiological studies suggest that estrogen treatment prior to or at the onset of menopause is associated with enhanced cognition and hippocampal function (Maki et al., 2011; Greendale et al., 2011) and can reduce the risk of $A D$ in postmenopausal women (Berent-Spillson et al., 
2010; Henderson and Brinton, 2010) while women not receiving the treatment following surgically-induced menopause were at a higher risk for neurodegenerative disease (Rocca et al., 2007; Rocca et al., 2008; Rocca et al., 2011).

AD is more common in women (Baum, 2005) and it has been suggested that post-menopausal decreased estrogen levels could be a risk factor for AD (Yue et al., 2005; Riedel et al., 2016). In a mouse model, estrogen depletion led to the accumulation of $A \beta$ in the CNS, which was reversed after administration of estradiol (Zheng et al., 2002). In another study with a rodent AD model, decreased estrogen was associated with increased $A \beta$ accumulation (Carroll et al., 2007) and ovariectomized mice showed reduced $A \beta$ load and improved cognitive performance following estrogen treatment (Carroll and Pike, 2008). In vitro studies revealed that estrogen up-regulates $A \beta$-degrading enzyme neprilysin, which leads to more efficient clearance of $A \beta$ (Liang et al., 2010). In rodents, estrogen treatment during aging prevents age-related memory deficits (Gibbs, 2000) and there is evidence that the same is true in humans (Sherwin, 2009; Sherwin et al., 2011).

Additionally, there is a relationship between estrogen signaling and the risk for $A D$ because $A D$ affects women differently than men (Carter et al., 2012; RegitzZagrosek and Seeland, 2012). Women are more vulnerable to more severe behavioral effects of $A D$ and more pronounced cognitive decline than men (Chapman et al., 2011; Irvine et al., 2012; Hall et al., 2012). Furthermore, APOE $\varepsilon 4$, the strongest genetic risk factor for sporadic $A D$, has been associated with higher risk for $A D$ in women than in men and APOE $\varepsilon 2$, a neuroprotective variant, confers greater protection against $A D$ in 
men than in women (Altmann et al., 2014; Ungar et al., 2014). Moreover some studies showed that estrogen has an effect on the expression of APOE, the genetic risk factor for $A D$, as activation of ER $\alpha$ upregulates APOE expression while ER $\beta$ decreases APOE expression (Wang et al., 2006).

\section{Estrogen signaling in hippocampal function}

Estrogen has been shown to enhance several measures of synaptic plasticity in the rodent hippocampus: it increases size and density of hippocampal dendritic spines in CA1 (Gould et al., 1990; Woolley and McEwen, 1992), as well as the magnitude of LTP (Scharfman et al., 2003; Smith and McMahon, 2006; Scharfman and MacLusky, 2006a; Scharfman and MacLusky, 2006b; Foy et al., 2008a; Foy et al., 2008b). Two types of estrogen receptors: ERa and ER $\beta$ are both expressed in the hippocampus (Mitra et al., 2003). They function via classical nuclear signaling pathways where, upon ligand binding, the receptors form dimers with other ERs and translocate to the nucleus where they activate estrogen response elements and modulate gene transcription (Nilsson et al., 2001). Another mechanism of action of ERs involves receptors that reside in the membrane and do not translocate to nucleus when activated, instead these receptors act with growth factor receptors and G protein-coupled receptors to activate kinase cascades (Levin, 2005; Hammes and Levin, 2007; Vasudevan and Pfaff, 2007; Vasudevan and Pfaff, 2008). Transcriptional effects of ER signaling via nuclear pathways is a slower process and takes 12-24 hours (Vasudevan et al., 2001; GottfriedBlackmore et al., 2007) whereas membrane bound ER pathways are much faster and 
the effects can be seen in minutes to hours after estrogen exposure (Akama and McEwen, 2003; Fernandez et al., 2008; Yuen et al., 2011).

Both ERa and ER $\beta$ are important for hippocampal function and knockout of either form of the receptor impairs hippocampal-dependent learning (Fugger et al., 2000; Rissman et al., 2002; Day et al., 2005) although deletion of ER $\beta$ in a middle-aged mouse model provided protection against cognitive decline (Han et al., 2013).

Differential distribution of ERs within the cell revealed by electron microscopy suggests different functions of those receptors (McEwen and Milner, 2007; Spencer et al., 2008b) although both receptors have been implicated in synaptic potentiation, synaptic depression and synapse formation in hippocampal neurons (Day et al., 2005; Szymczak et al., 2006; Liu et al., 2008).

Hippocampal CA1 neurons demonstrate reversible synaptogenesis in response to estrogen stimulation in female rats (McEwen et al., 1995; Woolley, 1999a; Woolley, 1999b) in a rapid manner. During the 5-day rat estrous cycle, synapses are induced and then disappear within 12 hours under the influence of progesterone (McEwen et al., 1995). This estrogen-induced spine generation appears to be an ERa-dependent process as a rapid spinogenesis was experimentally induced with an ERa- but not ER $\beta$ specific agonist (Phan et al., 2011). Estrogen regulates expression of pre- and postsynaptic proteins in female rat hippocampus (Waters et al., 2009) and female mouse hippocampus (Spencer et al., 2008a; Spencer et al., 2008c). Estrogen receptors in the hippocampus are largely nonnuclear (McEwen and Milner, 2007), they are found in dendrites, dendritic spines, presynaptic terminals of neurons as well as glial cells 
(Herrick et al., 2006; Hart et al., 2007; Ledoux et al., 2009). Even more specifically, ERa labeling in terminals is often associated with vesicles (Hart et al., 2007) and ER $\beta$ is often associated with both pre- and postsynaptic mitochondria (Milner et al., 2005). The expression of ERs in the hippocampus is dynamic and changes under the influence of estrogens as well as a function of aging. It has been shown that postsynaptic expression of ERa is regulated by estrogen in young but not aged female rats and that ER $\beta$ remains sensitive to the effects of estrogen regardless of age (Waters et al., 2011). During the low estrogen period in the female cycle, there is increased labeling of ERa and ER $\beta$ at dendritic spines (Mitterling et al., 2010) and both receptors contribute to estrogen regulation of synaptic proteins: estrogen and both ER $\alpha$ and ER $\beta$ agonists have been shown to increase expression of PSD-95 and only ER $\beta$ agonists regulate expression of AMPA receptor subunits GluR2 andGluR3 (Waters et al., 2009). Nonnuclear ERs also initiate signaling pathways that regulate transcriptional events. For example, estrogen rapidly increased phosphorylated CREB in cell nuclei of hippocampal neurons (Lee et al., 2004) as well as activated phosphoinositol-3 kinase (PI3K) and phosphorylation of AKT and LIM kinase (Znamensky et al., 2003; Akama and McEwen, 2003; Spencer et al., 2008a; Yuen et al., 2011). Estrogen signaling activated PI3K that leads to the activation of LIMK1 and phosphorylation of cofilin. This leads to disinhibition of actin polymerization and allows for filopodia formation that will eventually create synaptic contacts. Additionally, PI3K phosphorylates AKT that leads to phosphorylation of translation repressor protein 4E-BP1 that in turn allows for increased translation of PSD-95 - a process that promotes spine and synapse formation (Figure 1.5) (McEwen et al., 2012). 


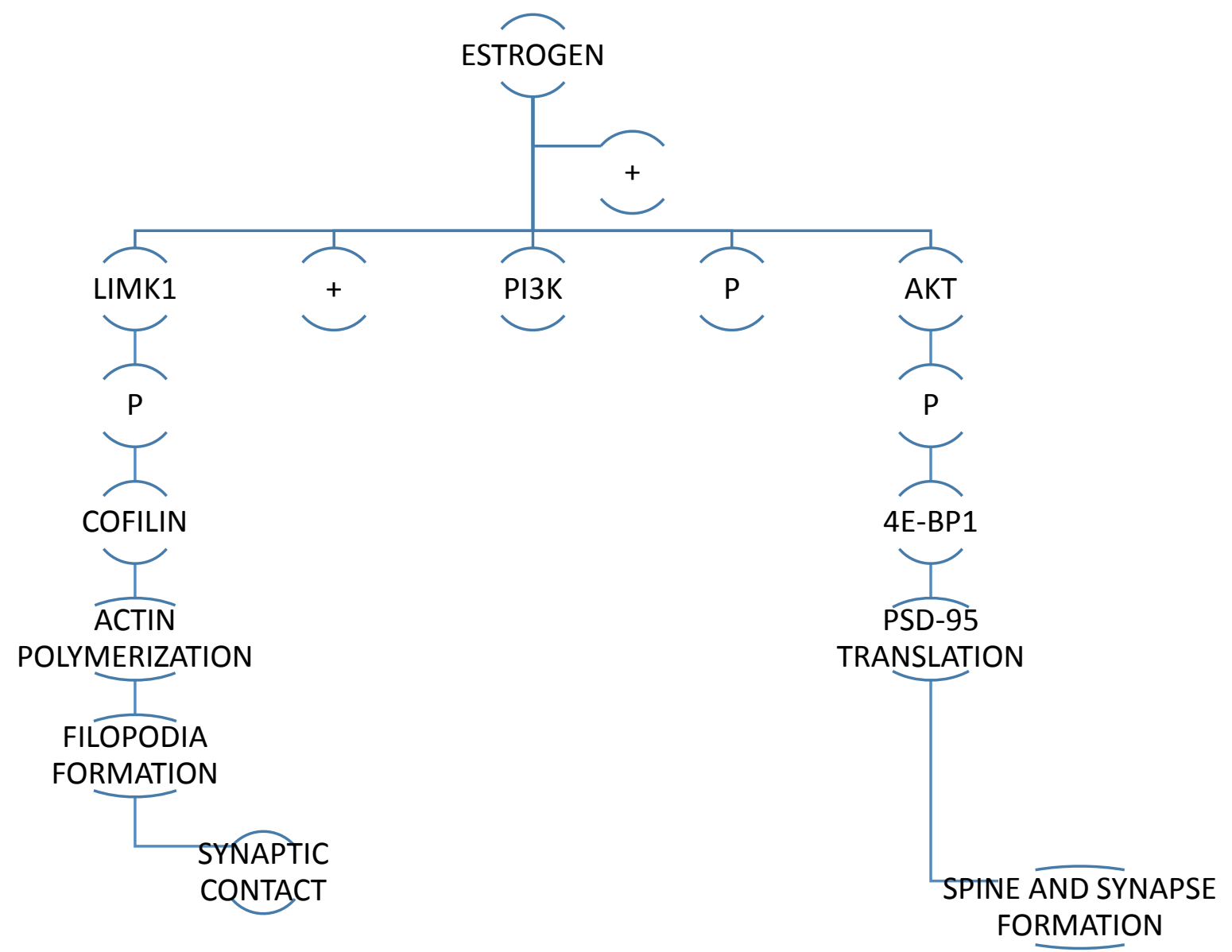

Figure 1.5 Estrogen signaling pathways and synaptogenesis. (+) activation, (P) phosphorylation

The exact mechanism of estrogen-mediated activation of PI3K is not clear but a direct interaction between ER a and PI3K has been described (Mannella and Brinton, 2006). ER $\beta$ has been shown to play a role in hippocampal CREB signaling, synaptic protein expression and spatial memory (Abraham et al., 2003; Rhodes and Frye, 2006; Liu et al., 2008) and long-term oral treatment with ERß-selective SERM improved 
behavioral outcomes and decreased $A \beta$ load in a transgenic mouse model of $A D$ (Zhao et al., 2013). It has recently been suggested that maintaining ERa function might be a critical process in preventing cognitive decline (Zhang et al., 2011) which was validated when eliminating $E R \beta$ in middle-aged mice had a protective effect on cognitive function, and the similar effect was seen when ERa levels were increased (Han et al., 2013). Aromatase, an enzyme that produces estrogen, is enriched at synapses and has been shown to localize at presynaptic structures in the cortex (Srivastava et al., 2010) as well as male and female hippocampus (Tabatadze et al., 2014). Estrogen has been shown to increase the spine density in both cortex and hippocampus, interestingly, the receptors involved were different depending on structures involved. In cortical neurons, spinogenesis was stimulated via ER $\beta$ (Srivastava et al., 2010) whereas in the hippocampus, estrogen increased the spine density via ERa-dependent pathway (Mukai et al., 2007).

Estrogen has been shown to modulate the morphology of dendritic spines in hippocampal and cortical neurons (Mukai et al., 2007; Woolley, 2007; Srivastava et al., 2008; Srivastava et al., 2013). Systemic injection of estrogen increased hippocampal CA1 dendritic spine density (MacLusky et al., 2005; Inagaki et al., 2012) and this increase is associated with enhanced hippocampal synaptic plasticity (Woolley et al., 1997; Foy et al., 1999; Mukai et al., 2007) and memory formation (Inagaki et al., 2012; Phan et al., 2012). Spinogenesis requires production of proteins, a process that could occur via estrogen receptor nuclear translocation-dependent mechanisms but the rapid response to systemic administration of estrogen suggests that local protein synthesis mechanisms might be involved. One of those mechanisms - mammalian target of 
rapamycin (mTOR) signaling pathway - is activated by multiple kinases including extracellular signal-regulated kinase (ERK) (Winter et al., 2011). Both ERK and mTOR have been shown to be necessary for object recognition and spatial memory consolidation tasks in mice (Fortress et al., 2013) and ERK activation was shown to be an essential process for estrogen-induced spinogenesis in cultured neurons and organotypic slices (Mukai et al., 2007; Srivastava et al., 2008; Hasegawa et al., 2015; Murakami et al., 2015) and recently in hippocampal CA1 in mice (Tuscher et al., 2016).

Another study that investigated mechanisms by which estrogen potentiates synaptic transmission in hippocampus found that estrogen increases presynaptic glutamate release as well as postsynaptic glutamate sensitivity and found that the mechanisms of this enhancement is different for females and males (Oberlander and Woolley, 2016). In females, estrogen activated ER $\beta$ to increase glutamate release and via G protein-coupled estrogen receptor 1 (GPER1) to increase sensitivity to glutamate whereas in males, estrogen increases glutamate release via ERa and glutamate sensitivity via ERß.

Additional evidence especially pertinent to our research came from a study of spontaneously hypercholesterolemic Watanabe rabbits. The examination of brains of female Watanabe rabbits at different ages compared to cholesterol-diet fed New Zealand White rabbits showed that high circulating cholesterol is associated with increased $A \beta$ immunoreactivity but this increase is attenuated in females at peak reproductive age due to high circulating estrogen levels (Sparks et al., 2002). 


\section{Mitochondria and $A D$}

Mitochondria are organelles that provide energy and there is evidence that their dysfunction is implicated in AD pathology (Johri and Beal, 2012). Mitochondrial dysfunction has been shown to occur well before any detectable neuropathological hallmarks of AD manifest (Mosconi et al., 2008) and it has been suggested that mitochondrial dysfunction leading to increased oxidative stress and neurodegeneration is associated with cognitive decline (Reddy, 2009; Stavros, 2013). Mitochondrial deficits have been shown to occur before AD symptomology and are exacerbated in female models during reproductive senescence (Yao et al., 2009; Yao and Brinton, 2012; Yao et al., 2012).

In the early stages of $A D$, structural changes as well as a decreased number of mitochondria in synaptic terminals have been found (Baloyannis, 2011; Stavros, 2013). AD patients' brains show increased levels of oxidative stress when compared to controls but it is unclear what role oxidative stress plays in neurodegeneration. There is some evidence that high cholesterol initiates $A \beta$ formation which causes further oxidative damage to the cell (Yan et al., 2000). In rabbits, a high-cholesterol diet is associated with an increase in markers of oxidative stress that is reduced when the antioxidant vitamin E is administered (Prasad and Kalra, 1993; Mantha et al., 1993). Tissue homogenates from AD brains exhibit evidence of cellular damage including induction of glucose-6-phosphate dehydrogenase (Martins et al., 1986), chromatin degradation (Mecocci et al., 1994; Cotman, 1998) and mitochondrial DNA damage (Mecocci et al., 1994). AD brains also show evidence of vascular pathology and hypo- 
perfusion which can contribute to oxidative injury. The localization of ER- $\beta$ in mitochondria suggests an important role for estrogen signaling in neuroprotection from insults that compromise mitochondrial function (Yang et al., 2004; Simpkins et al., 2008; Yang et al., 2009; Simpkins et al., 2010).

\section{Synaptic loss in $A D$}

In addition to the hallmark accumulation of $A \beta$ and tau phosphorylation in $A D$ brains, there is a considerable loss of synapses, neuronal degeneration and brain atrophy as the disease progresses (Scheff et al., 2006; Scheff et al., 2007; Scheff et al., 2015) that has been shown to correlate with cognitive decline (Scheff et al., 2006). It has also been reported that as the number of synapses decreased, the size of remaining synapses increased early in the course of the disease (DeKosky and Scheff, 1990), but this neuroplastic compensatory effect was not maintained as the disease progressed (Mufson et al., 2015). Analysis of synaptic genes in individual neurons in the CA1 of the hippocampus in subjects with a diagnosis ranging from normal cognition to moderate $A D$ showed significant downregulation of genes involved in synaptic processes including synaptophysin and PSD-95 in mild cognitive impairment (MCI) and in AD brains compared to cognitively normal subjects (Counts et al., 2014).

Congruently, cholesterol-fed transgenic animals showed a marked reduction in synaptophysin immunoreactivity, a marker often used for quantification of synapses (Umeda et al., 2012). PSD-95 is another synaptic marker, a scaffold protein, and a 
critical component of synapses. It has been shown that there is a decrease in PSD-95 expression in $\mathrm{MCl}$ subjects and that this decrease correlates with cognitive decline (Scheff et al., 2016). Dendritic spine maturation is accompanied by a translocation of PSD-95 from dendritic shaft into the spine (Gerrow et al., 2006). In cortical neurons, stimulation of ERß is associated with an increase of PSD-95 expression in spines and decrease in dendritic shafts while the total levels of PSD-95 remained unchanged (Srivastava et al., 2010) suggesting maturation of the spines is an ER $\beta$-dependent process in the cortex while in the hippocampus increase in the spine density is an ERadependent process (Mukai et al., 2007).

\section{Rabbit model of $A D$}

Progress in research on AD has been lagging because of the small number of appropriate animal models of the disease. Spontaneous development of AD pathology is very rare in non-human species which makes studying the disease even more troublesome. Therefore, we have to rely on genetic, biochemical and dietary manipulations to create known symptoms of the disease. Rodents are a staple of biomedical research animal models because of their short lifespan and experimental potential. Unfortunately, rodents do not develop $A \beta$ spontaneously and the amino acid sequence of rodent $A \beta$ is different than that of humans. Transgenic mouse models introduced in 1990's presented the possibility of introducing human genes into the mouse genome and allowed for manipulation of $A D$ specific pathology, mainly $A \beta$ plaques and tau tangles. Importantly, these readily available transgenic models were 
developed based on the autosomal dominant mutations present in a very small percentage of $A D$ patients. Mouse $A D$ models created by introducing human genes into their genome have been invaluable for studying $A \beta$ - and tau- related mechanisms of $A D$, however transgenic models show little to no neuronal loss and their cholinergic system is not compromised as it is in AD patients. Because of these limitations, we need to include other models of AD that exhibit cognitive, physiological and molecular pathology comparable to those found in AD patients. Rabbits, dogs and non-human primates have the advantage over rodents as the sequence of their $A \beta$ is almost identical with that of humans (Johnstone et al., 1991).

One of the major findings in $A D$ brains is accumulation of $A \beta$ plaques in the hippocampus, a finding that was thought to be unique to AD pathology. In the early 1980's Dr. D. Larry Sparks, who at the time performed autopsies, had noted that cognitively normal individuals also show presence of $A \beta$ plaques in hippocampus and investigation of cause of death of these individuals revealed that the plaques were found in subjects suffering from coronary artery disease and hypertension (Sparks et al., 1990b). Because of these findings, Sparks and colleagues turned to an established animal model of coronary artery disease in order to investigate the relationship between heart disease and A . Originally described in 1913 by Nikolaj Nikolajewitsch Anitschkow, the cholesterol-fed rabbit is a well-established animal model of experimental atherosclerosis (Finking and Hanke, 1997). While the cardiovascular effects of high cholesterol in this model have been described in great detail, no one assessed the cognitive function and brain pathology of those animals. Sparks and colleagues fed the rabbits a high-cholesterol diet for various periods of time and showed 
that the diet-induced hypercholesterolemia is associated with increased $A \beta$ immunoreactivity in hippocampal and cortical tissue of those animals and that the degree of pathology was correlated with the length of dietary treatment (Sparks et al., 1994).

Age is the greatest risk factor for $A D$ (Costantini et al., 2005) which presents a major challenge in studying the disease in animal models. Longitudinal laboratory investigations are costly and difficult to conduct, hence within the confines of a study design we often must resort to extreme treatments to induce desired effects in an acceptable period of time. Studies using cholesterol-fed rabbits usually use adolescent animals because they tend to tolerate the extreme diet better than aged animals. Cholesterol-fed rabbits experience many systemic side effects related to the extremely high cholesterol content administered in a short period of time. Adult and aged animals tend to succumb to hepatotoxicity faster and have more severe symptoms ultimately leading to the increase mortality. By using adolescent animals in our study, we were minimizing systemic effects of cholesterol while still investigating the effects of the diet on the brain in subjects before or at the start of AD symptomology. This is especially important in the light of temporal relationship of hypercholesterolemia in midlife increasing risk of $A D$ later in life.

Feeding rabbits with a diet enriched with $2 \%$ cholesterol for as little as eight weeks results in many pathological findings similar to those seen in AD patients including deposits of $A \beta$ (Figure 1.4), gliosis, increased levels of APOE, phosphorylated tau protein and increases in ventricular volume (Sparks, 1997; Zatta et al., 2002; Ghribi 
et al., 2006; Woodruff-Pak et al., 2007; Jaya Prasanthi et al., 2008; Lemieux et al., 2010; Deci et al., 2012; Schreurs et al., 2013a). Studies that investigated cognitive function in this model showed negative effects of high cholesterol diet on long term memory (Darwish et al., 2010; Schreurs et al., 2013b) which is consistent with the clinical findings (Solomon et al., 2009a; Zambon et al., 2010).

Gender is also an important factor in AD risk. Females are more likely to succumb to $A D$ and post-menopausal loss of estrogen neuroprotection has been implicated as a causative factor. The studies that investigated the effects of highcholesterol diet on AD pathology in male and female rabbits concluded that estrus protects spontaneously hypercholesterolemic female rabbits from aberrant $A \beta$ production in the brain (Sparks et al., 2002) while comparison of cholesterol-fed males and females showed that an 8-week diet treatment of males resulted in similar degree of pathology as 12-week diet treatment of female rabbits (Sparks, 2008). This finding was used to support the use of males for further studies investigating the role of hypercholesterolemia in AD development. 


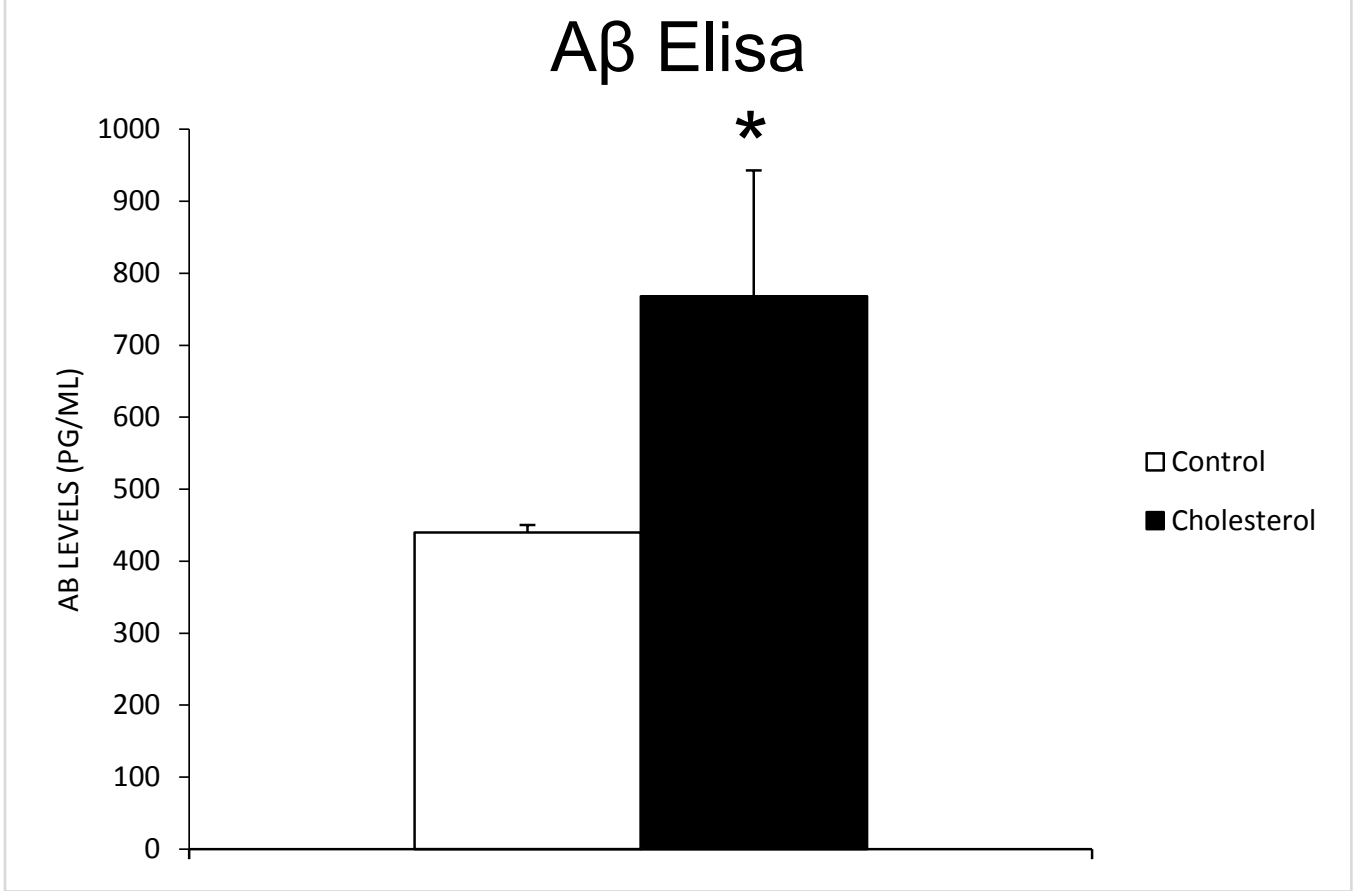

Figure 1.4 A $A$ levels in cortex of control and cholesterol-fed rabbits (Schreurs Lab unpublished data). 
Chapter 2: Objectives and rationale 
Study 1: Determine if high cholesterol diet increases 27-OHC content in the brain.

CNS cholesterol is efficiently isolated from peripheral cholesterol by the BBB. In contrast to cholesterol, side-chain oxidized metabolites of cholesterol such as $24-\mathrm{OHC}$ and $27-\mathrm{OHC}$ can cross the $\mathrm{BBB}$ in both directions. $24-\mathrm{OHC}$ flows from the brain into the circulation (Lutjohann et al., 1996; Russell et al., 2009) while 27-OHC flows from periphery into the CNS (Leoni et al., 2003; Heverin et al., 2005). Despite cholesterol's inability to enter the brain, hypercholesterolemia is a risk factor for AD (Launer et al., 2001; Kivipelto et al., 2001a; Pappolla et al., 2003). There is a close correlation between cholesterol and 27-OHC levels in the circulation (Babiker et al., 2005) and hypercholesterolemia is likely to result in increased uptake of this oxysterol into the brain. In this experiment we wanted to determine if a high-cholesterol diet leading to hypercholesterolemia had an effect on $27-\mathrm{OHC}$ in the brain.

Study 2: Determine if 27-OHC level has an effect on ER signaling and neuroprotection.

Estrogen signaling has been shown to have neuroprotective effects and modulate synaptic plasticity in the brain, and these functions are mediated by both ERa and ERß (Dhandapani and Brann, 2002; Fernandez et al., 2008; Liu et al., 2008;

Spencer et al., 2008c). In AD, the hippocampus is one of the first regions of the brain to experience synaptic loss resulting in memory deficits and disorientation in AD patients (Hampel et al., 2008) but the mechanisms involved in hippocampal degeneration are not clear. In the hippocampus, EM studies revealed that ER $\alpha$ and ER $\beta$ are located 
predominantly at extra-nuclear sites including dendritic spines, axons, terminals and glia which provides compelling evidence that estrogens' effects on synapses occur locally rather than through regulation of transcription (Milner et al., 2005; Mitterling et al., 2010). ERa tends to localize to the dendritic spines, axons and axon terminals, astrocytes and microglia (Milner et al., 2005; Sierra et al., 2008). ERß, on the other hand, is found mainly near the plasma membrane of somata, dendritic shafts and spines in hippocampal neurons as well as axon and axon terminals and in the cytoplasm near and within mitochondria (Yang et al., 2004; Milner et al., 2005). In the present experiment, we want to determine whether there are differences in expression of ERa and ER $\beta$ and the nature of these differences in the brains of hypercholesterolemic rabbits and controls.

Estrogen receptors are nuclear receptors that, in addition to central functions in reproductive biology, mediate estrogen regulation of a number of other physiologic processes (Deroo and Korach, 2006). The cardiovascular protection observed in premenopausal females has been largely attributed to the beneficial effects of estrogen on endothelial function and lipid profile (Mendelsohn and Karas, 1999; Murphy and Steenbergen, 2007). Umetani et al. (Umetani et al., 2007) discovered that 27-OHC antagonizes the estrogen-dependent production of NO by vascular cells. Other cell type-specific pro-estrogenic actions of $27-\mathrm{OHC}$ were also reported (Umetani et al., 2007; DuSell et al., 2008), confirming it as a SERM. Through its actions on both ERs and liver $\mathrm{X}$ receptors, $27-\mathrm{OHC}$ acts on osteoblasts resulting in increased bone resorption in mice (DuSell et al., 2010; Nelson et al., 2011). Furthermore, the action of 27-OHC on ER's has been shown in breast cancer cells were $27-\mathrm{OHC}$ acts as a partial 
agonist promoting tumor growth (Nelson et al., 2013; Wu et al., 2013). These findings suggest that $27-\mathrm{OHC}$ may counteract estrogen protection in the CNS as well and lead to AD-like pathology.

Study 3: Determine correlations between 27-OHC, ER expression, synaptic protein expression, neurodegeneration and performance on the discrimination memory task in cholesterol-fed rabbit model of $A D$.

Estrogen signaling might influence development and progression of AD. Both ER $\alpha$ and ER $\beta$ mediate classical nuclear genomic as well as membrane non-genomic signaling cascades. Estrogen signaling is important in learning and memory, cognitive decline and neuroprotection. Moreover, examination of post mortem brain tissue from AD patients showed decreased levels of ERa in hippocampus (Hu et al., 2003; Lu et al., 2004) and an increase in ER $\beta$ expression (Savaskan et al., 2001) compared to controls. Furthermore the decreased level of ERa is correlated with poorer cognitive performance in AD patients (Kelly et al., 2008). ERa has also been implicated in regulating synaptogenesis and maintaining synaptic health (Benvenuti et al., 2005; Spampinato et al., 2012a; Spampinato et al., 2012b), therefore one would expect to see changes in the level of neurodegeneration as well as in synaptic number as it relates to ERa expression. Neurodegeneration, an early finding in AD pathology development, is usually associated with a decrease in synaptic marker PSD-95 expression (Merlo et al., 2016). It was therefore important to measure PSD-95 levels in hippocampal tissue. 
Chapter 3: Measurement of 27-hydroxycholesterol in the hippocampus 
Oxysterols are derivatives of cholesterol formed either by actions of cytochrome P450 enzymes or by autoxidation. Recently, oxysterols have been shown to be biologically active in a tissue- and receptor-dependent manner (Radhakrishnan et al., 2007; Bauman et al., 2009), specifically when binding ERs (Umetani et al., 2007; DuSell et al., 2008; DuSell et al., 2010; Chambliss et al., 2010; Umetani and Shaul, 2011;

Nelson et al., 2011; Ishikawa et al., 2013; Nelson et al., 2013; Wu et al., 2013; Umetani et al., 2014). Moreover, changes in oxysterol levels have been documented in neurodegenerative diseases (Bogdanovic et al., 2001; Heverin et al., 2004).

Because oxysterols are usually present in biological tissue at very low levels compared to cholesterol and the concentration of oxysterols in human circulation varies widely from laboratory to laboratory (Luu et al., 2016), development of accurate and sensitive analytical methods of measuring oxysterols have been challenging in many ways. For example, the low concentrations of oxysterols accompanied by an excess of cholesterol in biological preparations necessitate complicated derivatization procedures and long run times often requiring large volume samples.

\section{Liquid Chromatography - Mass Spectrometry Introduction}

Liquid Chromatography - Mass Spectrometry (LC-MS) is an analytical chemistry technique for identification, quantification and mass analysis of materials. LC utilizes a compound's intrinsic affinity for a mobile phase (typically a buffered solvent) and a stationary phase column. The dissolved sample is introduced into continuous solvent 
flow and travels through the column. Compounds present in the sample mixture are separated in the column based on their affinity for the stationary phase (column) or mobile phase (solvent). After separation, the particles pass through a mass detector. The mass detector qualifies the substances based on retention time (how long it takes for the substance to clear the column) and quantitates the substances based on peak intensity and peak area. Chromatography is a technique with great resolution but accurately identifying and quantifying substances can be difficult especially when analyzing biological samples with multiple components that elute at approximately the same time.

MS on the other hand is a highly sensitive detection technique that separates ionized samples into components based on mass-to-charge ratios and the intensity of each ion is measured. Mass spectra indicate concentration of ions of given mass which is extremely valuable information for quantitative analysis. Specific molecules have specific mass profiles and MS technology allows one to obtain mass information directly. This technique, however, can be problematic when analyzing a sample with multiple components such as biological tissue as it is almost impossible to separate the individual molecules from hundreds of them with similar mass. Combining LC separation with MS qualitative capabilities allows the analysis of multicomponent samples to be more specific to the molecule of interest because it allows the analysis of the mass spectra along with retention times.

Different types of sample ionization can be used to increase the selectivity of the LC-MS method for the compound of interest and include Electrospray lonization (ESI), 
Atmospheric Pressure Chemical lonization (APCl) and Atmospheric Pressure

Photoionization (APPI). In ESI, the sample is dispersed into an aerosol, the solvent is removed and negative or positive ions are produced. The molecular weight of the molecule is revealed and very little fragmentation of compounds takes place. In APCI and APPI, colliding the molecules with reactive gas ions produces $[\mathrm{M}+\mathrm{H}]$ ions and the solvent is removed by heating. ESI is used mostly for polar molecules that provide their own charge while APCI/APPI is more useful in analyzing non-polar substances since collisions with reactive gas might provide a molecule with charge (Harwood and Handelsman, 2009; Kostiainen and Kauppila, 2009).

For the analysis of $27-\mathrm{OHC}$ in this study, we used the APCI method where ions generated by an APCI source are stripped of solvent, focused into a beam, and then delivered to the quadrupole. Both direct current and high frequency alternating current are applied to the quadrupole so that only the ions with the target mass-to-charge ratio successfully pass through the quadrupole. Ions that reach a detector are quantified and converted into an output file.

\section{Materials and methods}

Chemicals. All chemicals were HPLC grade and purchased from ThermoScientific. 27$\mathrm{OHC}$ standard was purchased from Research Plus Inc (Barnegat NJ). A stock solution of $0.5 \mathrm{mg} / \mathrm{ml}$ was made by dissolving $27-\mathrm{OHC}$ in $\mathrm{MeOH}$, further dilutions were made by adding more $\mathrm{MeOH}$. 
Animals, diet and tissue collection. The subjects were $10 \mathrm{New}$ Zealand White male rabbits (Oryctolagus cuniculus) 3-4 months of age weighing approximately $2 \mathrm{~kg}$ upon arrival that were part of a larger study investigating the role of cholesterol on learning and memory (Schreurs et al., 2013b). Animals were housed individually with free access to food and water and maintained on a 12-hour light-dark cycle. All the experiments followed guidelines of National Institutes of Health and were approved by West Virginia University Animal Care and Use Committee. Rabbits were assigned to two dietary groups: control or high cholesterol diet. Control diet animals received Purina 5326 chow, and the high cholesterol diet group received Purina 5326 plus 2\% cholesterol chow (T.R. Last Co., Gibsonia, PA). All the rabbits were kept on their respective diets for a total of 11 weeks. At the conclusion of the study, animals were deeply anesthetized with a mixture of ketamine $(500 \mathrm{mg} / \mathrm{kg})$ and xylazine $(10 \mathrm{mg} / \mathrm{kg})$ and overdosed with Somnasol before transcardial perfusion with artificial CSF solution. Whole brains were collected, hippocampi dissected and flash frozen and stored at $-80^{\circ} \mathrm{C}$ until analysis. Before euthanasia, transcardial blood was collected in EDTA tubes and centrifuged, and the serum was frozen and stored at $-80^{\circ} \mathrm{C}$ until analysis.

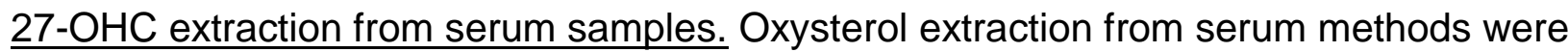
adapted from Ahonen et al. (Ahonen et al., 2014). Briefly, $1 \mathrm{~mL}$ of methyl t-butyl ether (MTBE) was added to a $150 \mu \mathrm{L}$ of rabbit serum. Sample was vortexed for 1 minute and centrifuged at $2000 \mathrm{rpm}$ for 5 minutes. MTBE phase was filtered into a glass sample vial through a $0.2 \mu \mathrm{m}$ syringe filter (Corning Incorporated) and evaporated to dryness. Samples were reconstituted in $100 \mu \mathrm{L}$ of $5 \%$ ammonium acetate $(50 \mathrm{mM}$, pH 4.5 with 
acetic acid):methanol:acetonitrile (1:3:6, v/v) and vortexed just before the analysis by the liquid chromatography-mass spectrometry (LC-MS) system.

27-OHC extraction from hippocampus. Methods of oxysterol extraction from the brain were developed based on Ahonen et al. (Ahonen et al., 2014). Briefly, the intact left hippocampi were weighed and homogenized using ultrasonication, and $0.5 \mathrm{~mL}$ dichloromethane (DCM): methanol mixture $(1: 1, \mathrm{v} / \mathrm{v})$ was added to tissue and sonicated on an ice bath for 1 minute. Samples were centrifuged at $13200 \mathrm{rpm}$ for 5 minutes, then supernatants removed and the procedure repeated. After the second extraction, supernatants were collected and evaporated to dryness. Immediately before analysis by LC-MS, the samples were reconstituted in $100 \mu \mathrm{L}$ of methanol, centrifuged at 13200 rpm for 5 minutes and the supernatants collected into glass sample vials.

Immediately before analysis by LC-MS, the samples were reconstituted in $100 \mu \mathrm{L}$ of methanol, centrifuged at $13200 \mathrm{rpm}$ for 5 minutes, the supernatants collected into glass sample vials and placed in the Dionex UltiMate 3000RS Nano LC system autosampler (ThermoScientific).

\section{$\underline{\text { LC-MS method and results }}$}

LC: Extracts from hippocampal tissue $(1 \mu \mathrm{L})$ were injected into a Dionex UltiMate 3000RS Nano LC system (ThermoScientific) using a 2.5 $\mu \mathrm{m}$ XBridge BEH C8 column, $300 \mu \mathrm{m} \times 150 \mathrm{~mm}$ (Waters) with a flow rate of $5 \mu \mathrm{L} / \mathrm{min}$. 27-OHC was eluted using a gradient of $20 \% \mathrm{~A}$ (water with $5 \mathrm{mM}$ of ammonium formate) and $80 \%$ B (100\% methanol with $5 \mathrm{mM}$ ammonium formate) for 10 minutes. The gradient was then transitioned from 80 to $99 \%$ B for 5 minutes, then maintained at $99 \%$ B for 10 minutes, followed by a re- 
equilibration period when the column was returned to $80 \% \mathrm{~B}$ in 5 minutes and maintained to the end of the 35-minute run. $27-\mathrm{OHC}$ eluted at 20.56 minutes (Figure 3.1). Figure 3.2 shows representative chromatograms of a control (A) and cholesterolfed (B) rabbit's hippocampal sample.

MS spectra of a diluted stock standard sample showed abundant protonated molecules and fragment ions formed by loss of 1-3 water molecules. The selected ion monitoring (SIM) measurement method allows detection of substances based on mass which allows quantitative analysis even when LC separation is inadequate and impurities are introduced into the detector. Based on the MS spectra, the most abundant ion based on highest intensity was chosen for SIM experiments in order to maximize sensitivity. The most abundant fragment for the $27-\mathrm{OHC}$ standard was $\mathrm{m} / \mathrm{z}$ (mass-to-charge-ratio) of 386.5. Intra-day and inter-day repeatability studies were conducted using a $1 \mu \mathrm{g} / \mathrm{ml}$ standard sample. A freshly prepared standard sample was injected 10 times for intra-day analysis. Relative standard deviations were calculated from standard deviation of the mean and calculated as a percentage of the mean. The relative standard deviations were $0.73 \%$ for retention time and $16.64 \%$ for relative abundance in intra-day evaluations. For inter-day evaluations, stock dilution samples were freshly prepared on five consecutive days and injected five times. Relative standard deviations were calculated from the standard deviation of the mean and calculated as a percentage of the mean. The relative standard deviations were $0.97 \%$ for retention time and $9.51 \%$ for relative abundance in inter-day evaluations. The repeatability and accuracy of the method is well within the generally accepted range of 
$80-120 \%$. Each of the samples was analyzed in three separate injections, and data points represent a mean of those three separate injections.

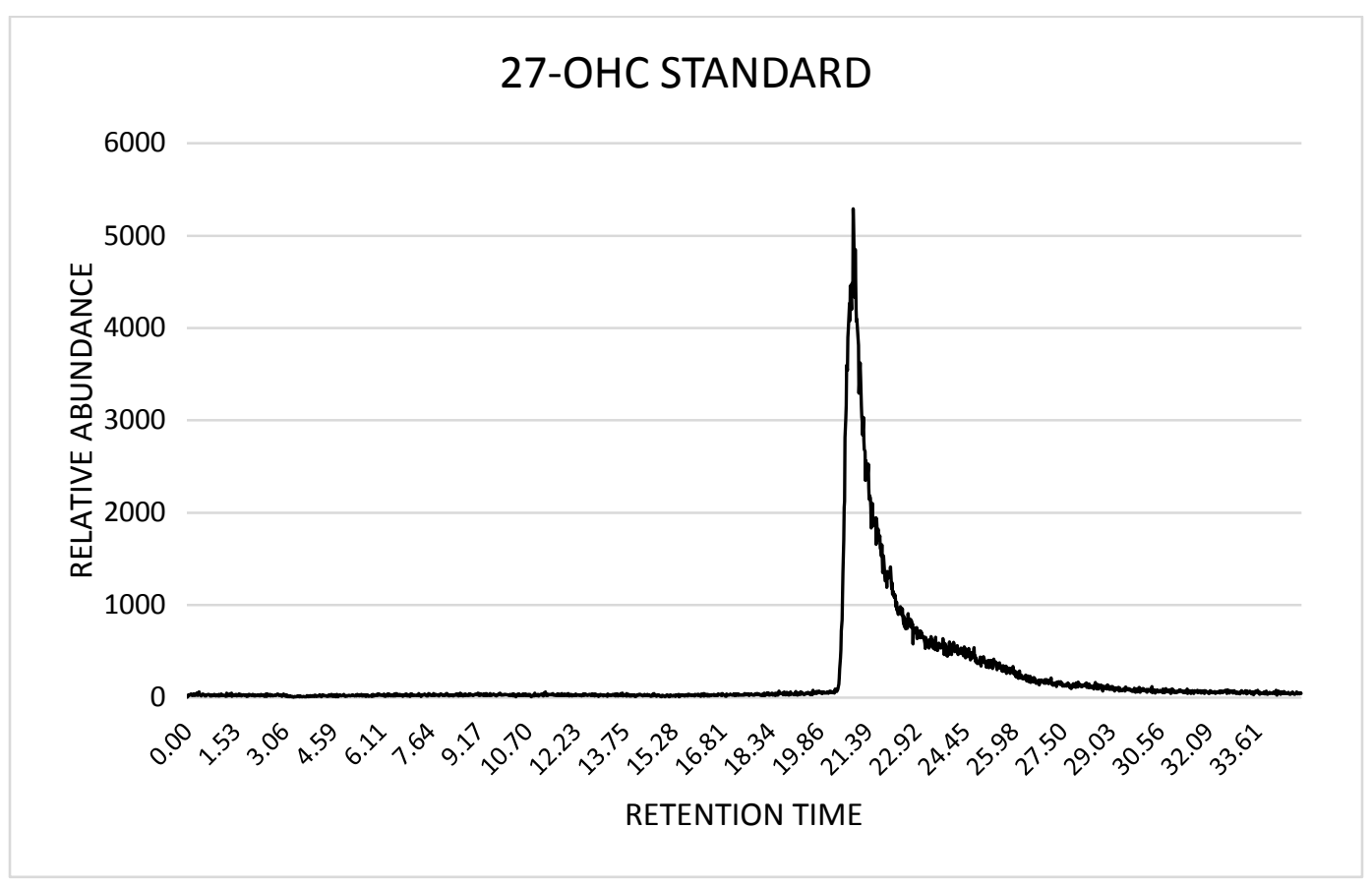

Figure 3.1 Chromatogram of 27-OHC standard. 


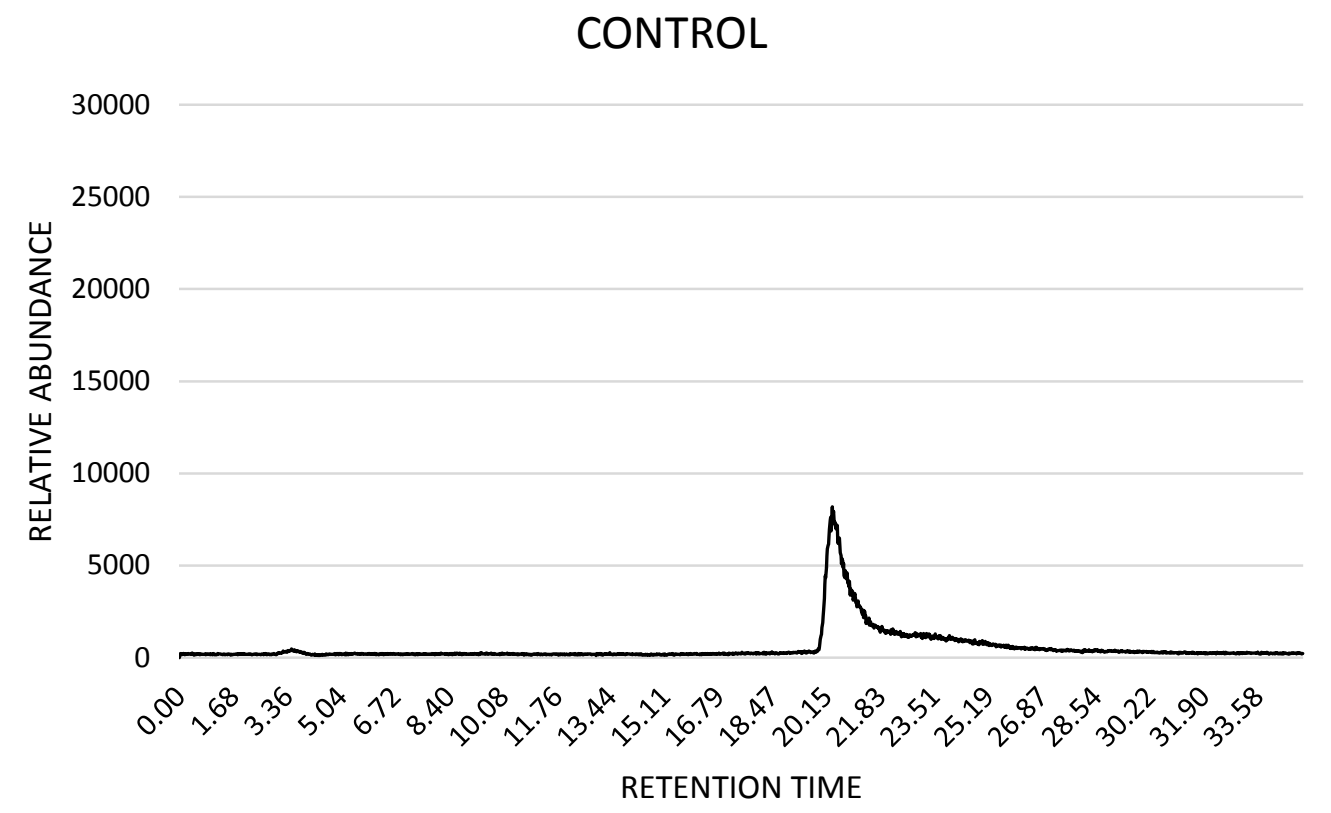

A.

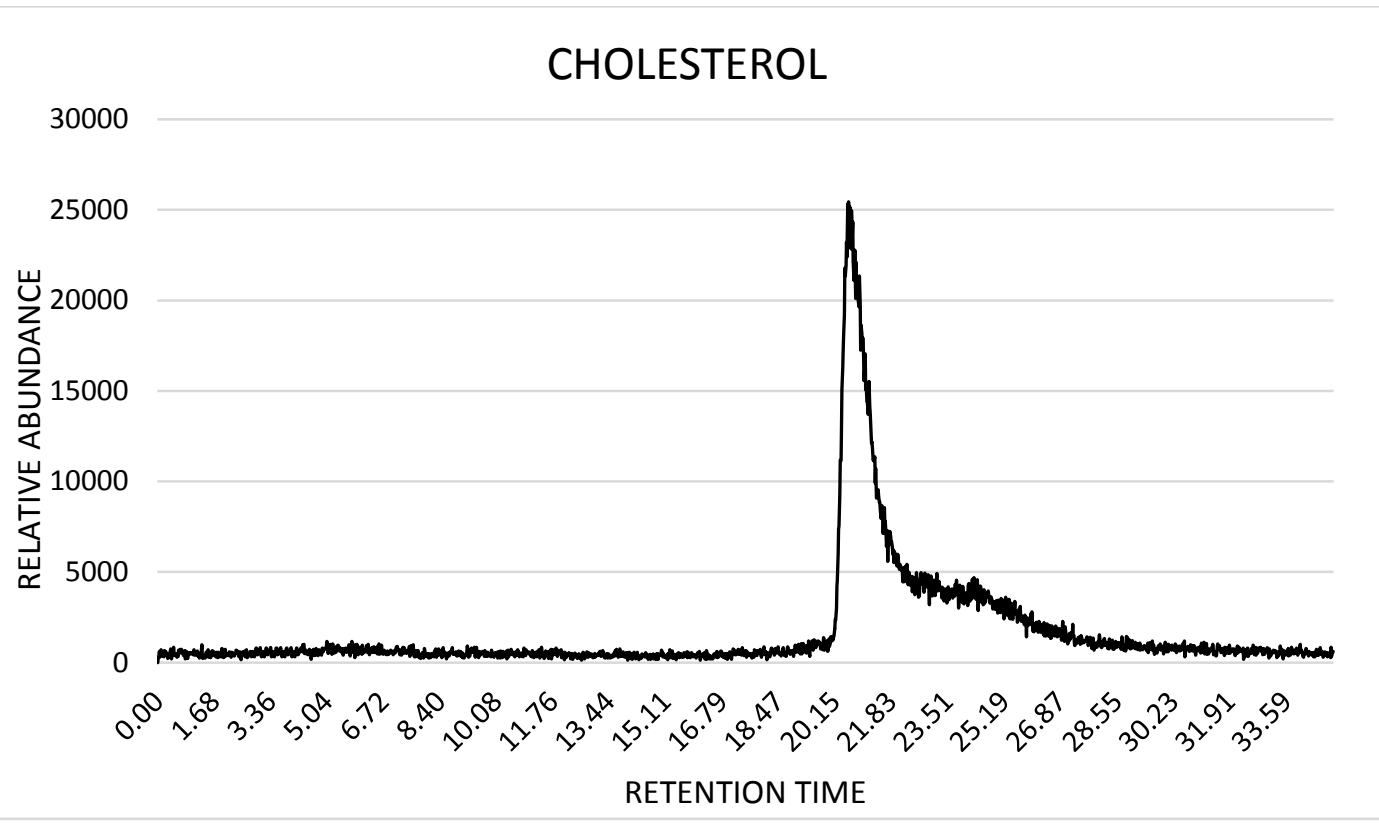

Figure 3.2 Representative chromatograms of control (A) and cholesterol-fed rabbit (B) hippocampal sample. 


\section{Summary and conclusions}

The aim of this study was to develop an MS-based method for the analysis of oxysterols from brain tissue. The evaluation of this method shows good repeatability and the results demonstrate good quantitative performance. Many methods of analyzing oxysterols have been described previously including gas chromatography (GC) (Lutjohann et al., 1996; Griffiths and Wang, 2011), gas chromatography-mass spectrometry (GC-MS)(Griffiths et al., 2013) and high performance liquid chromatography (HPLC) (Griffiths et al., 2013). These methods however are limited in the analysis of complex biological samples. GC-MS is selective and sensitive but it requires very time-consuming derivatization of oxysterols from tissue (Lutjohann et al., 1996; Griffiths and Wang, 2011). The methods we used have been validated in another laboratory (Ahonen et al 2014) and were easily adapted to our experimental conditions. We were able to show that a high-cholesterol diet increases levels of $27-\mathrm{OHC}$ in serum and the brain and with further development we would like to continue the work looking at other oxysterols implicated in AD such as $24-\mathrm{OHC}$. 
Chapter 4: 27-hydroxycholesterol effects on estrogen receptor signaling and estrogen receptor pathway downstream targets 


\section{$\underline{\text { Abstract }}$}

Hypercholesterolemia has been implicated in numerous health problems from cardiovascular disease to neurodegeneration. High serum cholesterol levels in midlife have been associated with an increased risk of developing AD later in life which suggests that the pathways leading to AD pathology might be activated decades before the symptoms of the disease are detected. Cholesterol-fed animals, particularly cholesterol-fed rabbits, exhibit brain pathology similar to the changes found in brains of Alzheimer's patients. Dietary cholesterol, which cannot pass the blood brain barrier, is thought to influence central nervous system homeostasis by increased transport of its circulatory breakdown product, $27-\mathrm{OHC}$, into the brain. $27-\mathrm{OHC}$ is an endogenous SERM. Estrogen-mediated non-reproductive functions require ERs and include modulation of mitochondrial function and structure, as well as regulation of synaptogenesis in the brain. ERs are located in brain areas affected early in AD pathogenesis, including the hippocampus. Here we report that increase in serum cholesterol, induced by feeding rabbits a high-cholesterol diet, is associated with higher levels of $27-\mathrm{OHC}$ in the brain as well as increased levels of neurodegeneration in the hippocampus. Furthermore, these results are accompanied by changes in expression of ERs in the hippocampus as well as a decrease in hippocampal mitochondria. These findings provide an important insight into one of the possible mechanisms involved in the development of $A D$, and shed light on the processes that may antedate beta amyloid and tau phosphorylation changes currently hypothesized to cause AD symptomology and pathology. 


\section{Introduction}

As the population of Western countries ages, dementia is becoming a major health concern. Over the last few decades, numerous risk factors contributing to late onset AD development and progression have been investigated. These include diabetes mellitus, hypertension, atherosclerosis and hypercholesterolemia (Panza et al., 2010). High serum cholesterol in midlife is associated with an increased risk of $A D$ (Kivipelto et al., 2002; Whitmer et al., 2005; Solomon et al., 2009b). Moreover, obese individuals with high blood pressure and high cholesterol are six times more likely to develop AD than individuals without these risk factors (Luchsinger and Gustafson, 2009). Most existing research investigating the role of cholesterol in increasing the risk of $A D$ has focused on how cholesterol affects APP processing and $A \beta$ clearance (Burns and Rebeck, 2010; Posse de Chaves, 2012; Maulik et al., 2013; Ong et al., 2013) even though recent findings in middle-aged neurologically healthy subjects indicate that $A \beta$ accumulation might be a reactive process with little mechanistic connection to disease development (Fornicola et al., 2014).

A connection between cholesterol and $A \beta$ aggregation characteristic of $A D$ in an animal model was first shown in cholesterol-fed rabbits (Sparks et al., 1994), and numerous experiments since have found that cholesterol increases $A \beta$ in in-vitro and invivo models of AD (Ghribi et al., 2006; Jaya Prasanthi et al., 2008; Lemieux et al., 2010). Treatment of rodents with dietary cholesterol resulted in memory impairment characteristic of AD (Zhang et al., 2015; Heverin et al., 2015) which we also have shown to be the case in the cholesterol-fed rabbit (Sparks and Schreurs, 2003; Darwish et al., 2010; Schreurs et al., 2012; Schreurs, 2013; Schreurs et al., 2013b). The inability 
of cholesterol to cross the blood brain barrier and the fact that a high-cholesterol diet does not change cholesterol content in the rabbit brain (Ghribi et al., 2006; Darwish et al., 2010) suggest that serum cholesterol by itself does not increase AD risk. This assumption was validated in a study that reported memory impairment in cholesterol-fed mice but not in cholesterol-fed mutant mice lacking the enzyme CYP27A1 that metabolizes cholesterol into 27-OHC (Heverin et al., 2015). This study suggested that 27-OHC mediated the negative effects of cholesterol on memory. Additionally, increased levels of 27-OHC have been found in AD brains (Heverin et al., 2004); therefore, increased flux of this cholesterol metabolite into the brain could play an important role in the cascade of events that lead to the development of late-onset $A D$ (Bjorkhem et al., 2009; Marwarha and Ghribi, 2015).

A significant insight into a possible mechanism underlying the relationship between $27-\mathrm{OHC}$ and $\mathrm{AD}$ came about with the discovery that $27-\mathrm{OHC}$ is an endogenous SERM (DuSell and McDonnell, 2008; DuSell et al., 2008). SERMs are able to act as ligands for different isoforms of ERs, including ERa and ERß, in a tissuedependent agonist or antagonist manner (Umetani et al., 2007; DuSell et al., 2010; Umetani and Shaul, 2011; Nelson et al., 2013; Wu et al., 2013; Umetani et al., 2014).

The purpose of this study was to explore potential $27-\mathrm{OHC}$-mediated changes in the hippocampus of rabbits fed a high-cholesterol diet. We chose to focus on the hippocampus because it is an area of the brain important for learning and memory and affected early and profoundly in AD pathology (Braak et al., 1993). We examined the levels of 27-OHC in hippocampal tissue of hypercholesterolemic and control animals as well as the expression of target ERs, mitochondria and the postsynaptic marker PSD- 
95. We hypothesized that higher levels of cholesterol metabolism in the periphery would result in an increased flux of $27-\mathrm{OHC}$ into the brain and that the surge of this SERM into the hippocampus would affect ER signaling and its downstream targets - mitochondria and synapses.

\section{Methods}

Animals, diet and tissue collection. The subjects were 32 New Zealand White male rabbits (Oryctolagus cuniculus) 3-4 months of age weighing approximately $2 \mathrm{~kg}$ upon arrival that were part of a larger study investigating the role of cholesterol on learning and memory (Schreurs et al., 2013b). Animals were housed individually with free access to food and water and maintained on a 12-hour light-dark cycle. All the experiments followed guidelines of National Institutes of Health and were approved by West Virginia University Animal Care and Use Committee. Rabbits were assigned to two dietary groups: control or a high-cholesterol diet. Control diet animals received Purina 5326 chow, and the high cholesterol diet group received Purina 5326 plus $2 \%$ cholesterol chow (T.R. Last Co., Gibsonia, PA). All the rabbits were kept on their respective diets for a total of 11 weeks. At the conclusion of the study, animals were deeply anesthetized with a mixture of ketamine $(500 \mathrm{mg} / \mathrm{kg})$ and xylazine $(10 \mathrm{mg} / \mathrm{kg})$ and overdosed with Somnasol before transcardial perfusion with either artificial CSF solution or $0.5 \%$ paraformaldehyde. Brains were collected and flash frozen or postfixed in $4 \%$ paraformaldehyde solution for further processing. Before euthanasia, transcardial blood was collected in EDTA tubes and centrifuged, and the serum was frozen and stored at $80^{\circ} \mathrm{C}$ until analysis. 


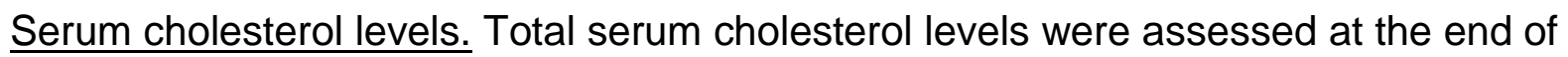
the experiment using a colorimetric kit (BioAssay Systems, ECCH-100) following the manufacturer's instructions.

Neurodegeneration: Fluoro-Jade C staining. Fluoro-Jade C staining was performed based on previously published methods (Schmued et al., 2005). Brains stored in paraformaldehyde were cryoprotected in sucrose and formaldehyde solution then sectioned using a freezing microtome (Microm HM450). Coronal 50- $\mu \mathrm{m}$ sections of the dorsal hippocampus were mounted on gelatin coated slides. Every $3^{\text {rd }}$ section was collected, and an average of 15 sections from each subject were processed. Mounted sections were dried overnight and processed with a Fluoro-Jade $\mathrm{C}$ staining kit (HistoChem Inc). Slides were incubated in 70\% ethanol and sodium hydroxide solution (9:1 ratio) for 5 minutes. They were then rinsed for 2 minutes in $70 \%$ ethanol followed by 2 minutes in distilled water, then incubated in $0.06 \%$ potassium permanganate solution for 10 minutes and again for 2 minutes in a distilled water rinse. Slides were then transferred to the Fluoro-Jade C solution with DAPI as the fluorescent Nissl counter stain and incubated for 10 minutes. This was followed by three 1-minute distilled water rinses after which slides were placed on a slide warmer at $50^{\circ} \mathrm{C}$ for at least 5 minutes. Semi-dried slides were then cleared in xylenes for 2-3 minutes each and coverslipped using DPX (Sigma) as the mounting medium. Slides were imaged using a confocal microscope (LSM710, Carl Zeiss International). Digital images were collected and stained cells were counted using Image $\mathrm{J}$ software $(\mathrm{NIH})$ by a researcher $(\mathrm{SWB})$ blind to the experimental conditions. 
Fluorescent ER antibody staining. Immunofluorescent staining was performed using manufacturer recommended protocols. Brains stored in paraformaldehyde were cryoprotected in sucrose and formaldehyde solution and then sectioned using a sliding microtome. Coronal 50- $\mu \mathrm{m}$ sections of dorsal hippocampus were mounted on gelled slides. Slides underwent an antigen retrieval protocol in $10 \mathrm{mM}$ citrate buffer $\mathrm{pH} 6.0$ for 40 minutes at $60^{\circ} \mathrm{C}$. The sections were washed in phosphate buffered saline (PBS) plus Tween ( $\mathrm{pH}$ 7.4) six times for 5 minutes each at room temperature. After incubation in $5 \%$ normal goat serum in PBS+tween for 2 hours, sections were incubated in primary antibodies (mouse monoclonal anti-mitochondria (ab3298, Abcam) dilution 1:500, mouse monoclonal ERa (MA1-27107, ThermoScientific) dilution 1:200, rabbit polyclonal ERß (PA5-16476, ThermoScientific) dilution 1:200) for 48 hours at $4^{\circ} \mathrm{C}$. Again, the sections were washed with PBS, 6 times for 5 minutes each before secondary antibody incubation (goat anti-rabbit IgG AF488 (ab150077, Abcam) dilution 1:1000, goat antimouse IgG AF488 (ab150113, Abcam) dilution 1:1000) for 4 hours at room temperature. After a final series of rinses (PBS 6 times for 5 minutes each), slides were coverslipped using fluoromount G containing a DAPI counterstain. Slides were imaged on a LSM710 confocal microscope (Carl Zeiss International) and digital images processed as stated above.

$\underline{27-O H C}$ extraction from serum samples. Oxysterol extraction methods were adapted from Ahonen et al. (Ahonen et al., 2014). Briefly, $1 \mathrm{~mL}$ of methyl t-butyl ether (MTBE) was added to a $150 \mu \mathrm{L}$ of rabbit serum. Sample was vortexed for 1 minute and centrifuged at 2000 rpm for 5 minutes. MTBE phase was filtered into a glass sample vial through a $0.2 \mu \mathrm{m}$ syringe filter (Corning Incorporated) and evaporated to dryness. 
Samples were reconstituted in $100 \mu \mathrm{L}$ of $5 \%$ ammonium acetate $(50 \mathrm{mM}, \mathrm{pH} 4.5$ with acetic acid):methanol:acetonitrile (1:3:6, v/v) and vortexed just before the analysis by the LC-MS system.

27-OHC extraction from hippocampus. Methods of oxysterol extraction from the brain were developed based on Ahonen et al. (Ahonen et al., 2014). Briefly, the intact left hippocampi were weighed and homogenized using ultrasonication, and $0.5 \mathrm{~mL}$ dichloromethane (DCM): methanol mixture $(1: 1, \mathrm{v} / \mathrm{v})$ was added to tissue and sonicated on an ice bath for 1 minute. Samples were centrifuged at $13200 \mathrm{rpm}$ for 5 minutes, then supernatants removed and the procedure repeated. After the second extraction, supernatants were collected and evaporated to dryness. Immediately before analysis by LC-MS, the samples were reconstituted in $100 \mu \mathrm{L}$ of methanol, centrifuged at 13200 rpm for 5 minutes and the supernatants collected into glass sample vials.

27-OHC levels: Liquid Chromatography-Mass Spectrometry. Extracts from hippocampal tissue and rabbit's serum $(1 \mu \mathrm{L})$ were injected into a Dionex UltiMate 3000RS Nano LC system (ThermoScientific) using a custom made $2.5 \mu \mathrm{m}$ XBridge BEH C8 column, $300 \mu \mathrm{m} \times 150 \mathrm{~mm}$ (Waters) with a flow rate of $5 \mu \mathrm{L} / \mathrm{min}$. 27-OHC was eluted using a gradient of $20 \% \mathrm{~A}$ (water with $5 \mathrm{mM}$ of ammonium formate) and $80 \% \mathrm{~B}(100 \%$ methanol with $5 \mathrm{mM}$ ammonium formate) for 10 minutes. The gradient was then transitioned from 80 to $99 \%$ B for 5 minutes, then maintained at $99 \%$ B for 10 minutes, followed by a reequilibration period when the column was returned to $80 \% \mathrm{~B}$ in 5 minutes and maintained to the end of the 35 -minute run. $27-\mathrm{OHC}$ eluted at 20.56 minutes.

Western Analysis of ER, mitochondria and PSD-95 protein levels. Protein levels were quantified using an automated Simple Western "Wes" system from ProteinSimple 
(O'Neill et al., 2006; Beccano-Kelly et al., 2014). It is a capillary electrophoresis assay that automatically loads, separates and detects proteins. Procedures were performed with the manufacturer's reagents following the manufacturer's protocol. Briefly, the lysate was mixed with fluorescent standard master mix and heated at $95^{\circ} \mathrm{C}$ for 5 minutes. The samples, blocking reagents, primary and secondary antibodies and chemiluminescent substrate were dispensed into a microplate included in manufacturer's kit. The prepared microplate and the capillary cartridge were placed into a Wes instrument (ProteinSimple), and the program was run using default settings. During the electrophoresis, proteins were separated by size and immobilized into the capillary wall, and chemiluminescent signals were read by Compass software (version 2.6.5 ProteinSimple) which analyzed the area under the curve for each antibody. The area under the curve represents the signal intensity of the chemiluminescent reaction and is proportional to the amount of target protein in a respective capillary (Hartz et al., 2016). The data were analyzed by a blinded researcher (SWB) and normalized to $\beta$ actin levels (mouse monoclonal anti- $\beta$-actin (sc-47778, Santa Cruz Biotechnology, Inc.)).

Antibodies used for Western analysis include: mouse monoclonal anti-mitochondria (ab3298, Abcam) dilution 1:50, mouse monoclonal ERa (MA1-27107, ThermoScientific) dilution 1:50, rabbit polyclonal ERß (PA5-16476, ThermoScientific) dilution 1:50, mouse monoclonal PSD-95 (MA1-046, ThermoScientific) dilution 1:50.

Data analysis. All the data analysis was performed by a researcher blinded to experimental conditions (SWB). For statistical analysis one-way ANOVA was performed with significance set at $p<0.05$. Data are presented as mean \pm SEM. 


\section{$\underline{\text { Results }}$}

\section{Serum cholesterol and hippocampal 27-OHC.}

Feeding rabbits a high-cholesterol diet for 11 weeks significantly increased serum cholesterol. The mean serum cholesterol level for cholesterol-fed animals was significantly higher than for animals in the control group. The control group had a mean serum cholesterol level of $15.6 \mathrm{mg} / \mathrm{dL}$ whereas the cholesterol-fed group had a mean serum total cholesterol of $992.6 \mathrm{mg} / \mathrm{dL}$ as measured by a colorimetric kit $[F(1,8)=61.11$, $p<0.001$ ] (Fig. 4.1)

Spectrometric analysis of $27-\mathrm{OHC}$ levels in serum as well as hippocampal tissue showed the level of $27-\mathrm{OHC}$ in serum was significantly increased following a highcholesterol diet, from $15.4 \mathrm{ng} / \mathrm{mL}$ in the control group to $34.7 \mathrm{ng} / \mathrm{mL}$ in the cholesterolfed group $[F(1,8)=47.6, p<0.001]$ (Fig. 4.2 A). Similarly the hippocampal level of 27$\mathrm{OHC}$ was significantly increased in the cholesterol-fed group, from $6.8 \mathrm{ng} / \mathrm{mg}$ in the control group to $26.9 \mathrm{ng} / \mathrm{mg}$ in the cholesterol-fed group $[F(1,8)=32.11, \mathrm{p}<0.001]$ (Fig. $4.2 \mathrm{~B})$. 


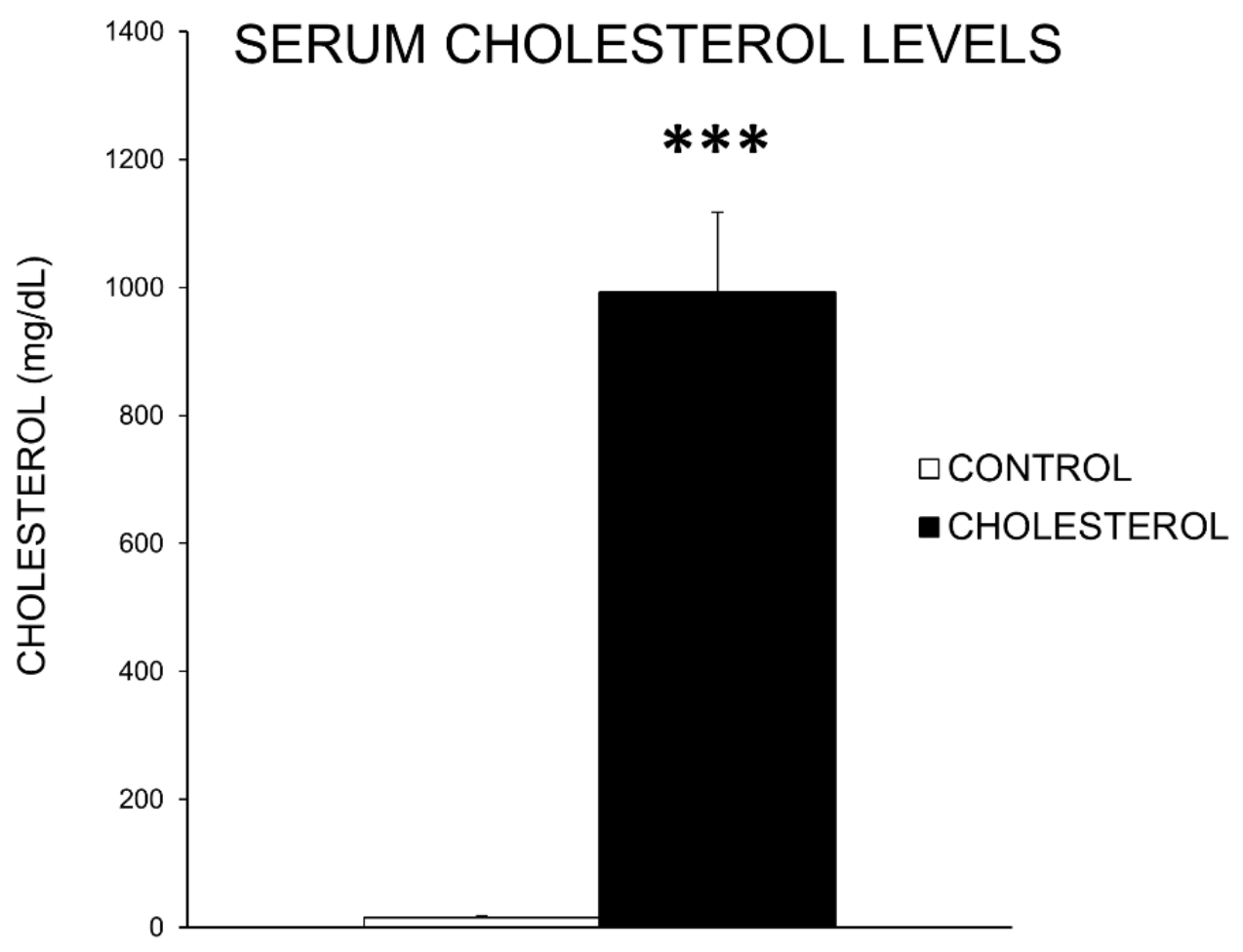

Figure 4.1. Serum cholesterol. Mean serum cholesterol levels for control group $(n=5)$ was $15.6 \mathrm{mg} / \mathrm{dL}$ while high-cholesterol animals $(n=5)$ average serum total cholesterol was $992.6 \mathrm{mg} / \mathrm{dL}$ as measured by a colorimetric kit $\left(\mathrm{p}^{* * *}<0.001\right)$. 


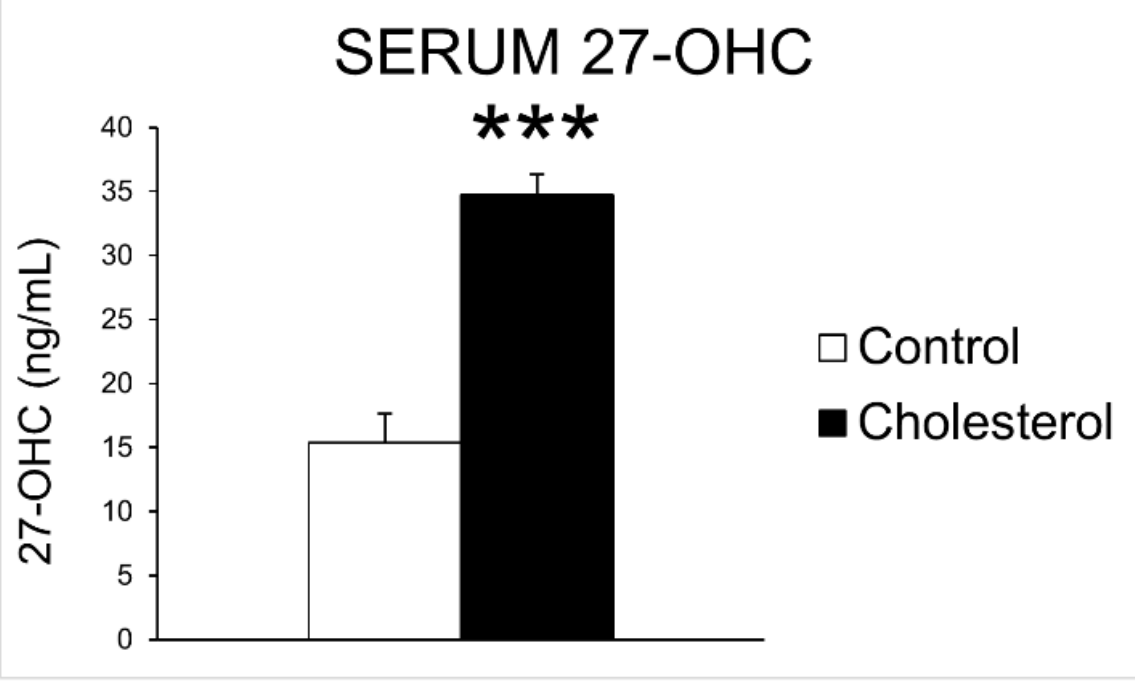

A

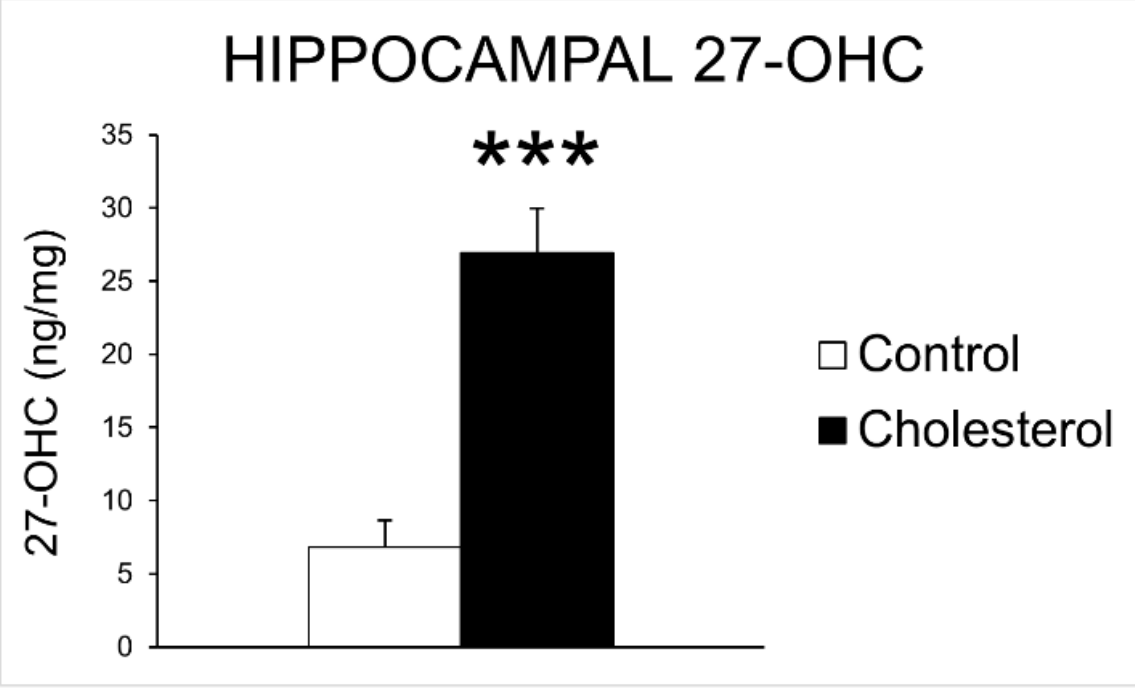

Figure 4.2. $27-\mathrm{OHC}$ levels in serum and hippocampus. Serum level of $27-\mathrm{OHC}$ was significantly increased following a high-cholesterol diet, from $15.4 \mathrm{ng} / \mathrm{mL}$ in control group $(n=5)$ to $34.7 \mathrm{ng} / \mathrm{mL}$ in cholesterol-fed animals $\left(n=5, p^{* \star *}<0.001\right)(A)$, and similarly the hippocampal level of $27-\mathrm{OHC}$ increased from $6.8 \mathrm{ng} / \mathrm{mg}$ in control group $(n=5)$ to $26.9 \mathrm{ng} / \mathrm{mg}$ in cholesterol-fed group $\left(\mathrm{n}=5, \mathrm{p}^{* * *}<0.001\right)(B)$. 


\section{Neurodegeneration.}

Analysis of Fluoro-Jade C staining in hippocampal tissue indicated that the highcholesterol diet was associated with significantly increased levels of neurodegeneration in $\mathrm{CA} 1 / 2[F(1,8)=9.60, \mathrm{p}<0.05]$ and $\mathrm{CA} 3$ of hippocampus $[F(1,8)=22.70, \mathrm{p}<0.001]$ but not in the dentate gyrus $[F(1,8)=0.85, \mathrm{p}=0.384]$ (Fig. 4.3)

\section{FLUORO JADE C STAINED NEURONS}

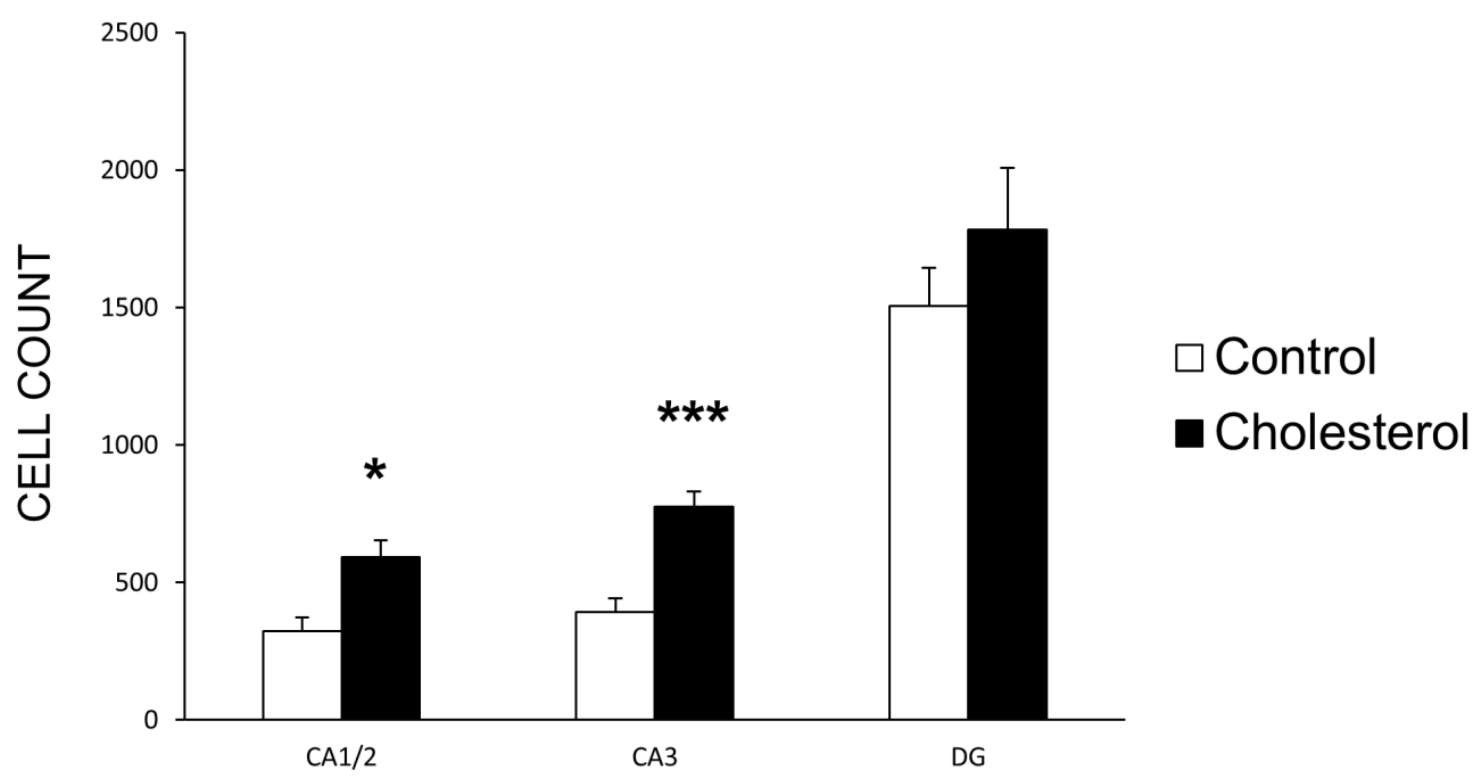


Figure 4.3. Neurodegeneration - Fluoro Jade C staining of hippocampal sections. Data are mean $( \pm$ SEM) counts of stained cells for control $(n=4)$ and cholesterol-fed $(n=6)$ groups in each respective region of dorsal hippocampus (CA1/2; $\left.\mathrm{p}^{*}<0.05\right), \mathrm{CA} 3$; $\left.\mathrm{p}^{* * *}<0.001\right)$ and dentate gyrus (DG).

\section{Hippocampal estrogen receptors and their downstream targets.}

Figure 4.4 A shows representative fluorescent confocal images of the hippocampus of a control rabbit labeled with anti-ER $\alpha$ antibody in green and DAPI staining nuclei blue. Figure 4.4 B depicts the same antibody labeling in the hippocampus of a cholesterol-fed rabbit. In rabbits fed a high-cholesterol diet, immunofluorescent staining of ERa was decreased significantly in CA1/2 $[F(1,14)=55.89, \mathrm{p}<0.001]$ and $\mathrm{DG}[F(1,14)=6.36, \mathrm{p}<0.05]$ (Fig. $4.4 \mathrm{C})$. Western blot analysis of whole hippocampal homogenate showed a significant decrease in ERa $[F(1,6)=18.62, p<0.05]$ (Fig. 4.4 D) .

Figure 4.5 A shows representative fluorescent confocal images of labeling of ER $\beta$ (green) and the nucleus marker DAPI (blue) in the hippocampus from a control rabbit (left) and in the hippocampus from a cholesterol-fed (right). There was an increase in $E R \beta$ immunofluorescent staining in $C A 3[F(1,15)=5.85, p<0.05]$ and $D G$ $[F(1,14)=5.68, p<0.05]$ in cholesterol-fed rabbits compared to controls (Fig. $4.5 \mathrm{~B}$ ). In area $\mathrm{CA} 1 / 2$ there was a trend for increased levels of staining for $\operatorname{ER} \beta[F(1,15)=4.15$, $p=0.06]$ in cholesterol-fed rabbits. Western blot analysis of whole hippocampus 
homogenates suggested somewhat higher levels of ER $\beta$ in hypercholesterolemic subjects although this difference was not statistically significant (data not shown).

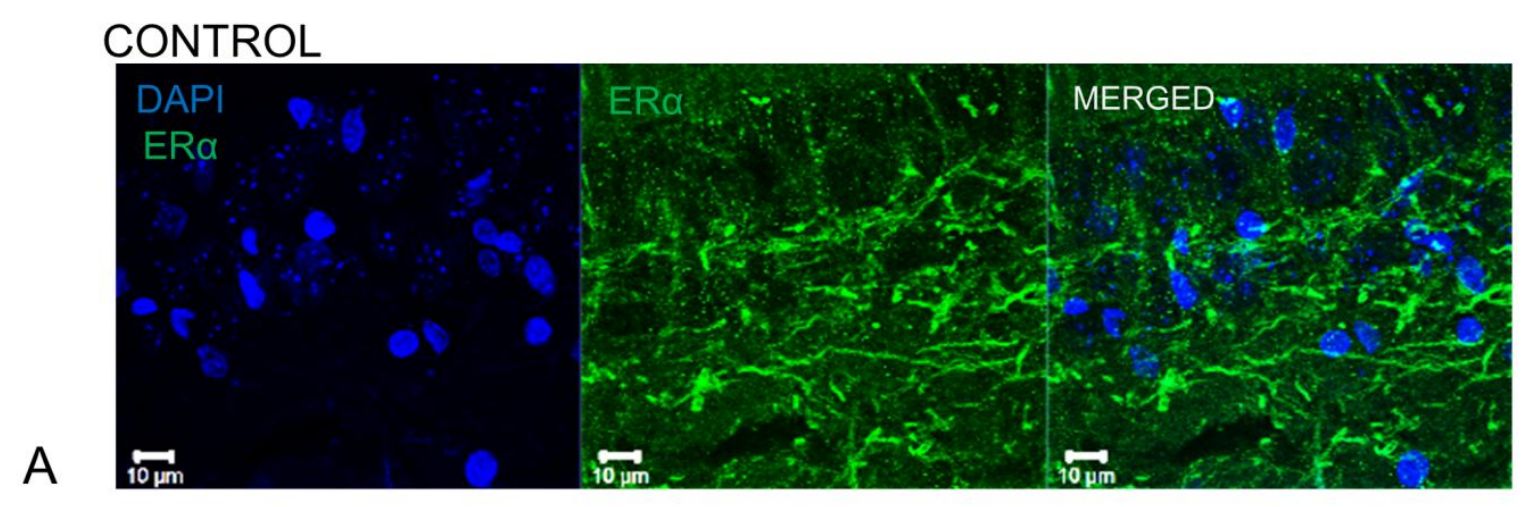

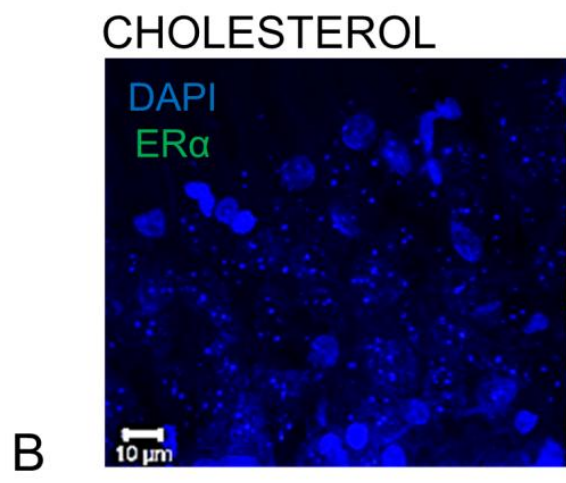

ER a FLUORESCENT COUNT

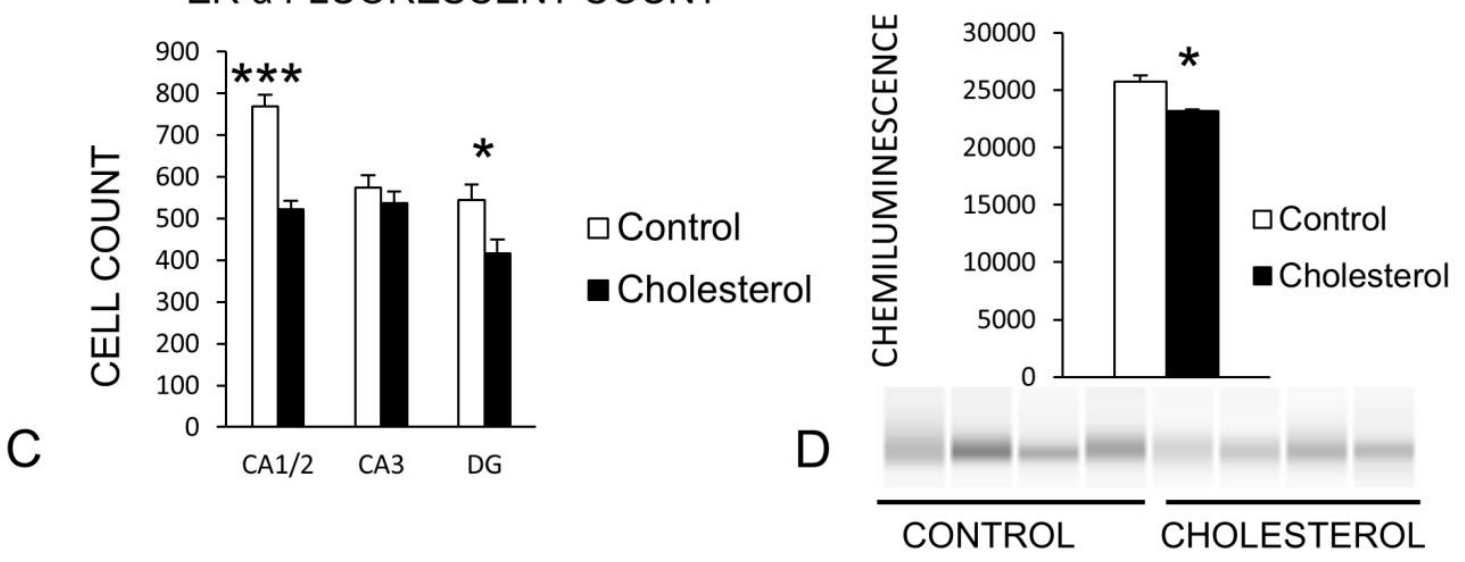

Figure 4.4. High-cholesterol diet reduces ERa in the hippocampus. Representative confocal images of control hippocampus section with DAPI staining nuclei blue and 
green fluorescence labeling ER $\alpha(A)$. ER $\alpha$ labeling decreased in rabbits fed a highcholesterol diet (B). Mean count of stained cells for control $(n=7)$ and cholesterol $(n=9)$ groups in each respective region of dorsal hippocampus showed a decrease in the amount of staining in rabbits fed a high-cholesterol diet (CA1/2 $\left(\mathrm{p}^{* * *}<0.001\right), \mathrm{CA} 3$ and dentate gyrus DG $\left.\left(p^{*}<0.05\right)\right)(C)$. Western blot showed significant downregulation of ER alpha $\left(p^{*}<0.05\right)$ in hippocampal tissue (control group $n=4$, cholesterol $\left.n=4\right)(D)$.
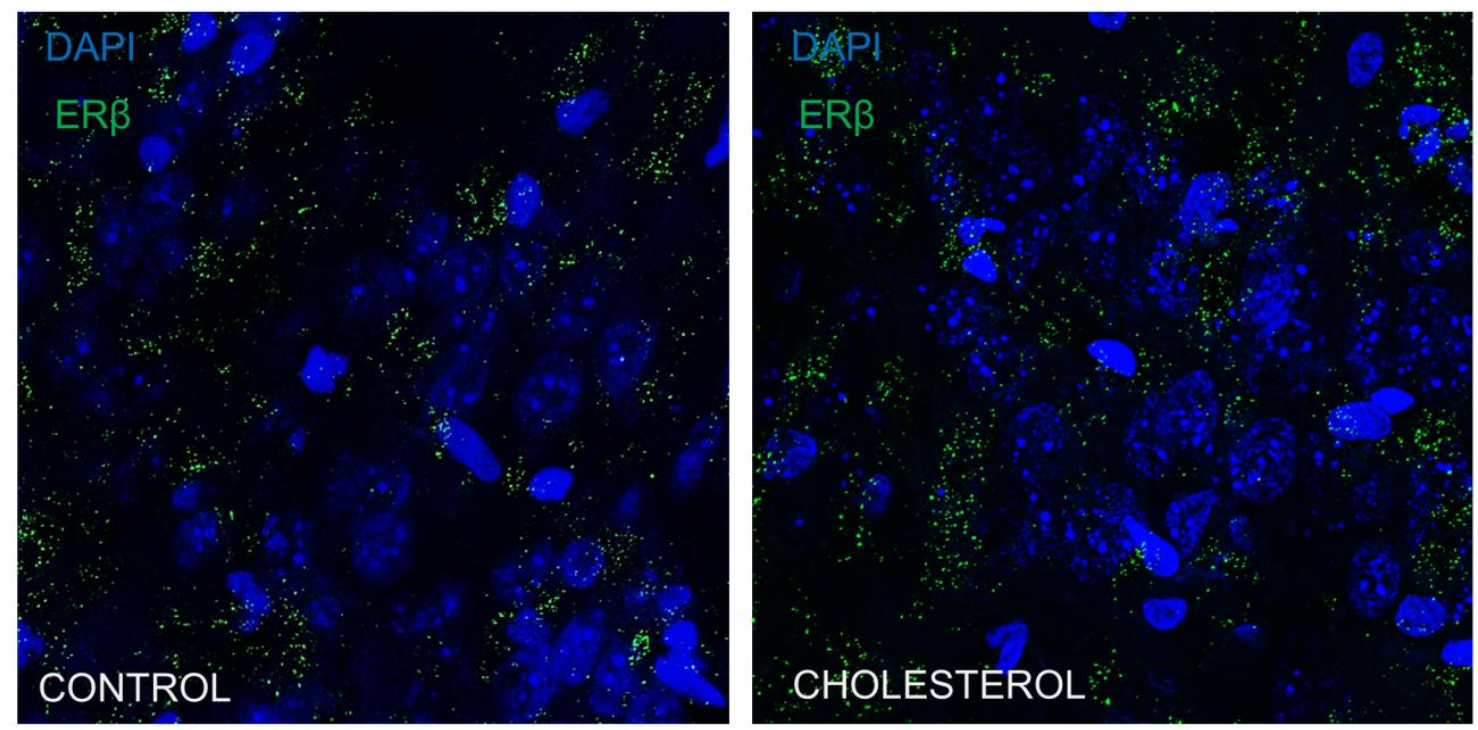

\section{ER $\beta$ FLUORESCENT COUNT}

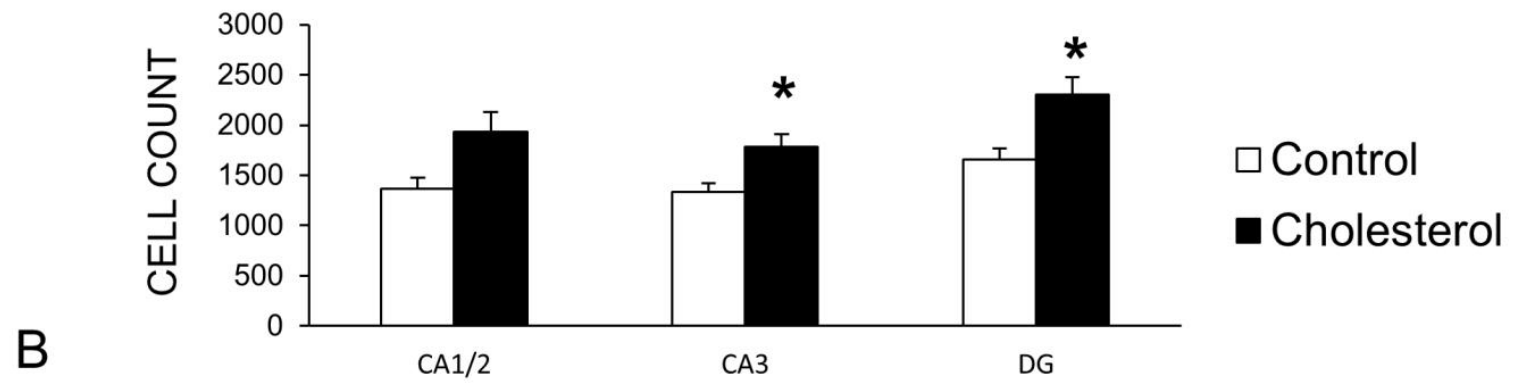

Figure 4.5. ERß labeling in hippocampus increased following a high-cholesterol diet.

Representative images of ERß (green) fluorescent labeling in hippocampus. 
Cholesterol-fed subject (right) shows and increase in ER $\beta$ staining relative to control (left) (DAPI - blue - stains nuclei)(A). Fluorescent labeling for ER $\beta$ was quantified using Image $\mathrm{J}$ and a one-way ANOVA showed a significant effect of the high-cholesterol diet on the number of ER $\beta$ in areas CA3 and DG of the hippocampus $\left({ }^{*} p<0.05\right.$ and ${ }^{* *} p<0.05$ respectively). Data from CA1 were also consistent with these findings although not statistically significant $(p=0.06)$ (control group $n=6$, cholesterol $n=11)(B)$.

Finally, cholesterol-fed rabbits exhibited lower levels of post-synaptic marker PSD-95 in hippocampus $[F(1,6)=10.40, p<0.05]$ (Fig 4.6) as well as a decrease in levels of mitochondria $[F(1,6)=17.057, \mathrm{p}<0.01]$ (Fig. 4.7) compared to controls. 


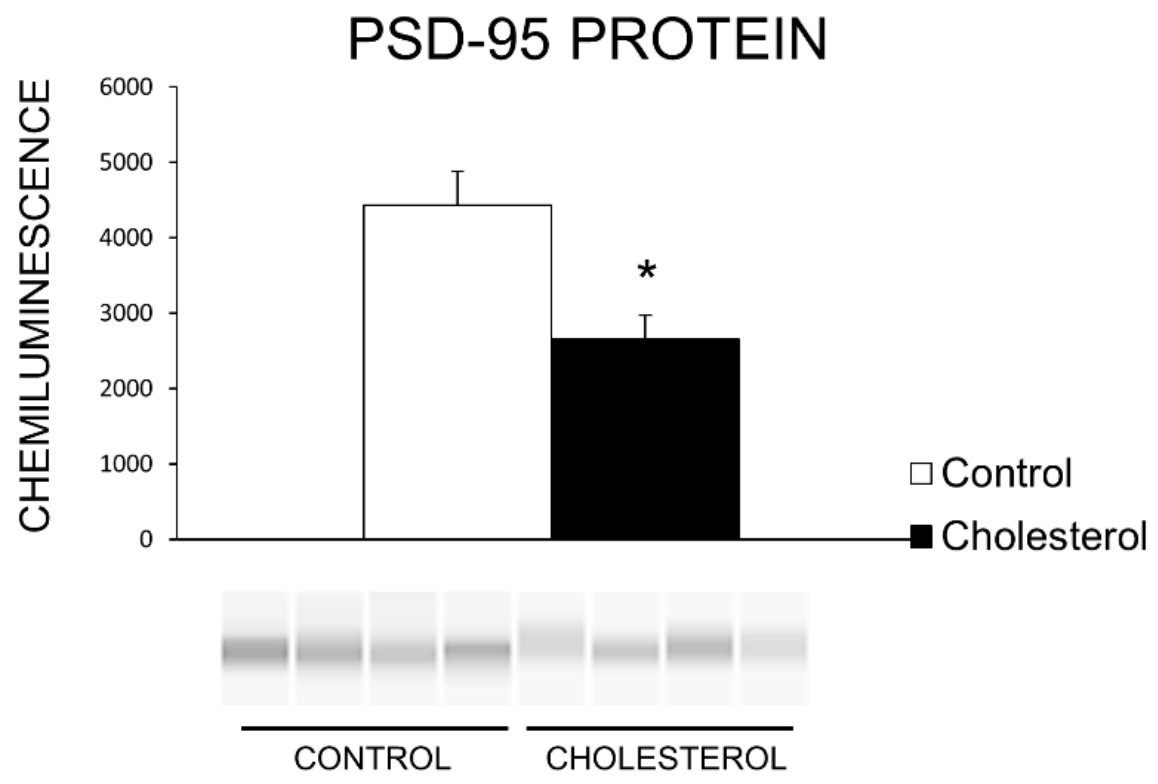

Figure 4.6. Post-synaptic protein PSD-95 in hippocampus. Western blot showed significant downregulation of post-synaptic marker PSD-95 in rabbits fed the highcholesterol diet $(p<0.05)$ (control group $n=4$, cholesterol $n=4)$. 


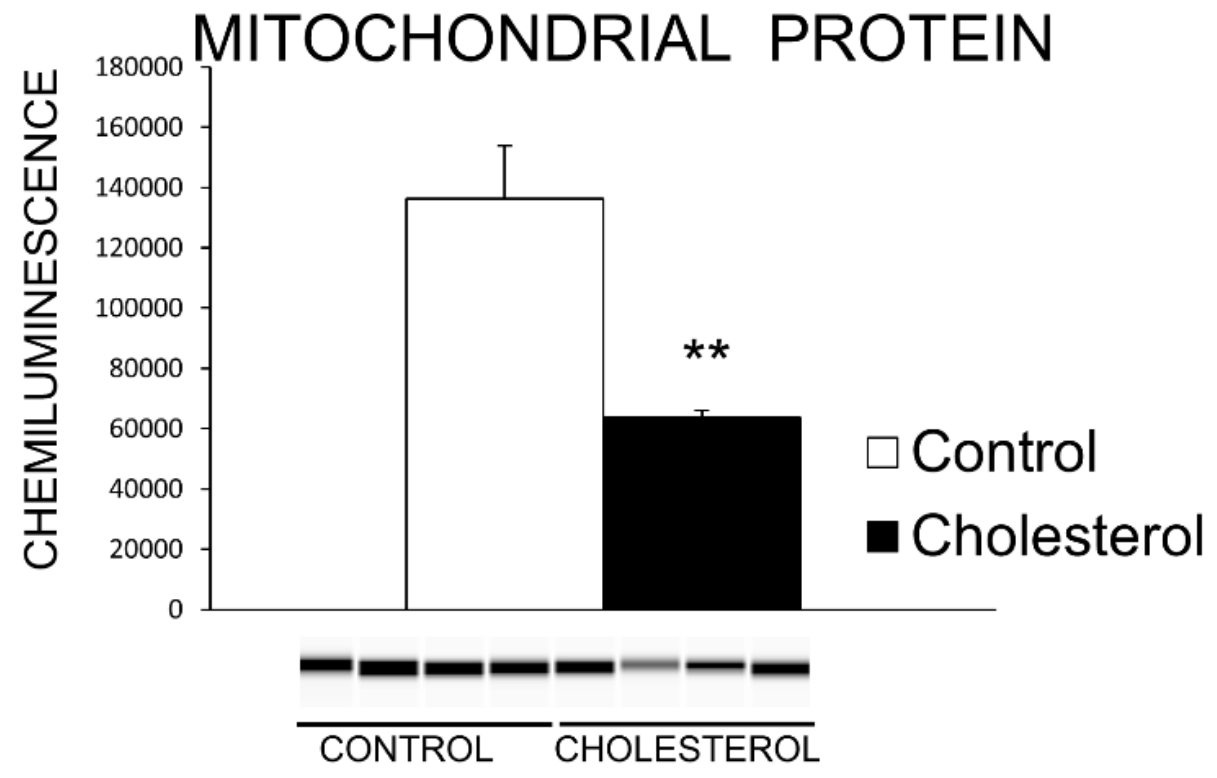

Figure 4.7. Mitochondrial protein content in hippocampus. Western blot showed significant downregulation of mitochondrial protein in rabbits fed the high-cholesterol diet $(p<0.005)$ (control group $n=4$, cholesterol $n=4)$.

\section{$\underline{\text { Discussion }}$}

In this study we were able to show for the first time that high serum cholesterol in a cholesterol-fed rabbit is accompanied by increased levels of $27-\mathrm{OHC}$ in the hippocampus and provide an indication of possible mechanisms responsible for AD-like 
pathology related to hypercholesterolemia. Based on our results, we suggest that there may be an association between the levels of $27-\mathrm{OHC}$, an endogenous estrogen modulator, and expression of ERs in the rabbit hippocampus. Moreover, we report that a high-cholesterol diet is associated with higher levels of neurodegeneration in the hippocampus as well as decreased levels of mitochondria and synaptic marker protein PSD-95 which could be a downstream result of aberrant ER signaling.

The cholesterol-fed rabbit model of AD shows a multitude of pathological findings similar to those seen in $A D$ patients including $A \beta$ deposits, neurofibrillary tangles, apoptosis, microglia activation, and increased ventricular volume (Ghribi et al., 2006; Jaya Prasanthi et al., 2008; Prasanthi et al., 2010; Deci et al., 2012) as well as cognitive deficits (Sparks and Schreurs, 2003; Darwish et al., 2010; Schreurs et al., 2012; Schreurs, 2013; Schreurs et al., 2013b). Here we also demonstrated that a highcholesterol diet is associated with significant levels of neurodegeneration in the hippocampus. This is an important finding because hippocampal neurodegeneration is one of the hallmarks of $A D$ neuropathology and an aspect often lacking in transgenic models of the disease based on autosomal dominant forms of AD (Richner et al., 2009; West et al., 2009). Mutations of APP (St George-Hyslop et al., 1987; Goate et al., 1991), presenilin-1 (St George-Hyslop et al., 1992; Van et al., 1992; Sherrington et al., 1995) or presenilin-2 (Sherrington et al., 1996) all result in an abnormally high $A \beta$ burden as well as some cognitive deficits characteristic in patients with familial AD. Transgenic rodents containing mutations in genes encoding for APP and enzymes involved in APP processing present with A $\beta$ plaques accompanied by cognitive deficits, but most of these models fail to show a loss of synapses and neurons in the 
hippocampus (Richner et al., 2009; West et al., 2009). Consequently, clinical trials based on research with genetically modified animals targeting $A \beta$ have been discouraging (Benilova et al., 2012),(Castello and Soriano, 2014). Moreover, studies utilizing those models provided very few answers regarding the etiology of late onset (sporadic) AD. This suggests that there might be important mechanistic differences between early and late onset forms of dementia, and there is a need for non-transgenic models such as the cholesterol-fed rabbit for studying the causes of more common sporadic AD.

Many studies have investigated the correlation between oxysterol levels and neurodegenerative disease but their findings are somewhat inconsistent (Lutjohann et al., 2000; Heverin et al., 2004; Solomon et al., 2009b; Zuliani et al., 2011; Mateos et al., 2011a; Hughes et al., 2012; Hughes et al., 2013). Some of these inconsistencies arise from the fact that subject cohorts comprised different disease stages and subtypes. The appropriate time for clinical assessment and treatment is especially important as midlife cardiovascular risk factors confer increased risk for developing $A D$, but once dementia begins, these risk factors diminish (Beach et al., 2011), a finding that might account for inconsistencies in studies of diet affecting AD patients. In this study we used a cholesterol-fed rabbit model of sporadic $A D$ that removes many of these inconsistencies to investigate the role of $27-\mathrm{OHC}$ at a relatively early time point during the progression of well-characterized AD-like pathology (Sparks et al., 1990a; Sparks et al., 1994).

An increase of the oxysterol $27-\mathrm{OHC}$ in hippocampus in this study is especially important in the light of recent findings regarding the function of this oxysterol. This biologically active molecule has the potential to bind to estrogen receptors and either 
activate or inhibit ER-dependent pathways. Since its identification as the first endogenous estrogen receptor modulator (DuSell et al., 2008), 27-OHC has been extensively studied in known estrogen-regulated tissues and cell types. It has been shown to act as a partial agonist of ERa in breast cancer cells (DuSell et al., 2008; Wu et al., 2013), and bone tissue (DuSell et al., 2010; Nelson et al., 2011), but in the cardiovascular system, 27-OHC competitively antagonizes estrogen's actions on ERa and ER $($ Umetani et al., 2007) and promotes inflammation and atherosclerosis via ER $\alpha$ signaling (Umetani et al., 2014). Not much is known at present about the biological actions of $27-\mathrm{OHC}$ in the brain although it has been shown that $27-\mathrm{OHC}$ adversely affects cognition in rodents (Zhang et al., 2015; Heverin et al., 2015). Here we report that an increase in $27-\mathrm{OHC}$ in the hippocampus is accompanied by changes in ER expression, a finding that could indicate a mechanistic link between oxysterols and neurodegeneration.

In our study we used male rabbits in order to eliminate the protective effects of estrogen seen in female rabbits with elevated cholesterol (Sparks, 2008). Both ERa and ER $\beta$ are localized throughout the hippocampal formation and there are no significant sex differences in ER distribution in the hippocampus of rodents, primates or humans (McEwen et al., 1995; McEwen et al., 2012; Foster, 2012; Han et al., 2013; Hara et al., 2015) making our study relevant to both males and females. It has been shown that $A D$ is more common in women (Brookmeyer et al., 2011), and women experience more severe behavioral and cognitive symptoms during the progression of the disease (Chapman et al., 2011; Irvine et al., 2012). Early research into possible reasons for this sex difference was based on the fact that women tend to live longer and hence have a 
higher susceptibility to developing the disease. However, more recent studies indicate that there must be other factors predisposing women to a higher risk for AD (Zhao et al., 2016), and one of these is the loss of neuroprotection mediated by the loss of estrogen at menopause.

Downregulation of ERa in the hippocampus of hypercholesterolemic rabbits in our study could indicate that $27-\mathrm{OHC}$ antagonizes the beneficial effects of estrogen signaling through ERa receptor. A decrease in hippocampal ERa has been associated with estrogen depletion in rodents while ER $\beta$ levels remained unchanged (Zhang et al., 2011; Qu et al., 2014) implicating ERa as an important element in estrogen-mediated neuroprotection. Neuroprotective roles of estrogen have been extensively studied, and there are many reports that estrogen affects cognitive function in humans and in animal models (Srivastava et al., 2013; Han et al., 2013; Hara et al., 2015). The importance of estrogen signaling in the hippocampus came to light with the discovery of estrogeninduced synapse formation (Gould et al., 1990). ERa and ERß receptors function differently in regulating synaptic connectivity in the hippocampus: activating ERa increases the density of dendritic spines in CA1 (Phan et al., 2011) while treatment with ER $\beta$ agonists has the opposite effect (Szymczak et al., 2006) suggesting the importance of ERa in synaptogenesis. Moreover, in an organotypic hippocampal culture, estrogen treatment prevented $A \beta$-induced neuronal death and that same neuroprotective effect was achieved with the use of an ERa selective agonist (Merlo et al., 2016). The same study also showed that neuronal death was correlated with a decrease in the post-synaptic marker PSD-95. Therefore, we suggest that low levels of ERa associated with the high-cholesterol diet in our study could be responsible for a 
reduction in the post-synaptic marker PSD-95. Additionally, upregulation of ER $\beta$ has been shown to have a negative effect on synaptic function by downregulating synaptopodin, an actin associated post-synaptic protein (Fester et al., 2013). The increase in ER $\beta$ levels and the decreased number of mitochondria observed in our study are presumably connected because it has been shown that mitochondrial ER $\beta$ can have detrimental effects on mitochondrial function (Yang et al., 2009).

In summary we demonstrate here that diet-induced hypercholesterolemia causes an increase in $27-\mathrm{OHC}$ in hippocampus. Our results suggest that $27-\mathrm{OHC}$ is an active molecule that is associated with downregulation in expression of ERa and the synaptic marker PSD-95, and increased levels of ER $\beta$ possibly linked to decreased mitochondria in hippocampal cells. We suggest that $27-\mathrm{OHC}$ modulates ER signaling that leads to the loss of estrogen-related neuroprotection which might explain one of the mechanisms of 27-OHC-related neurodegeneration described in both in-vivo (Mateos et al., 2011a) and in-vitro systems (Bjorkhem et al., 2009; Mateos et al., 2011b).

Sporadic AD is a heterogeneous disorder, and there are many well-characterized risk factors influencing an individual's chance of developing this disease as well as its progression. We conclude that there is sufficient evidence linking life style risk factors like hypercholesterolemia with a biological predisposition to develop AD. In this study we examined some of the elements that could be involved in mechanisms leading to dementia, suggesting a role for high levels of $27-\mathrm{OHC}$ in the hippocampus and associated ER signaling dysfunction. 
Chapter 5: Additional data supporting the negative effects of high-cholesterol diet on hippocampus. 


\section{Introduction}

This section describes experiments conducted early in project development as well as some correlational studies that were conducted after data collection was completed. Behavioral procedures and data are from Schreurs et al. (2013b).

The neuropathological hallmarks of $A D$ include $A \beta$ plaque accumulation, neurofibrillary tangle formation, and synaptic and neuronal loss. How these factors ultimately contribute to memory loss and cognitive deficits that clinically characterize the disease remains unclear. Synaptic loss is a major contributor to brain atrophy seen in $A D$ and can be shown with immunohistochemical studies using antibodies against preor postsynaptic proteins such as PSD-95. Synaptic loss has been correlated with cognitive decline in AD (DeKosky and Scheff, 1990; Scheff et al., 2007). Additionally mitochondrial alterations have been described in AD brains and correlated with synaptic loss (Baloyannis, 2011; Padurariu et al., 2012; Stavros, 2013).

Mitochondria, the power generators of the cell, respond to energy demands and approximately one third of mitochondria are in motion at any given time (Wagner et al., 2003; Lifshitz et al., 2003). These organelles are transported to regions where the need for energy is particularly high, such as synapses, which have high energy demand subserving neuronal communication (Brown et al., 2006). Moreover, mitochondrial activity is mediated by estrogens as both ERa and ER $\beta$ have been found in the membrane and cytoplasm of mitochondria (Chen et al., 2008) and increased levels of ER $\beta$ could have a negative effects on mitochondrial function (Yang et al., 2009). 


\section{Materials and methods}

Animals. The subjects were 32 New Zealand White male rabbits (Oryctolagus cuniculus) 3-4 months of age weighing approximately $2 \mathrm{~kg}$ upon arrival that were part of a larger study investigating the role of cholesterol on learning and memory (Schreurs et al., 2013b). Animals were housed individually with free access to food and water and maintained on a 12-hour light-dark cycle. All the experiments followed guidelines of National Institutes of Health and were approved by West Virginia University Animal Care and Use Committee. Rabbits were assigned to two dietary groups: control or high cholesterol diet. Control diet animals received Purina 5326 chow, and the high cholesterol diet group received Purina 5326 plus 2\% cholesterol chow (T.R. Last Co., Gibsonia, PA). All the rabbits were kept on their respective diets for a total of 11 weeks.

Apparatus. The apparatus has been detailed by Schreurs and Alkon (1990) who modeled their apparatus after those described by Gormezano (Coleman \& Gormezano, 1971; Gormezano, 1966). Each rabbit was restrained in a Plexiglas box and trained in a sound-attenuating, ventilated chamber (Coulbourn Instruments, Allentown, PA; Model E10-20). A stimulus panel containing a speaker and a house light (10-W, 120-V incandescent lamp) was mounted at a 450 angle, $15 \mathrm{~cm}$ anterior to and $15 \mathrm{~cm}$ above the subject's head. An ambient noise level of $65 \mathrm{~dB}$ was provided by an exhaust fan. A programmable air pressure delivery system (Model ER-3000, Tescom Corp., Elk River, $\mathrm{MN}$ ) was used to deliver a puff of air through a tube (1 $\mathrm{mm}$ internal diameter) positioned $5 \mathrm{~mm}$ from and perpendicular to the center of the cornea. 
Details of transducing nictitating membrane (NM) movements have been reported previously (Gormezano \& Gibbs, 1988; Schreurs \& Alkon, 1990). A 1-mm hook connected to an L-shaped lever containing a freely moving ball and socket joint was attached to a 6-0 nylon loop sutured into, but not through, the NM. The other end of the lever was attached to a potentiometer (Novotechnik US Inc., Southborough, MA; Model P2201) that, in turn, was connected to a 12-bit analog-to-digital converter (5-ms sampling rate; $0.05-\mathrm{mm}$ resolution). Individual analog-to-digital outputs were stored on a trial-by-trial basis for subsequent analysis. Data collection, analysis and stimulus delivery were accomplished using a LabVIEW system (National Instruments, Austin, $\mathrm{TX})$.

Behavioral training. All rabbits received one day of handling and brief restraint, one day of adaptation, 24 daily sessions of two-tone discrimination training, eight weeks of $2 \%$ cholesterol or normal chow, one brief session of tone testing immediately followed by one brief session of discrimination reminder training, and then 18 daily sessions of discrimination reversal. The cholesterol diet was started after discrimination testing and was maintained during retraining, and reversal making the total time on the diet 11 weeks.

Brief handling and restraint was used to begin to acclimate rabbits to the behavioral procedures. This was continued the next day with the adaptation session which allowed rabbits to further habituate to restraint and become familiar with the training chambers. On the adaptation day, the rabbits were restrained, prepared for recording of nictitating membrane (NM) movement and then adapted to the training chambers for the length of 
time of subsequent training sessions (60 min). Discrimination training was used to establish responding to one tone, a conditioned stimulus (CS) $(8 \mathrm{kHz}, \mathrm{CS}+)$ that was followed by air puff unconditioned stimulus (US) and not to another tone (1 kHz, CS-) not followed by air puff. Each of the 24 discrimination sessions consisted of 60 presentations of a $400-\mathrm{ms}, 8-\mathrm{kHz}, 82-\mathrm{dB}$ tone CS that coterminated with a $100-\mathrm{ms}$, 4psi air puff US (i.e., 300-ms interstimulus interval,) and 60 presentations of a $400-\mathrm{ms}, 1$ $\mathrm{kHz}, 82-\mathrm{dB}$ tone that was presented alone. To equate the level of discrimination in each treatment group, rabbits were assigned to dietary treatment conditions based on their levels of responding to CS+ and CS- at the end of discrimination training. Following eight weeks on their respective diets, rabbits were exposed to a brief session of discrimination testing during which both CS+ and CS- were presented alone. The testing session consisted of 30 presentations of the $400-\mathrm{ms}, 8-\mathrm{kHz}, 82-\mathrm{dB}$ tone (CS+) and 30 presentations of the $400-\mathrm{ms} 1-\mathrm{kHz}, 82-\mathrm{dB}$ tone (CS-) with no presentations of air puff. We used only 30 presentations of each stimulus to test memory and immediately followed testing with a brief session of discrimination reminder training in order to minimize any extinction effects from CS alone presentations. The reminder training session consisted of 30 presentations of the $400-\mathrm{ms}, 8-\mathrm{kHz}, 82-\mathrm{dB}$ tone CS+ that coterminated with a $100-\mathrm{ms}, 4-p s i$ air puff US and 30 presentations of the $400-\mathrm{ms}$ $1-\mathrm{kHz}, 82-\mathrm{dB}$ tone $\mathrm{CS}-$ that was presented alone. Beginning the next day, all rabbits received 18 daily sessions of discrimination reversal training during which the tone that previously served as CS $+(8 \mathrm{kHz})$ became the CS- and was no longer followed by air puff and the tone that previously served as CS- $(1 \mathrm{kHz})$ became the CS+ and was always followed by air puff. Thus, each of the discrimination reversal sessions consisted 
of 60 presentations of the $400-\mathrm{ms}, 1-\mathrm{kHz}, 82-\mathrm{dB}$ tone $\mathrm{CS}$ that coterminated with a $100-$ ms, 4-psi air puff US (CS+) and 60 presentations of a $400-\mathrm{ms} 8-\mathrm{kHz}$ tone CS that was presented alone (CS-). For all sessions, stimulus presentations were delivered, on average, every $30 \mathrm{~s}(25-35 \mathrm{~s}$ range) with the restriction that no more than three of the same stimulus type (CS+ or CS-) could occur consecutively. The tones were not counterbalanced within groups because pilot testing revealed that although having identical intensities $(82 \mathrm{~dB})$, the $1-\mathrm{kHz}$ tone was more salient than the $8-\mathrm{kHz}$ tone. As a result, both cholesterol-fed and normal chow control rabbits were unable to learn the discrimination reversal when the CS+ was initially the $1-\mathrm{kHz}$ tone and CS- was the 8$\mathrm{kHz}$ tone within the limited time available (Nokia \& Wikgren, 2010). The time allotted for reversal training was limited as a result of the cholesterol diet causing hepatotoxicity that compromises the health of the rabbits as noted above (Kainuma et al., 2006; Song et al., 2000; Sparks et al., 2007). This occurred despite a high-fiber diet used to slow the absorption of cholesterol (Kritchevsky \& Story, 1978). Therefore, we needed to use a reversal paradigm that allowed a significant level of discrimination to occur within the available time for the reversal training. The high levels of discrimination and discrimination reversal observed across all groups to the specific tones used as CS+ and CS- suggest that any sensory or performance effects of the independent variables (cholesterol) were not confounded with associative effects.

Behavioral data. A nictitating membrane conditioned response (CR) was defined as any extension of the nictitating membrane exceeding $0.5 \mathrm{~mm}$ that was initiated after CS onset but prior to US onset on CS+ trials and at the point at which the US would have occurred on CS- trials. 
Electron microscopy. Hippocampal sections were post-fixed for 1 hour in $1 \%$ osmium tetroxide, dehydrated through a series of alcohol washes and propylene oxide, and embedded in a polymer resin. Ultrathin sections (70 nm thick) were cut on a Leica EM UC7 ultratome (Leica, Wien, Austria). Sections were imaged on a Libra 120 transmission electron microscope (TEM) (Zeiss) and digital micrographs were acquired using a digital camera system (Gatan). Degenerating organelles were identified by analyzing the morphology of mitochondria and identifying disruptions in the membrane or cristae morphology. It is assumed that these alterations lead to complete degeneration appearing as empty myelin sheaths and membrane-encased "holes" that are thought to represent degenerated dendrites or neuronal cell bodies (Alan Peters and Claire Folger Sethares, 2014). This data was not quantified.

A $\beta$ ELISA. The kit (catalog \# KHB3441) was purchased from Invitrogen (Camarillo, CA) and manufacturer's directions were followed for tissue analysis. Standard curve correlating optical density and concentration of $A \beta$ was established and sample's concentration $(\mathrm{pg} / \mathrm{ml})$ was obtained.

\section{$\underline{\text { Results }}$}

$\underline{\text { High-cholesterol diet and cognition }}$ 
Severe memory loss is an important clinical finding in $A D$ and one of the mechanisms responsible for this this deficit is disruption in cholinergic neurotransmission and neuronal degeneration in the hippocampal formation (WoodruffPak et al., 2007). Rabbits have been used in studying learning and memory with eyeblink conditioning for decades and were an essential model used to characterize eyeblink conditioning pathways. In delay classical conditioning, a neutral stimulus, such as tone, is the conditioned stimulus (CS) that overlaps and is followed by an air-puff or a periorbital shock called the unconditioned stimulus (US) that normally elicits a reflex. In the delay paradigm, the CS and US overlap and terminate together but there is a delay after the CS and before US onset. Studies that investigated delay conditioning showed that acquisition of the task is dependent on the deep cerebellar nuclei but disruption of cholinergic signaling in hippocampus significantly impairs learning (Solomon et al., 1983). On the other hand, trace eyeblink conditioning is a procedure where the hippocampus is essential for acquisition of the task. In the trace paradigm, the CS ends before the onset of the US so there is a "trace" between the two stimuli. For rabbits, a trace greater than $300 \mathrm{~ms}$ makes hippocampus indispensable for the acquisition to occur (Moyer, Jr. et al., 1990).

We have shown previously that a high-cholesterol diet has detrimental effects on the long term memory of classical conditioning of the rabbit NM response that was acquired before the start of the cholesterol diet (Darwish et al., 2010) which is consistent with reports of high-cholesterol diet association with cognitive impairment in humans (Solomon et al., 2009a; Zambon et al., 2010). 
In our behavioral paradigm, the rabbits were able to learn to discriminate between two tones and respond to CS+ but not to CS- by the end of 24 daily sessions of discrimination training. Animals were then placed on different dietary treatments and eight weeks after the beginning of a high-cholesterol or control diet were tested to assess the levels of responding to CS+ and CS-. Figure 5.1 shows that cholesterol-fed rabbits show lower level of responding to CS+ than control animals suggesting that cholesterol-fed rabbits did not remember the discrimination as well as control rabbits.

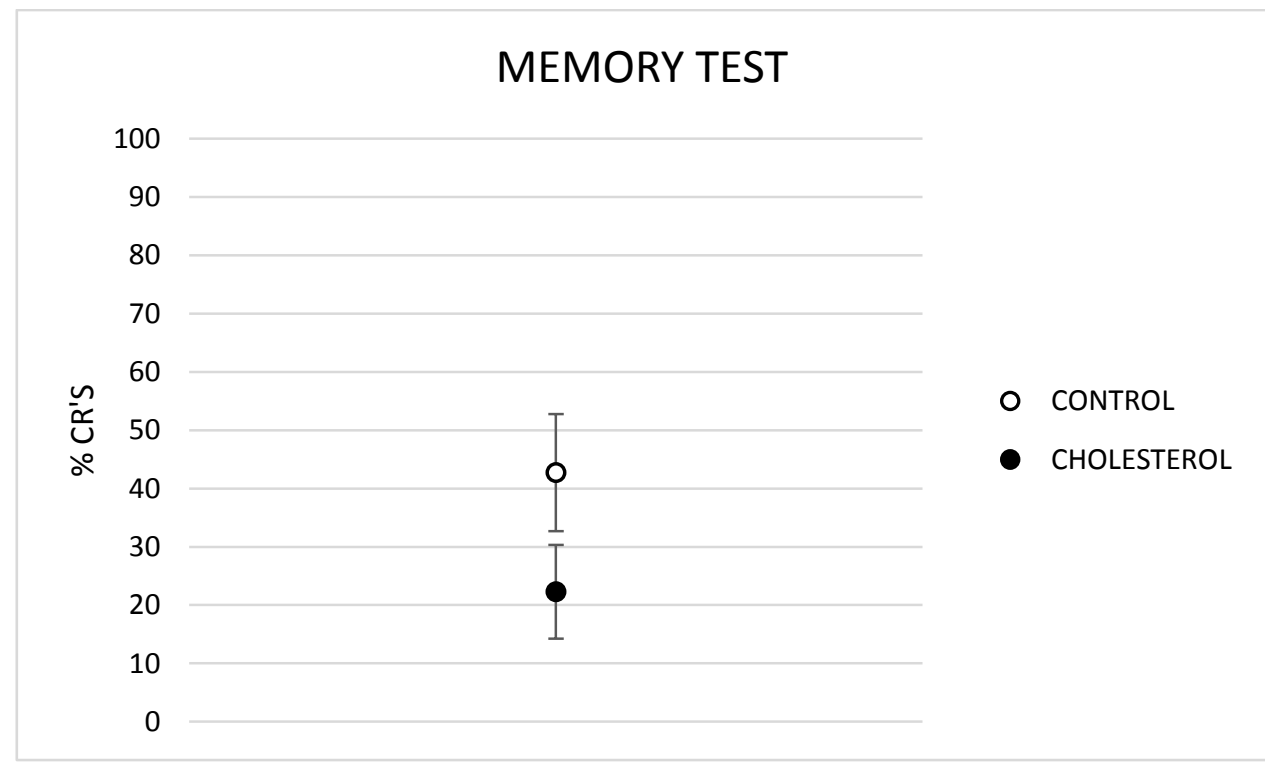

Figure 5.1 Mean ( \pm SEM) percent conditioned responding (CRs) to CS+ on memory test following an eight-week dietary treatment of either high-cholesterol or control diet. Data from Schreurs et al (2013b)

Loss of synapses has been shown to correlate with a decrease in cognitive function more than any other AD-associated neuropathology (Terry et al., 1991). Our 
correlation analysis shows that there is a correlation between the levels of PSD-95, a synaptic marker, and performance on the memory test (Pearson correlation $r=0.90$ and coefficient of determination $r^{2}=0.80$ ) (Figure 5.2). There was no correlation of those two variables in the control group.

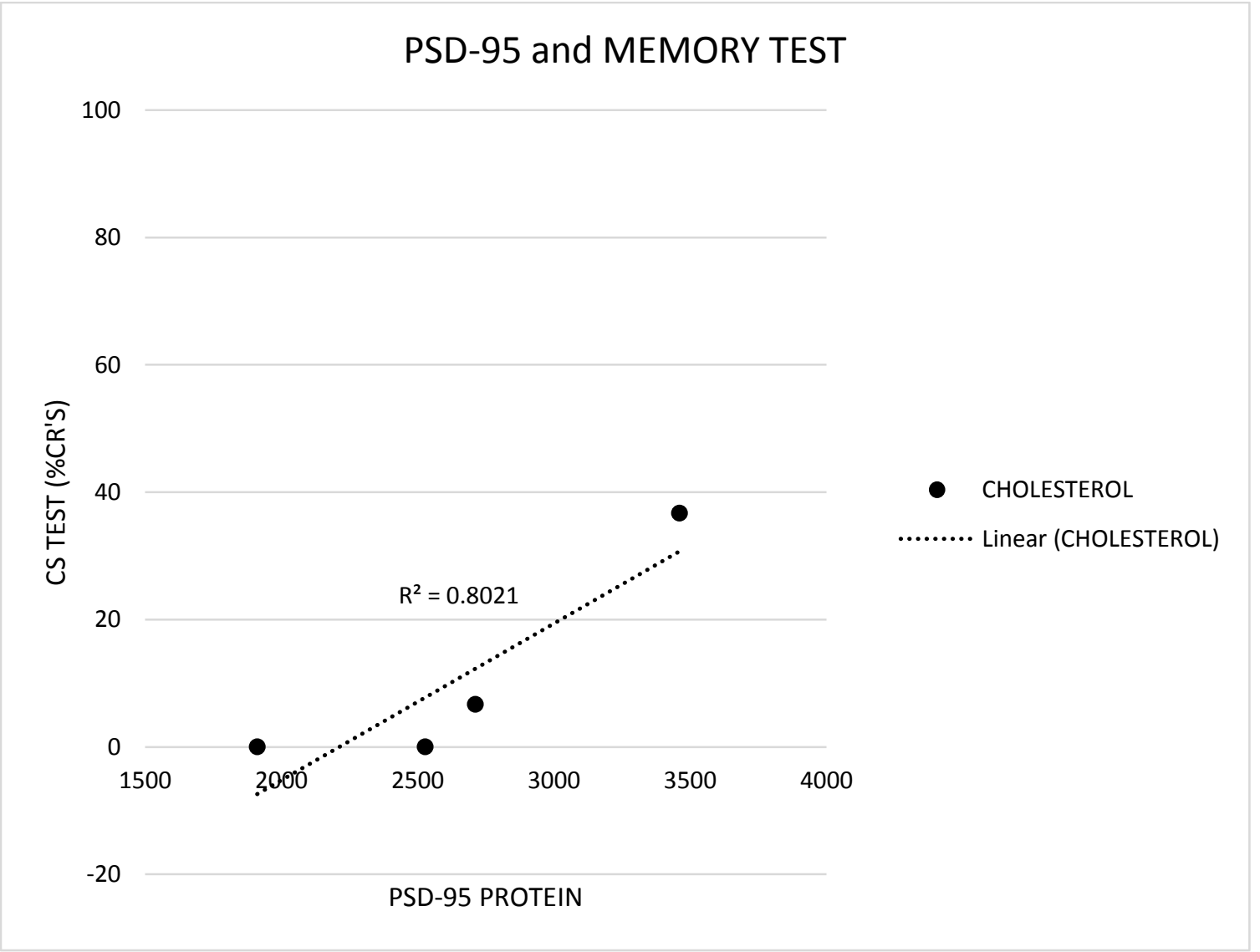

Figure 5.2 Correlation of synaptic marker PSD-95 and memory test. 
Moreover, ultrastructural examination of hippocampal tissue from cholesterol-fed and control animals showed that many presynaptic terminals of cells from the dorsal hippocampus of cholesterol-fed animals contain synaptic vesicles with abnormal morphology which are also decreased in number in comparison with normal control brains (Figure 5.3). Electron micrographs also show evidence of neurodegenerative changes present in dorsal hippocampus of cholesterol-fed rabbits that present as so-called myelin balloons, empty myelin sheets thought to be degenerating axons (Peters and Folger Sethares, 2014) (Figure 5.4).
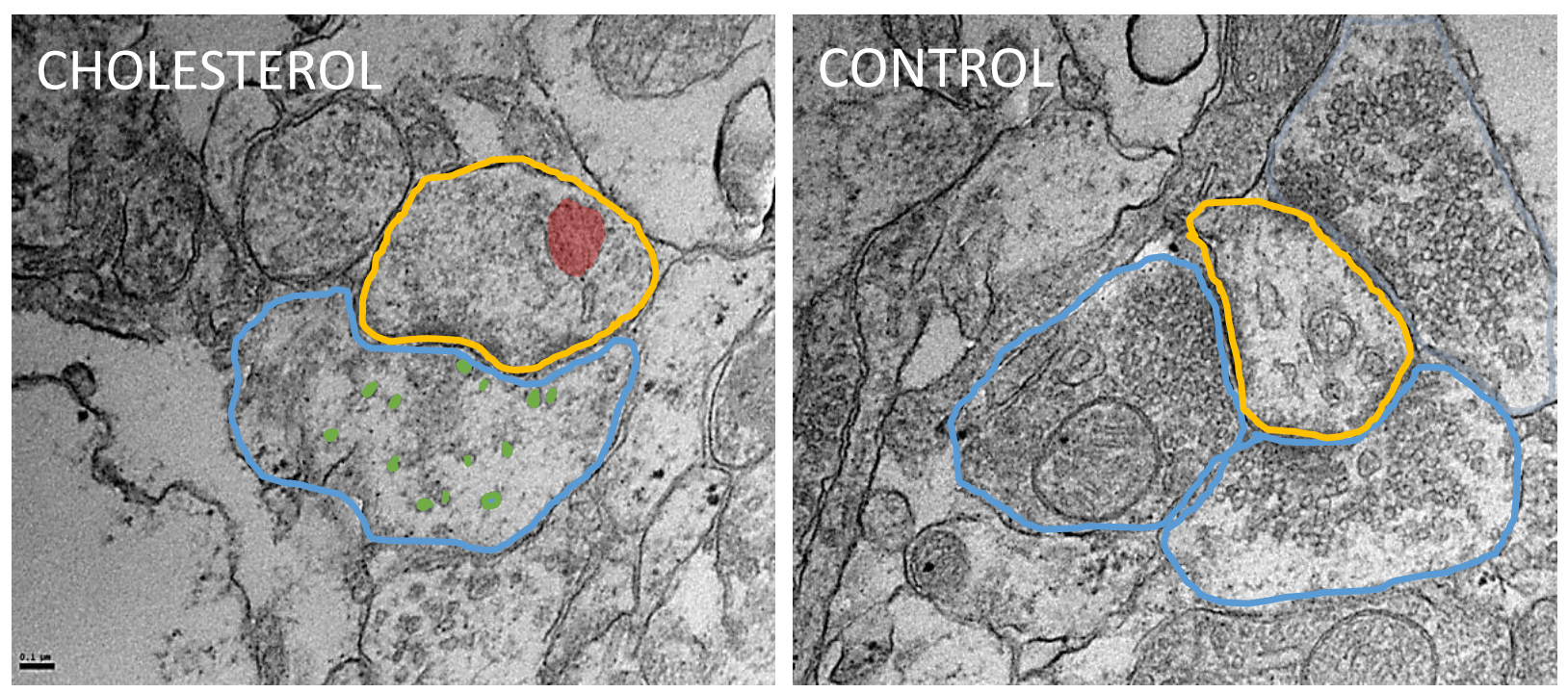

Figure 5.3 An example of an electron micrograph from the dorsal hippocampus of a rabbit fed a high-cholesterol diet for 11 weeks shows electron dense mitochondrion (shaded red) lacking cristae structure in a postsynaptic terminal (orange outline) as well as marked poverty of synaptic vesicles (shaded green) at the presynaptic terminal (blue outline) and lack of mitochondria. In contrast, the control section shows several synapses in a single field of view. Note the retained ultrastructure of postsynaptic spine 
(orange outline) and presynaptic boutons (blue outline) containing numerous synaptic vesicles. Magnification 31,000x, scale bar $0.1 \mu \mathrm{m}$.
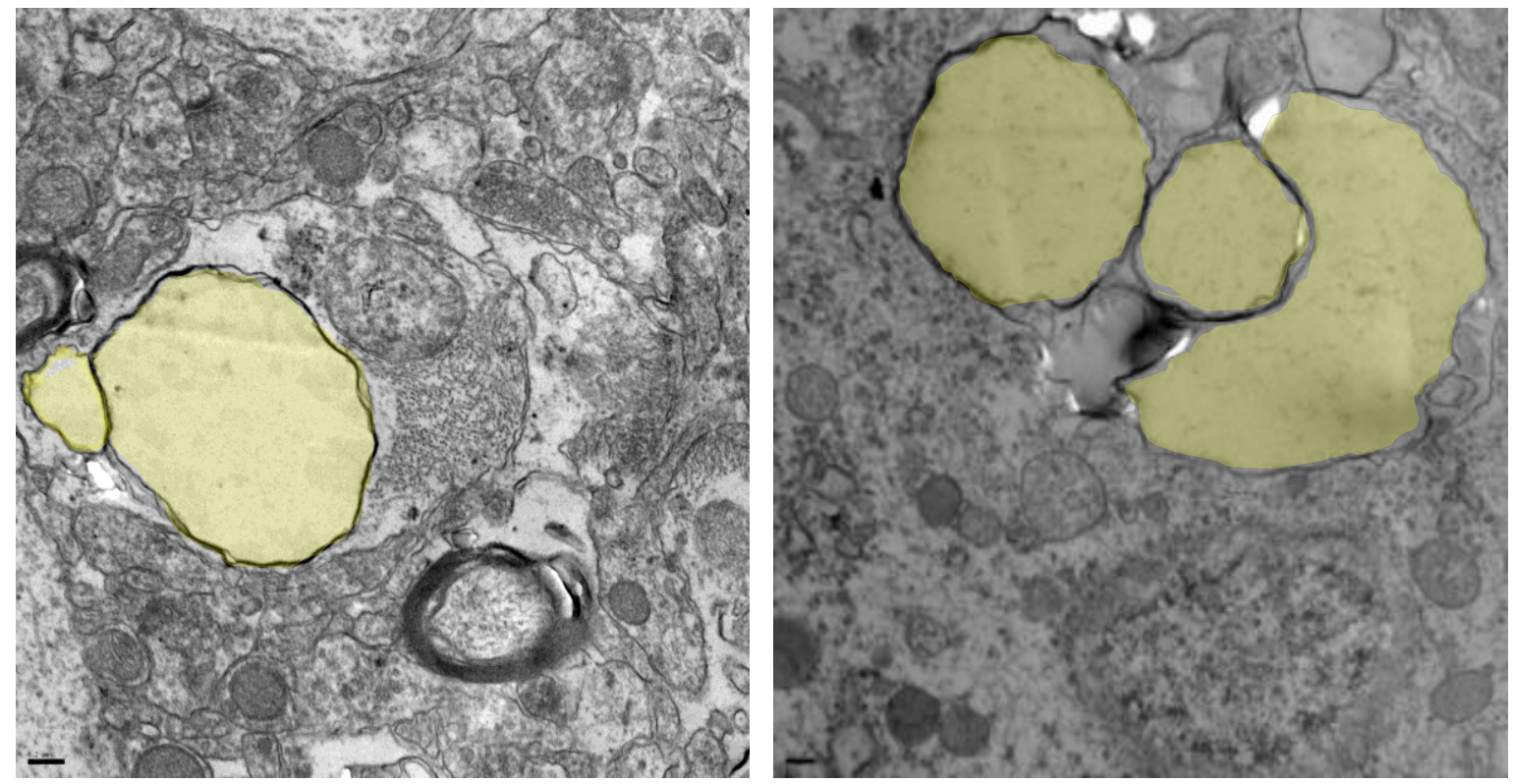

Figure 5.4 Myelin balloons (shaded yellow) seen on the sections from a cholesteroldiet animal thought to correspond to degenerating axons. Magnification 20,000x, scale bar $0.2 \mu \mathrm{m}$.

\section{$\underline{27-\mathrm{OHC} \text { and estrogen signaling }}$}

Both ERa and ER $\beta$ are important for hippocampal function and cholesterol-diet induced increased 27-OHC levels appear to have an effect on the expression and 
possibly the function of these receptors in the hippocampus. We show here that there is a strong positive correlation between the levels of $27-\mathrm{OHC}$ and $\mathrm{ER} \beta$ in the hippocampus $\left(R^{2}=0.90, R=0.95\right)$ (Figure 5.5$)$, moreover we found strong negative correlations between the levels of 27-OHC and mitochondrial protein levels $\left(R^{2}=0.88\right.$, $R=-0.94)$ (Figure 5.6) and $E R \beta$ and mitochondrial proteins $\left(R^{2}=0.95, R=-0.97\right)$ (Figure 5.7).

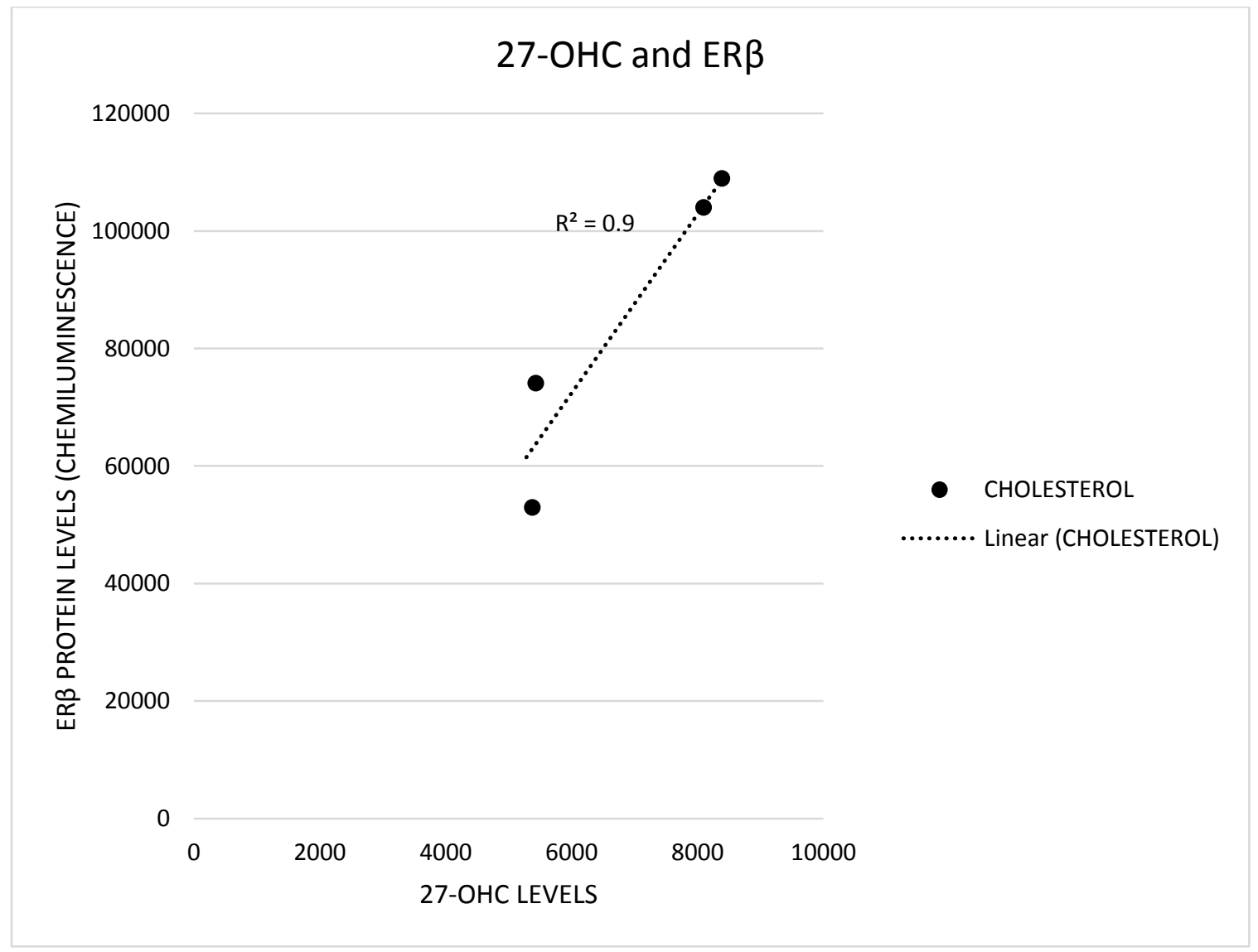

Figure 5.5 Correlation of the levels of $27-\mathrm{OHC}$ and ER $\beta$ in the hippocampus. 


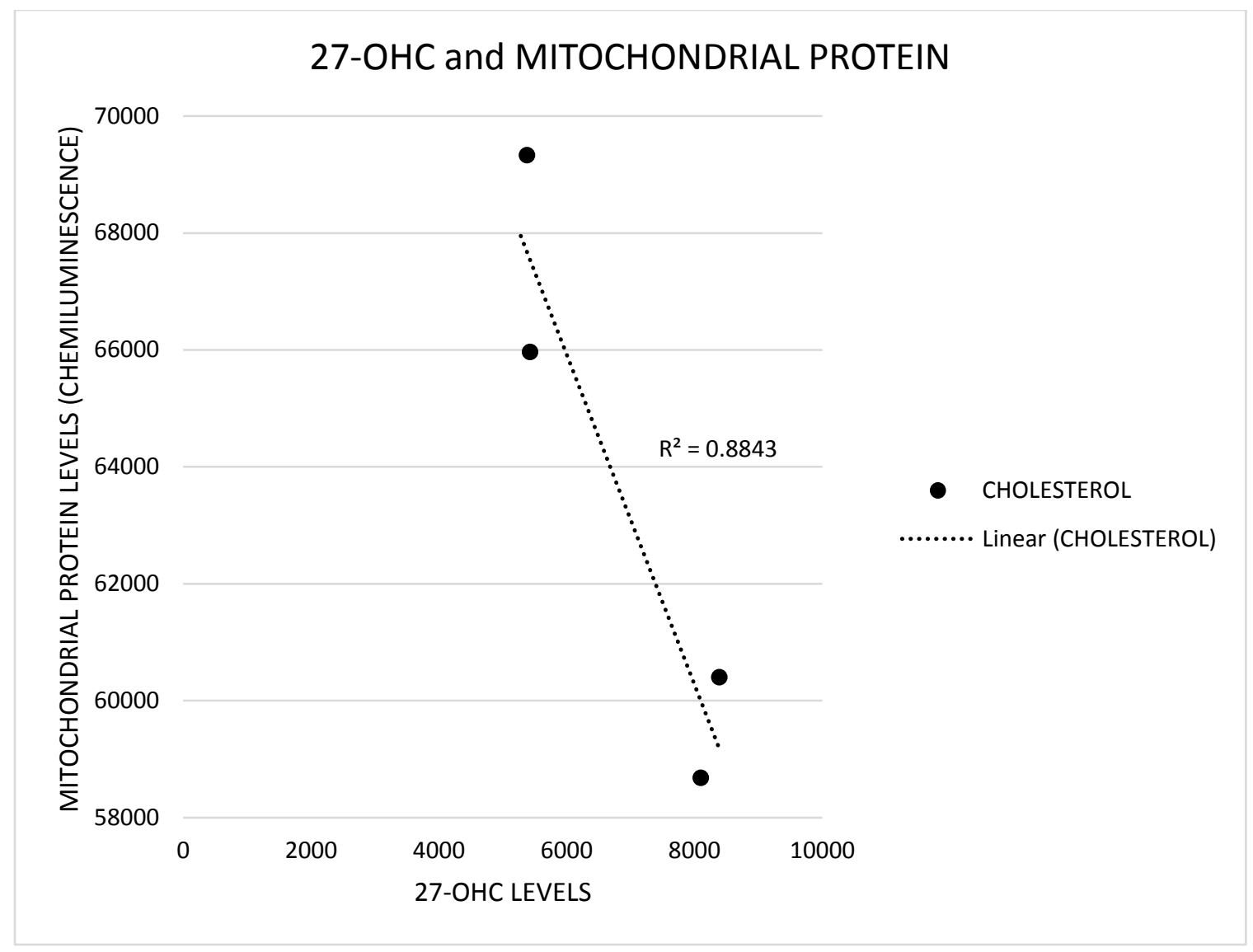

Figure 5.6 Correlation of the levels of $27-\mathrm{OHC}$ and mitochondrial protein in the hippocampus. 


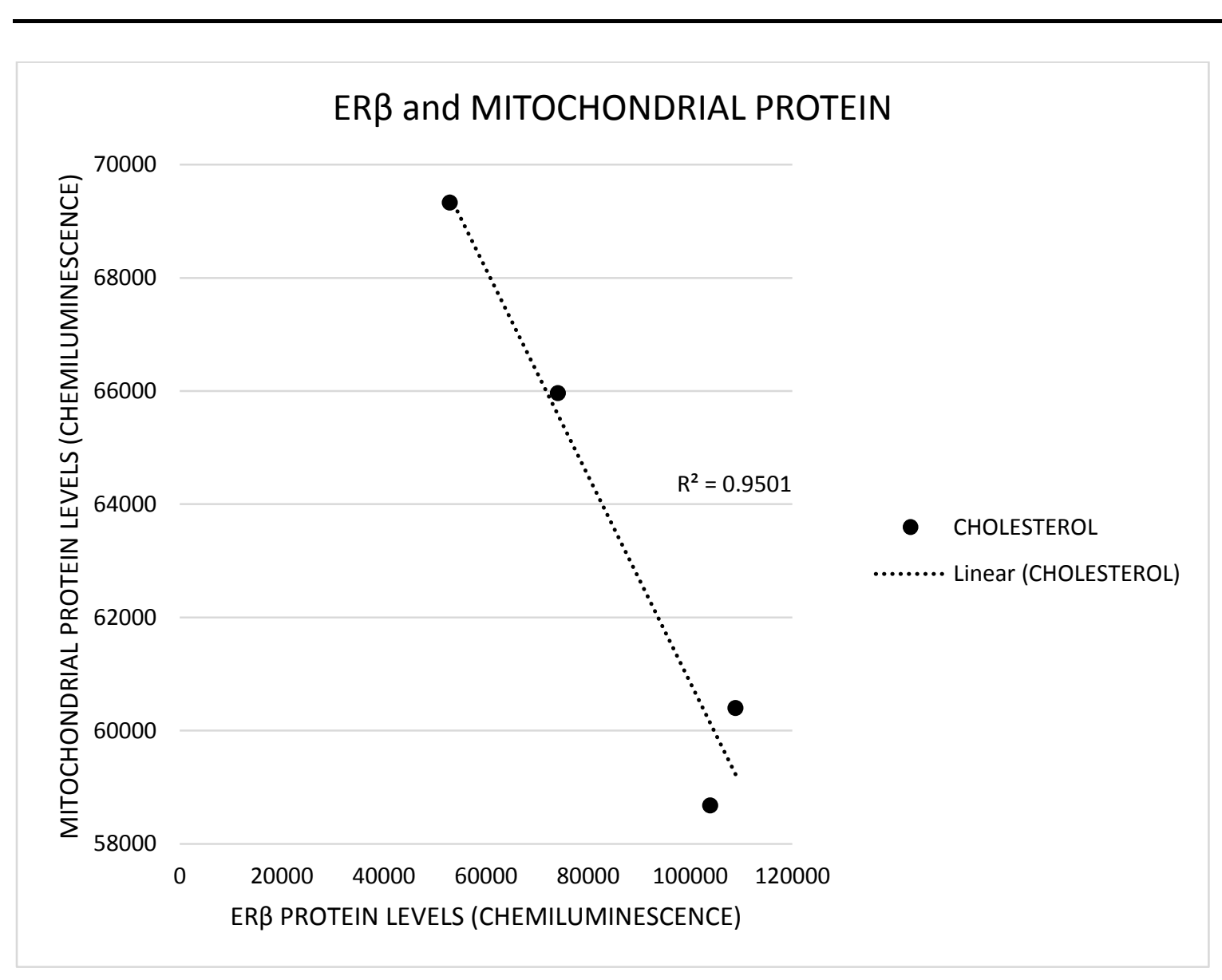

Figure 5.7 Correlation of the levels of ER $\beta$ and mitochondrial protein in the hippocampus. 
Chapter 6: General discussion 
$A D$ affects over 5 million people in the United States, it is the most common form of dementia, and it is the $6^{\text {th }}$ leading cause of death. Our current understanding of $A D$ comes from decades of work that focused on the $A \beta$ hypothesis of $A D$ that centers on the idea that $A \beta$ triggers pathogenic cascades causing synaptic deficits, altered neuronal activity, hyperphosphorylation of tau and neuronal death. In the case of familial $A D$, mutations in genes involved in $A \beta$ production indeed trigger increases in the generation of $A \beta$, but $A D$ animal models based on these mutations failed to recapitulate the full extent of the pathology found in $A D$ patients. Most transgenic models of $A D$ are able to recreate $A \beta$ pathology and some cognitive deficits found in AD patients but they fail to produce the tau pathology and neuronal death seen in AD patients (Gotz and Ittner, 2008; Chin et al., 2011). In this study, we employed a model of sporadic AD that shows a memory deficit also found in human patients afflicted with $A D$, as well as neurodegeneration and $A \beta$ deposits characteristic of the disease. Moreover, we were able to show, for the first time, that high serum cholesterol in a cholesterol-fed rabbit is accompanied by increased levels of $27-\mathrm{OHC}$ in the hippocampus and provide an indication of possible mechanisms responsible for AD-like pathology related to hypercholesterolemia. Based on our results, we suggest that there may be an association between the levels of $27-\mathrm{OHC}$, an endogenous estrogen modulator, and expression of ERs in the rabbit hippocampus.

In our first study, we measured levels of $27-\mathrm{OHC}$ in the serum and the hippocampus using LC-MS analytical methods. An increase of the oxysterol $27-\mathrm{OHC}$ in hippocampus in this study is especially important in the light of recent findings regarding the function of this oxysterol as a SERM. This biologically active molecule has the 
potential to bind the receptors and either activate or inhibit ER-dependent pathways. Since its identification as the first endogenous estrogen receptor modulator (DuSell et al., 2008), 27-OHC has been extensively studied in estrogen-regulated tissues and cell types. Not much is known at present about the biological actions of $27-\mathrm{OHC}$ in the brain although some recent studies show that $27-\mathrm{OHC}$ adversely affects cognition in rodents (Zhang et al., 2015; Heverin et al., 2015). The results of our second study showed that the increase in $27-\mathrm{OHC}$ in the hippocampus is accompanied by changes in ER expression, a novel and interesting finding that could indicate a mechanistic link between oxysterols and neurodegeneration. Studies investigating the role of oxysterols in neurodegenerative disorders are inconsistent in reporting a relationship between the levels of oxysterols in plasma and CSF and cognitive status of subjects in these studies (Lutjohann et al., 2000; Heverin et al., 2004; Solomon et al., 2009b; Zuliani et al., 2011; Mateos et al., 2011a; Hughes et al., 2012; Hughes et al., 2013). Some of these inconsistencies arise from the fact that subject cohorts comprised different disease stages and subtypes. Because of the temporal component of when in an individual's lifespan the hypercholesterolemia occurs, the appropriate time for clinical assessment and treatment is especially important. It has been shown that, once the disease is symptomatic, the effect of the risk factors diminishes (Beach et al., 2011).

$A D$ is more prevalent in women and post-menopausal loss of estrogen seems to be involved in the mechanism increasing that risk. Estrogen is a steroid hormone that regulates functions of multiple cells in multiple organ systems although it is primarily known for the promotion of female sexual characteristics and reproductive functioning. In women during their reproductive years, estrogen is produced primarily in the ovaries 
and adrenal glands and is distributed throughout the body via the circulatory system. A number of receptors and signaling pathways activate and regulate molecular and genomic downstream targets of estrogen signaling. Moreover estrogen can cross BBB and, more importantly, there is a significant production of estrogen from cholesterol in the CNS (Rune and Frotscher, 2005; Balthazart and Ball, 2006; Balthazart et al., 2006a; Balthazart et al., 2006b). It has been shown that ovarian estrogen drives approximately $15-25 \%$ of metabolic function in the brain and that the loss of circulating estrogen at menopause is associated with a decline in brain's metabolic functioning (Yao et al., 2009; Yao et al., 2012; Ding et al., 2013). Both nuclear ERs and membrane bound ERs are present in the brain where they provide a range of responses from rapid (effects seen in seconds to minutes) to long (hours and even days). One of the major functions of estrogen and estrogen signaling cascades in CNS cells is regulating energy supply in those cells (Rettberg et al., 2014) and, therefore, any changes in estrogen levels or estrogen receptors would have an effect on neuronal functioning. ER functions and cascades are well studied, however, the intricate neural circuit arrangement and how it is affected by modifications in estrogen signaling is an area of active investigation. Nuclear estrogen functions require ERs' dimerization for receptor complexes to translocate to the nucleus and bind to specific estrogen response elements or other transcription factors to regulate gene expression. Both ERa and ER $\beta$ promote expression of the genes required for glucose metabolism and transport and mitochondrial function while suppressing genes involved in ketone body metabolism, inflammation and $A \beta$ generation (Zhao et al., 2013). 
Estrogen signaling modulates fundamental functions in the CNS such as motor behavior, mood and mental state, and neuroprotection (McEwen, 2002). Many studies have shown a protective role of estrogen against neuronal death (Marin et al., 2003; Cordey and Pike, 2005; Cimarosti et al., 2005a; Cimarosti et al., 2005b; Lebesgue et al., 2009). In in vitro models of $A D$ based on $A \beta$ toxicity, estrogen treatment modified APP processing towards a non-amyloidogenic pathway (Nord et al., 2010) and increased $A \beta$ clearance (Zhao et al., 2011; Merlo and Sortino, 2012). In animal models of AD, estrogen administration prevented disease progression by reducing $A \beta$ as well as tau hyperphosphorylation (Carroll et al., 2007; Carroll and Pike, 2008; Carroll et al., 2008). These preclinical results laid the groundwork for estrogen therapy clinical trials and some of these studies showed that estrogen therapy reduced cognitive impairment in women when administered at the onset of menopause (Verghese et al., 2000; MacLennan et al., 2006). However the largest randomized trial investigating the effects of estrogen treatment, the Women's Health Initiative, reported that estrogen caused cognitive decline and dementia in women who initiated treatment later in life (older than 65 years old) (Espeland et al., 2004; Shumaker et al., 2004). In vitro experiments treated hippocampal neurons with $A B$ and reported that estrogen confers neuroprotection before or early during toxicity, whereas when estrogen was administered after $A \beta$ treatment it worsened neurodegeneration (Nilsen et al., 2006). This suggests that estrogen signaling might have both neuroprotective and neurotoxic effects. These findings further contributed to the creation of a critical period hypothesis (Sherwin, 2009) which suggests that estrogen treatment is beneficial if started at the onset of menopause but the same treatments will have no effect or could be harmful if 
started decades after menopause onset. This critical period hypothesis found support in a study by Whitmer et al. (Whitmer et al., 2011) who showed that estrogen therapy was protective if initiated at midlife but was detrimental if initiated in late life.

Cognitive decline has been shown to manifest as early as age 45 (Singh-Manoux et al., 2012; Joosten et al., 2013) which supports the theory that loss of cognitive function is a process that develops over decades and, as such, it has the potential to be modified. When combined with midlife risk factors for $A D$, these findings offer the possibility of developing interventions and treatments that could prevent or delay the symptoms of $A D$. In addition to loss of estrogen mediated neuroprotection, both hypercholesterolemia and obesity in midlife increase the risk of AD (Whitmer et al., 2005; Luchsinger and Gustafson, 2009; Whitmer et al., 2011) and it is important to note that ERs are present in adipose tissue and deposition of fat throughout the body has a different distribution pattern in men and women. Moreover, fat distribution of women changes after menopause and it is ER $\alpha$ that appears to positively regulate adipose metabolism whereas downregulation of ERa is associated with upregulation of ER $\beta$ that promotes unhealthy visceral adipose accumulation (Naaz et al., 2002; Tomicek et al., 2011). Additionally, APOE $\varepsilon 4$, the strongest genetic risk factor for sporadic $A D$, has been associated with higher risk for AD in women than in men and APOE $\varepsilon 2$, a neuroprotective variant, confers greater protection against $A D$ in men than in women (Altmann et al., 2014; Ungar et al., 2014). Notkola and colleagues reported that controlling for APOE genotype in the cohort they studied strengthened the relationship between high serum cholesterol in midlife and AD risk later in life (Notkola et al., 1998). Moreover some studies showed that estrogen has an effect on the expression of APOE, 
the genetic risk factor for $A D$, as activation of ER $\alpha$ upregulates APOE expression while ER $\beta$ decreases APOE expression (Wang et al., 2006). Statins, a group of drugs that inhibit an enzyme crucial to cholesterol synthesis, have recently gained popularity due to their effectiveness in treating hypercholesterolemia. There was a certain expectation that because of their ability to lower serum cholesterol levels, statins would also prove to be beneficial in preventing or treating $A D$. Many studies have investigated the validity of the use of statins as AD modifying compounds. In vitro studies have shown the utility of statin treatment in controlling $A \beta$ levels (Buxbaum et al., 2001; Fassbender et al., 2001). Similar findings were reported in animal models of $A D$ with three weeks of statin administration resulting in lower $A \beta$ levels in guinea pig, and this effect was reversed when treatment was stopped (Fassbender et al., 2001; Lutjohann et al., 2004). In transgenic mice, statin treatment decreased A $\beta$ in the brain and soluble APP fragments were increased (Chauhan et al., 2004) and statin-treated mice performed better in a Morris water maze test than mice not treated with statins (Li et al., 2006). Unfortunately, human studies have been less consistent with the outcomes in a large part because of the complications in study design as well as participant's ages (Canevari and Clark, 2007; Santilli et al., 2007; Haag et al., 2009; Feldman et al., 2010; Sano et al., 2011).

In the brain a decrease in hippocampal ER $\alpha$ has been associated with estrogen depletion in rodents while ER $\beta$ levels remained unchanged (Zhang et al., 2011; Qu et al., 2014) implicating ERa as an important element in estrogen-mediated neuroprotection. Estrogen deprivation in animal models lead to an increase in proteasomal degradation of ERa in hippocampal neurons, a process that was prevented when estrogen was administered before but not after ovariectomy (Zhang et al 2011) 
demonstrating the importance of circulating ligand levels for the regulation of receptor number. Moreover, treatment with an ER $\alpha$-selective agonist prevented $A \beta$-induced neuronal death and a decrease in the post-synaptic marker PSD-95 (Merlo et al., 2016). Therefore, we suggest that a downregulation of ERa associated with the highcholesterol diet in our study, and possibly caused by a direct action of $27-\mathrm{OHC}$ on the receptor, could be responsible for a reduction in the post-synaptic marker PSD-95. PSD-95 is a key marker of estrogen action related to spine synapse formation and its decrease in our study is indicative of decline in cognitive function that seems to be ERdependent.

On the other hand, upregulation of ER $\beta$ has been shown to have a negative effect on synaptic function by downregulating synaptopodin, an actin associated postsynaptic protein (Fester et al., 2013) as well as detrimental effects on mitochondrial function (Yang et al., 2009). Mitochondria are abundant organelles and are believed to have evolved from incorporation of bacterial cells as they contain their own DNA, RNA and protein synthesis mechanisms. Diseases related to dysfunctional mitochondria are usually progressive and specific symptoms include cardiovascular disease, dementias, problems with hearing and vision, muscle and movement disorders, renal and endocrine disorders (Wallace, 2005). ER $\beta$ is found in mitochondria and shown to regulate mitochondrial function and gene expression (Simpkins Yi 2010; Milner et al 2005; Irwin et al 2012; Arnold, Victor 2012) which enables estrogen to regulate energy homeostasis. This is especially important in neurons as they require ATP for synaptic transmission (Brinton 2009). Even though long-term oral treatment with an ERßselective SERM improved behavioral outcomes and decreased A $\beta$ load in a transgenic 
mouse model of $A D$ (Zhao et al., 2013), eliminating ER $\beta$ in middle aged mice had a protective effect on cognitive function, and a similar effect was seen when ERa levels were increased (Han et al., 2013) although the mechanisms of this phenomenon are yet to be determined. Moreover, overexpression of ER $\beta$ in mouse hippocampus is associated with decreased neuronal spine formation which affects hippocampal memory (Szymczak et al., 2006). Therefore, the findings of our study suggest that a highcholesterol diet and the increased level of $27-\mathrm{OHC}$ in the hippocampus are associated with increases in ER $\beta$ expression which consequently might be harmful for mitochondrial function and lead to increased neurodegeneration in the affected cells.

The decrease in the number of mitochondria observed in our cholesterol-fed rabbit model is consistent with findings in ovariectomized rhesus monkeys that also exhibit cognitive deficits, an effect not seen in the animals undergoing natural menopause (Hara et al., 2015). This decline in metabolic capacity of the brain has also been observed in the studies investigating brain metabolism in women who did not receive supplemental estrogen during and after menopause (Maki and Resnick, 2000), but women who started estrogen therapy during perimenopause had preserved glucose metabolism in brain regions involved in cognitive decline such as hippocampus (Maki and Resnick, 2000; Maki et al., 2011; Rasgon et al., 2014a; Rasgon et al., 2014b). These findings support the role of estrogen in glucose metabolism in the brain and its importance in cognitive function but also suggest that any abrupt disruption of this tightly regulated estrogen-dependent network might make it vulnerable to neurotoxic insults such as $A B$. Moreover, hypometabolism in areas of the brain involved in learning and memory has been reported to occur decades before AD diagnosis (Rasgon et al., 
2014a). It is plausible that hypercholesterolemia and the resulting increase in $27-\mathrm{OHC}$, an endogenous ER modulator, during perimenopausal transition in women constitutes the missing link responsible for the neural tissue's vulnerability during that time. The effect that $27-\mathrm{OHC}$ has on ER signaling could provide insights into the mechanisms that could explain why some women are at a higher risk for $A D$. Maintaining neuronal responsiveness to estrogens might be crucial for prevention and delaying $A D$ symptomology in women undergoing reproductive senescence.

SERMs, a class of pharmacologics that act on ERs, could potentially aid in preserving cognitive functioning and nervous system physiology without affecting reproductive tissues. Treatment of ovariectomized rodents with a specific ER type agonist increases mitochondrial respiration rate in the hippocampus of those animals and both ER $\alpha$ - and ER $\beta$-specific ligands induced improvement in mitochondrial function (Irwin et al., 2012). The precise mechanisms for this have not yet been described and it is plausible that treatment with antagonists would result in a compromised bioenergetic phenotype in neuronal tissue. Following our findings, it is conceivable that in the hippocampus 27-OHC acts as a likely antagonist for both ER types.

It is plausible that estrogen and estrogen receptor modulators affect other signaling pathways. For example, estrogen signaling is important for the regulation of the brain's energy production and consumption as it has been shown to affect glucose transport and ATP production (Brinton, 2008). Ovariectomy causes a significant decline in multiple glucose transporters in the brain (Ding et al., 2013). GLUT-1 is a glucose transporter that regulates the entrance of glucose from the circulation into the brain and 
from the brain into glia. This transporter is very sensitive to changes in the available glucose levels and it is regulated by both glucose availability and demand as shown in the case of hypoglycemia where GLUT-1 was upregulated at the BBB (Carruthers et al., 2009). GLUT-3 is a transporter found on neuronal membranes that transports glucose into neurons, while GLUT-4 is also neuronal transporter that translocates from the cytoplasm into the membrane following insulin regulation. In animal models, estrogen treatment prevents an ovariectomy-induced decrease in these glucose transporters (Ding et al., 2013). The mechanisms by which estrogen influences glucose transporters and ultimately brain metabolism and energy production has been extensively studied especially as it relates to the insulin-sensitive glucose transporter (Garcia-Segura et al., 2010). Insulin growth factor 1 receptor (IGF1R) and ERa can form complex that leads to activation of Akt via the PI3K signaling pathway which leads to an increase in glucose transport through GLUT-4 (Cheng et al., 2000). Interestingly, AD patients exhibit low insulin and decreased insulin receptor levels in brain regions vulnerable to $A D$ pathology, especially in the hippocampus (Schioth et al., 2012a; Schioth et al., 2012b). It is possible; therefore, that the memory impairment seen early in the disease process could be explained by a metabolic decline due to attenuated estrogen and insulin signaling. It has been shown that intranasal insulin administration improved cognition in animal models as well as in patients with AD and healthy controls (Benedict et al., 2011). Insulin can cross the BBB and insulin receptors are expressed throughout the hippocampus (Burns and Rebeck, 2010). Insulin resistance results in reduced uptake of glucose from the blood and has been associated with obesity as well as decreased estrogen levels due to menopause (Luchsinger et al., 2011). Some animal models 
provide an insight into the mechanisms linking ER signaling and insulin production. For example, mice lacking the enzyme aromatase that converts testosterone to estrogen develop insulin resistance and increased visceral fat (Jones et al., 2000), and the same effects are seen in ERa knockout mice (Manrique et al., 2012). Even more importantly, ovariectomized animals experience increases in body weight and increased plasma glucose levels which can be reversed by estrogen treatment (Zhu et al., 2013). Prolonged insulin resistance leads to diabetes that is strongly linked to cognitive decline and an increased risk of AD (Williams et al., 2010; Vagelatos and Eslick, 2013).

The pattern of changes in ER expression we saw in our study is consistent with the results of local estrogen blockage resulting from inhibition of hippocampal aromatase activity where a drop in the levels of endogenous estrogen results in a decrease in ERa and an increase in ER (Rune and Frotscher, 2005). The authors also argued that hippocampus-derived estrogen is essential for hippocampal synaptic plasticity as incubation of hippocampal cultures with exogenous estrogen does not result in increase in neuronal spine density (Rune and Frotscher, 2005).

The results of our study, albeit correlational, provide an important insight into the intriguing theory that links hypercholesterolemia, loss of estrogen, and the risk of AD. The changes in ER expression in our model are similar to the changes implicated in the modifications accompanying perimenopausal transition in women that could account for the vulnerability of the female brain to neurodegenerative disorders such as AD (Brinton et al., 2015). In many women in perimenopause, the brain will adapt to the new levels of estrogen and its receptors but in some this compensatory adaptation might be defective 
and could lead to neurological symptoms. The increased circulating levels of $27-\mathrm{OHC}$ found in our study might have a negative effect on the adaptive processes accounting for an increased CNS vulnerability to $A D$ related changes. The compensatory processes that might be affected are yet to be identified but ER levels seem to be important. 27$\mathrm{OHC}$ is an active molecule that is associated with downregulation of the expression of ER $\alpha$ and the synaptic marker PSD-95, and increased levels of ER $\beta$ possibly linked to decreased mitochondria in hippocampal cells. We suggest that $27-\mathrm{OHC}$ modulates ER signaling that leads to the loss of estrogen-related neuroprotection which might explain one of the mechanisms of 27-OHC-related neurodegeneration described in both in-vivo (Mateos et al., 2011a) and in-vitro systems (Bjorkhem et al., 2009; Mateos et al., 2011b) and seen in our model as well. Therefore, the relative balance between endogenous estrogens, which decrease with age, starting in midlife, and the level of $27-\mathrm{OHC}$, an endogenous SERM, which is increased by hypercholesterolemia, might account for the increased risk for $A D$ later in life.

This project presents with several limitations. First, all of our findings are of correlational nature. The design of the study was intended to simulate a natural process where our only manipulation was a high-cholesterol diet. We believe that by not using artificially altered animal models with human genes we were able to make our model more relevant to human disease processes. This approach dictated that we investigate the changes that were occurring naturally, influenced only by the diet, without perhaps more sophisticated mechanistic manipulations. Correlational studies, like this one, are important for developing basic hypotheses that can be tested under rigorous conditions. Second, the concentration of cholesterol in the experimental diet is very high, and some 
might argue that those levels are not physiologically relevant to the human situation. We recognize that a more longitudinal model might be more germane, nonetheless logistical limitations of laboratory research dictated that we utilize this commonly accepted paradigm.

In the past, mostly male subjects were used in experiments investigating the role of cholesterol in AD. Because of the observation that female cholesterol-fed rabbits are more resistant to the $A \beta$ pathology but ultimately reach the same levels (Sparks, 2008) it became easier to use only males in these studies to minimize the time and maximize the results. With strong evidence that females might have an advantage due to high levels of circulating estrogen the assumption that cholesterol diet affects females and males the same way might not be the correct one. As we move forward, it is important to characterize the gender differences in cholesterol-fed rabbit model of $A D$.

Sporadic AD is a heterogeneous disorder, and there are many wellcharacterized risk factors influencing an individual's chance of developing this disease as well as its progression. We conclude that there is sufficient evidence linking life style risk factors like hypercholesterolemia with a biological predisposition to develop AD. In this study we examined some of the elements that could be involved in mechanisms leading to dementia, suggesting a role for high levels of $27-\mathrm{OHC}$ in the hippocampus and associated ER signaling dysfunction. 


\section{Reference List}

Abraham IM, Han SK, Todman MG, Korach KS, Herbison AE (2003) Estrogen receptor beta mediates rapid estrogen actions on gonadotropin-releasing hormone neurons in vivo. J Neurosci 23:5771-5777.

Abramov AY, lonov M, Pavlov E, Duchen MR (2011) Membrane cholesterol content plays a key role in the neurotoxicity of beta-amyloid: implications for Alzheimer's disease. Aging Cell 10:595-603.

Ahonen L, Maire FBR, Savolainen M, Kopra J, Vreeken RJ, Hankemeier T, Myohanen T, Kylli P, Kostiainen R (2014) Analysis of oxysterols and vitamin D metabolites in mouse brain and cell line samples by ultra-high-performance liquid chromatographyatmospheric pressure photoionization-mass spectrometry. Journal of Chromatography A 1364:214-222.

Akama KT, McEwen BS (2003) Estrogen stimulates postsynaptic density-95 rapid protein synthesis via the Akt/protein kinase B pathway. J Neurosci 23:2333-2339.

Alan Peters, Claire Folger Sethares (2014) The fine structure of the aging brain.

Allinson TM, Parkin ET, Turner AJ, Hooper NM (2003) ADAMs family members as amyloid precursor protein alpha-secretases. J Neurosci Res 74:342-352.

Altmann A, Tian L, Henderson VW, Greicius MD (2014) Sex modifies the APOE-related risk of developing Alzheimer disease. Ann Neurol 75:563-573.

Babiker A, Dzeletovic S, Wiklund B, Pettersson N, Salonen J, Nyyssonen K, Eriksson M, Diczfalusy U, Bjorkhem I (2005) Patients with atherosclerosis may have increased circulating levels of 27-hydroxycholesterol and cholestenoic acid. Scand J Clin Lab Invest 65:365-375.

Baloyannis SJ (2011) Mitochondria are related to synaptic pathology in Alzheimer's disease. Int J Alzheimers Dis 2011:305395.

Balthazart J, Baillien M, Ball GF (2006a) Rapid control of brain aromatase activity by glutamatergic inputs. Endocrinology 147:359-366.

Balthazart J, Ball GF (2006) Is brain estradiol a hormone or a neurotransmitter? Trends Neurosci 29:241-249.

Balthazart J, Cornil CA, Taziaux M, Charlier TD, Baillien M, Ball GF (2006b) Rapid changes in production and behavioral action of estrogens. Neuroscience 138:783-791. 
Barrett PJ, Song Y, Van Horn WD, Hustedt EJ, Schafer JM, Hadziselimovic A, Beel AJ, Sanders CR (2012) The amyloid precursor protein has a flexible transmembrane domain and binds cholesterol. Science 336:1168-1171.

Baum LW (2005) Sex, hormones, and Alzheimer's disease. J Gerontol A Biol Sci Med Sci 60:736-743.

Bauman DR, Bitmansour AD, McDonald JG, Thompson BM, Liang G, Russell DW (2009) 25-Hydroxycholesterol secreted by macrophages in response to Toll-like receptor activation suppresses immunoglobulin A production. Proc Natl Acad Sci U S A 106:16764-16769.

Beach TG, Maarouf CL, Brooks RG, Shirohi S, Daugs ID, Sue LI, Sabbagh MN, Walker DG, Lue L, Roher AE (2011) Reduced clinical and postmortem measures of cardiac pathology in subjects with advanced Alzheimer's Disease. BMC Geriatr 11:3.

Beccano-Kelly DA, Kuhlmann N, Tatarnikov I, Volta M, Munsie LN, Chou P, Cao LP, Han H, Tapia L, Farrer MJ, Milnerwood AJ (2014) Synaptic function is modulated by LRRK2 and glutamate release is increased in cortical neurons of G2019S LRRK2 knock-in mice. Front Cell Neurosci 8:301.

Benedict C, Frey WH, Schioth HB, Schultes B, Born J, Hallschmid M (2011) Intranasal insulin as a therapeutic option in the treatment of cognitive impairments. Exp Gerontol 46:112-115.

Benilova I, Karran E, De SB (2012) The toxic Abeta oligomer and Alzheimer's disease: an emperor in need of clothes. Nat Neurosci 15:349-357.

Benvenuti S, Luciani P, Vannelli GB, Gelmini S, Franceschi E, Serio M, Peri A (2005) Estrogen and selective estrogen receptor modulators exert neuroprotective effects and stimulate the expression of selective Alzheimer's disease indicator-1, a recently discovered antiapoptotic gene, in human neuroblast long-term cell cultures. J Clin Endocrinol Metab 90:1775-1782.

Berent-Spillson A, Persad CC, Love T, Tkaczyk A, Wang H, Reame NK, Frey KA, Zubieta JK, Smith YR (2010) Early menopausal hormone use influences brain regions used for visual working memory. Menopause 17:692-699.

Bjorkhem I, Cedazo-Minguez A, Leoni V, Meaney S (2009) Oxysterols and neurodegenerative diseases. Mol Aspects Med 30:171-179.

Bjorkhem I, Heverin M, Leoni V, Meaney S, Diczfalusy U (2006) Oxysterols and Alzheimer's disease. Acta Neurol Scand Suppl 185:43-49.

Bodovitz S, Klein WL (1996) Cholesterol modulates alpha-secretase cleavage of amyloid precursor protein. J Biol Chem 271:4436-4440. 
Bogdanovic N, Bretillon L, Lund EG, Diczfalusy U, Lannfelt L, Winblad B, Russell DW, Bjorkhem I (2001) On the turnover of brain cholesterol in patients with Alzheimer's disease. Abnormal induction of the cholesterol-catabolic enzyme CYP46 in glial cells. Neurosci Lett 314:45-48.

Braak H, Braak E, Bohl J (1993) Staging of Alzheimer-related cortical destruction. Eur Neurol 33:403-408.

Brinton RD, Yao J, Yin F, Mack WJ, Cadenas E (2015) Perimenopause as a neurological transition state. Nat Rev Endocrinol 11:393-405.

Brinton RD (2008) The healthy cell bias of estrogen action: mitochondrial bioenergetics and neurological implications. Trends in Neurosciences 31:529-537.

Brookmeyer R, Evans DA, Hebert L, Langa KM, Heeringa SG, Plassman BL, Kukull WA (2011) National estimates of the prevalence of Alzheimer's disease in the United States. Alzheimers Dement 7:61-73.

Brown MR, Sullivan PG, Geddes JW (2006) Synaptic mitochondria are more susceptible to Ca2+overload than nonsynaptic mitochondria. J Biol Chem 281:1165811668 .

Burns MP, Rebeck GW (2010) Intracellular cholesterol homeostasis and amyloid precursor protein processing. Biochim Biophys Acta 1801:853-859.

Bush Al, Tanzi RE (2008) Therapeutics for Alzheimer's disease based on the metal hypothesis. Neurotherapeutics 5:421-432.

Buxbaum JD, Geoghagen NS, Friedhoff LT (2001) Cholesterol depletion with physiological concentrations of a statin decreases the formation of the Alzheimer amyloid Abeta peptide. J Alzheimers Dis 3:221-229.

Canevari L, Clark J (2007) AlzheimerГÇÖs Disease and Cholesterol: The Fat Connection. Neurochem Res 32:739-750.

Carroll JC, Pike CJ (2008) Selective estrogen receptor modulators differentially regulate Alzheimer-like changes in female 3xTg-AD mice. Endocrinology 149:2607-2611.

Carroll JC, Rosario ER, Chang L, Stanczyk FZ, Oddo S, LaFerla FM, Pike CJ (2007) Progesterone and estrogen regulate Alzheimer-like neuropathology in female 3xTg-AD mice. J Neurosci 27:13357-13365.

Carroll JC, Rosario ER, Pike CJ (2008) Progesterone blocks estrogen neuroprotection from kainate in middle-aged female rats. Neurosci Lett 445:229-232.

Carruthers A, DeZutter J, Ganguly A, Devaskar SU (2009) Will the original glucose transporter isoform please stand up! Am J Physiol Endocrinol Metab 297:E836-E848. 
Carter CL, Resnick EM, Mallampalli M, Kalbarczyk A (2012) Sex and gender differences in Alzheimer's disease: recommendations for future research. J Womens Health (Larchmt ) 21:1018-1023.

Castellano JM, Kim J, Stewart FR, Jiang H, DeMattos RB, Patterson BW, Fagan AM, Morris JC, Mawuenyega KG, Cruchaga C, Goate AM, Bales KR, Paul SM, Bateman RJ, Holtzman DM (2011) Human apoE Isoforms Differentially Regulate Brain Amyloid Beta Peptide Clearance. Science Translational Medicine 3:89ra57.

Castello MA, Soriano S (2014) On the origin of Alzheimer's disease. Trials and tribulations of the amyloid hypothesis. Ageing Res Rev 13:10-12.

Chambliss KL, Wu Q, Oltmann S, Konaniah ES, Umetani M, Korach KS, Thomas GD, Mineo C, Yuhanna IS, Kim SH, Madak-Erdogan Z, Maggi A, Dineen SP, Roland CL, Hui DY, Brekken RA, Katzenellenbogen JA, Katzenellenbogen BS, Shaul PW (2010) Nonnuclear estrogen receptor alpha signaling promotes cardiovascular protection but not uterine or breast cancer growth in mice. J Clin Invest 120:2319-2330.

Chapman RM, Mapstone M, Gardner MN, Sandoval TC, McCrary JW, Guillily MD, Reilly LA, DeGrush E (2011) Women have farther to fall: gender differences between normal elderly and Alzheimer's disease in verbal memory engender better detection of Alzheimer's disease in women. J Int Neuropsychol Soc 17:654-662.

Chauhan NB, Siegel GJ, Feinstein DL (2004) Effects of lovastatin and pravastatin on amyloid processing and inflammatory response in TgCRND8 brain. Neurochem Res 29:1897-1911.

Chen JQ, Brown TR, Yager JD (2008) Mechanisms of hormone carcinogenesis: evolution of views, role of mitochondria. Adv Exp Med Biol 630:1-18.

Cheng CM, Reinhardt RR, Lee WH, Joncas G, Patel SC, Bondy CA (2000) Insulin-like growth factor 1 regulates developing brain glucose metabolism. Proc Natl Acad Sci U S A 97:10236-10241.

Chin AL, Negash S, Hamilton R (2011) Diversity and disparity in dementia: the impact of ethnoracial differences in Alzheimer disease. Alzheimer Dis Assoc Disord 25:187-195.

Cimarosti H, Siqueira IR, Zamin LL, Nassif M, Balk R, Frozza R, Dalmaz C, Netto CA, Salbego C (2005a) Neuroprotection and protein damage prevention by estradiol replacement in rat hippocampal slices exposed to oxygen-glucose deprivation. Neurochem Res 30:583-589.

Cimarosti H, Zamin LL, Frozza R, Nassif M, Horn AP, Tavares A, Netto CA, Salbego C (2005b) Estradiol protects against oxygen and glucose deprivation in rat hippocampal organotypic cultures and activates Akt and inactivates GSK-3beta. Neurochem Res 30:191-199. 
Corder EH, Saunders AM, Risch NJ, Strittmatter WJ, Schmechel DE, Gaskell PC, Jr., Rimmler JB, Locke PA, Conneally PM, Schmader KE, . (1994) Protective effect of apolipoprotein E type 2 allele for late onset Alzheimer disease. Nat Genet 7:180-184.

Corder EH, Saunders AM, Strittmatter WJ, Schmechel DE, Gaskell PC, Small GW, Roses AD, Haines JL, Pericak-Vance MA (1993) Gene dose of apolipoprotein E type 4 allele and the risk of Alzheimer's disease in late onset families. Science 261:921-923.

Cordey M, Pike CJ (2005) Neuroprotective properties of selective estrogen receptor agonists in cultured neurons. Brain Res 1045:217-223.

Costantini C, Kolasani RM, Puglielli L (2005) Ceramide and cholesterol: possible connections between normal aging of the brain and Alzheimer's disease. Just hypotheses or molecular pathways to be identified? Alzheimers Dement 1:43-50.

Cotman CW (1998) Apoptosis decision cascades and neuronal degeneration in Alzheimer's disease. Neurobiol Aging 19:S29-S32.

Counts SE, Alldred MJ, Che S, Ginsberg SD, Mufson EJ (2014) Synaptic gene dysregulation within hippocampal CA1 pyramidal neurons in mild cognitive impairment. Neuropharmacology 79:172-179.

Damoiseaux JS, Seeley WW, Zhou J, Shirer WR, Coppola G, Karydas A, Rosen HJ, Miller BL, Kramer JH, Greicius MD, Alzheimer's Disease Neuroimaging Initiative (ADNI) (2012) Gender Modulates the APOE e4 Effect in Healthy Older Adults: Convergent Evidence from Functional Brain Connectivity and Spinal Fluid Tau Levels. J Neurosci 32:8254-8262.

Darwish DS, Wang D, Konat GW, Schreurs BG (2010) Dietary cholesterol impairs memory and memory increases brain cholesterol and sulfatide levels. Behavioral Neuroscience 124:115-123.

Dasari B, Prasanthi JR, Marwarha G, Singh BB, Ghribi O (2011) Cholesterol-enriched diet causes age-related macular degeneration-like pathology in rabbit retina. BMC Ophthalmol 11:22.

Davis JN, Chisholm JC (1999) Alois Alzheimer and the amyloid debate. Nature 400:810.

Day M, Sung A, Logue S, Bowlby M, Arias R (2005) Beta estrogen receptor knockout (BERKO) mice present attenuated hippocampal CA1 long-term potentiation and related memory deficits in contextual fear conditioning. Behav Brain Res 164:128-131.

Deane R, Sagare A, Hamm K, Parisi M, LaRue B, Guo H, Wu Z, Holtzman DM, Zlokovic BV (2005) IgG-assisted age-dependent clearance of Alzheimer's amyloid beta peptide by the blood-brain barrier neonatal Fc receptor. J Neurosci 25:11495-11503. 
Deci S, Lemieux SK, Smith-Bell CA, Sparks DL, Schreurs BG (2012) Cholesterol increases ventricular volume in a rabbit model of Alzheimer's disease. J Alzheimers Dis 29:283-292.

DeKosky ST, Scheff SW (1990) Synapse loss in frontal cortex biopsies in Alzheimer's disease: correlation with cognitive severity. Ann Neurol 27:457-464.

Deroo BJ, Korach KS (2006) Estrogen receptors and human disease. J Clin Invest 116:561-570.

Dhandapani KM, Brann DW (2002) Protective effects of estrogen and selective estrogen receptor modulators in the brain. Biol Reprod 67:1379-1385.

Dietschy JM, Turley SD (2001) Cholesterol metabolism in the brain. Curr Opin Lipidol 12:105-112.

Ding F, Yao J, Rettberg JR, Chen S, Brinton RD (2013) Early decline in glucose transport and metabolism precedes shift to ketogenic system in female aging and Alzheimer's mouse brain: implication for bioenergetic intervention. PLoS ONE 8:e79977.

Disterhoft JF, Thompson LT, Moyer JR, Jr., Mogul DJ (1996) Calcium-dependent afterhyperpolarization and learning in young and aging hippocampus. Life Sci 59:413420.

DuSell CD, McDonnell DP (2008) 27-Hydroxycholesterol: a potential endogenous regulator of estrogen receptor signaling. Trends Pharmacol Sci 29:510-514.

DuSell CD, Nelson ER, Wang X, Abdo J, Modder UI, Umetani M, Gesty-Palmer D, Javitt NB, Khosla S, McDonnell DP (2010) The endogenous selective estrogen receptor modulator 27-hydroxycholesterol is a negative regulator of bone homeostasis. Endocrinology 151:3675-3685.

DuSell CD, Umetani M, Shaul PW, Mangelsdorf DJ, McDonnell DP (2008) 27hydroxycholesterol is an endogenous selective estrogen receptor modulator. Mol Endocrinol 22:65-77.

Edland SD, Wavrant-De VF, Compton D, Smith GE, Ivnik R, Boeve BF, Tangalos EG, Petersen RC (2003) Insulin degrading enzyme (IDE) genetic variants and risk of Alzheimer's disease: evidence of effect modification by apolipoprotein E (APOE). Neurosci Lett 345:21-24.

Espeland MA, Rapp SR, Shumaker SA, Brunner R, Manson JE, Sherwin BB, Hsia J, Margolis KL, Hogan PE, Wallace R, Dailey M, Freeman R, Hays J (2004) Conjugated equine estrogens and global cognitive function in postmenopausal women: Women's Health Initiative Memory Study. JAMA 291:2959-2968. 
Famer D, Meaney S, Mousavi M, Nordberg A, Bjorkhem I, Crisby M (2007) Regulation of alpha- and beta-secretase activity by oxysterols: cerebrosterol stimulates processing of APP via the alpha-secretase pathway. Biochem Biophys Res Commun 359:46-50.

Farrer LA, Cupples L, Haines JL (1997) Effects of age, sex, and ethnicity on the association between apolipoprotein e genotype and alzheimer disease: A metaanalysis. JAMA 278:1349-1356.

Fassbender K, Simons M, Bergmann C, Stroick M, Lutjohann D, Keller P, Runz H, Kuhl S, Bertsch T, von BK, Hennerici M, Beyreuther K, Hartmann T (2001) Simvastatin strongly reduces levels of Alzheimer's disease beta -amyloid peptides Abeta 42 and Abeta 40 in vitro and in vivo. Proc Natl Acad Sci U S A 98:5856-5861.

Feldman HH, Doody RS, Kivipelto M, Sparks DL, Waters DD, Jones RW, Schwam E, Schindler R, Hey-Hadavi J, DeMicco DA, Breazna A (2010) Randomized controlled trial of atorvastatin in mild to moderate Alzheimer disease: LEADe. Neurology 74:956-964.

Fernandez SM, Lewis MC, Pechenino AS, Harburger LL, Orr PT, Gresack JE, Schafe GE, Frick KM (2008) Estradiol-induced enhancement of object memory consolidation involves hippocampal extracellular signal-regulated kinase activation and membranebound estrogen receptors. J Neurosci 28:8660-8667.

Fester L, Labitzke J, Hinz R, Behem C, Horling K, Bernhard T, Bader MI, Vollmer G, Rune GM (2013) Estradiol responsiveness of synaptopodin in hippocampal neurons is mediated by estrogen receptor beta. J Steroid Biochem Mol Biol 138:455-461.

Finking G, Hanke H (1997) Nikolaj Nikolajewitsch Anitschkow (1885-1964) established the cholesterol-fed rabbit as a model for atherosclerosis research. Atherosclerosis 135:1-7.

Foley P (2010) Lipids in Alzheimer's disease: A century-old story. Biochimica et Biophysica Acta (BBA) - Molecular and Cell Biology of Lipids 1801:750-753.

Fornicola W, Pelcovits A, Li BX, Heath J, Perry G, Castellani RJ (2014) Alzheimer Disease Pathology in Middle Age Reveals a Spatial-Temporal Disconnect Between Amyloid-beta and Phosphorylated Tau. Open Neurol J 8:22-26.

Fortress AM, Fan L, Orr PT, Zhao Z, Frick KM (2013) Estradiol-induced object recognition memory consolidation is dependent on activation of mTOR signaling in the dorsal hippocampus. Learn Mem 20:147-155.

Foster TC (2012) Role of estrogen receptor alpha and beta expression and signaling on cognitive function during aging. Hippocampus 22:656-669.

Foy MR, Baudry M, Diaz BR, Thompson RF (2008a) Estrogen and hippocampal plasticity in rodent models. J Alzheimers Dis 15:589-603. 
Foy MR, Baudry M, Foy JG, Thompson RF (2008b) 17beta-estradiol modifies stressinduced and age-related changes in hippocampal synaptic plasticity. Behav Neurosci 122:301-309.

Foy MR, Xu J, Xie X, Brinton RD, Thompson RF, Berger TW (1999) 17beta-estradiol enhances NMDA receptor-mediated EPSPs and long-term potentiation. J Neurophysiol 81:925-929.

Fugger HN, Foster TC, Gustafsson J, Rissman EF (2000) Novel effects of estradiol and estrogen receptor alpha and beta on cognitive function. Brain Res 883:258-264.

Garcia-Segura LM, Arevalo MA, Azcoitia I (2010) Interactions of estradiol and insulinlike growth factor-I signalling in the nervous system: new advances. Prog Brain Res 181:251-272.

Gerrow K, Romorini S, Nabi SM, Colicos MA, Sala C, El-Husseini A (2006) A preformed complex of postsynaptic proteins is involved in excitatory synapse development. Neuron 49:547-562.

Ghribi O, Larsen B, Schrag M, Herman MM (2006) High cholesterol content in neurons increases BACE, beta amyloid, and phosphorylated tau levels in rabbit hippocampus. Experimental Neurology 200:460-467.

Gibbs RB (2000) Long-term treatment with estrogen and progesterone enhances acquisition of a spatial memory task by ovariectomized aged rats. Neurobiol Aging 21:107-116.

Giuffrida ML, Caraci F, Pignataro B, Cataldo S, De BP, Bruno V, Molinaro G, Pappalardo G, Messina A, Palmigiano A, Garozzo D, Nicoletti F, Rizzarelli E, Copani A (2009) Beta-amyloid monomers are neuroprotective. J Neurosci 29:10582-10587.

Goate A, Chartier-Harlin MC, Mullan M, Brown J, Crawford F, Fidani L, Giuffra L, Haynes A, Irving N, James L, . (1991) Segregation of a missense mutation in the amyloid precursor protein gene with familial Alzheimer's disease. Nature 349:704-706.

Gonzalo-Ruiz A, Perez JL, Sanz JM, Geula C, Arevalo J (2006) Effects of lipids and aging on the neurotoxicity and neuronal loss caused by intracerebral injections of the amyloid-beta peptide in the rat. Exp Neurol 197:41-55.

Gottfried-Blackmore A, Croft G, McEwen BS, Bulloch K (2007) Transcriptional activity of estrogen receptors ERalpha and ERbeta in the EtC.1 cerebellar granule cell line. Brain Res 1186:41-47.

Gotz J, Ittner LM (2008) Animal models of Alzheimer's disease and frontotemporal dementia. Nat Rev Neurosci 9:532-544. 
Gould E, Woolley CS, Frankfurt M, McEwen BS (1990) Gonadal steroids regulate dendritic spine density in hippocampal pyramidal cells in adulthood. J Neurosci 10:1286-1291.

Grant WB (1999) Dietary links to Alzheimer's disease: 1999 update. J Alzheimers Dis 1:197-201.

Greendale GA, Derby CA, Maki PM (2011) Perimenopause and cognition. Obstet Gynecol Clin North Am 38:519-535.

Griffiths WJ, Crick PJ, Wang Y (2013) Methods for oxysterol analysis: past, present and future. Biochem Pharmacol 86:3-14.

Griffiths WJ, Wang Y (2011) Analysis of oxysterol metabolomes. Biochim Biophys Acta 1811:784-799.

Haag MD, Hofman A, Koudstaal PJ, Stricker BH, Breteler MM (2009) Statins are associated with a reduced risk of Alzheimer disease regardless of lipophilicity. The Rotterdam Study. J Neurol Neurosurg Psychiatry 80:13-17.

Haass C, Selkoe DJ (2007) Soluble protein oligomers in neurodegeneration: lessons from the Alzheimer's amyloid beta-peptide. Nat Rev Mol Cell Biol 8:101-112.

Hall JR, Johnson LA, Barber RC, Vo HT, Winter AS, O'Bryant SE (2012) Biomarkers of basic activities of daily living in Alzheimer's disease. J Alzheimers Dis 31:429-437.

Hammes SR, Levin ER (2007) Extranuclear steroid receptors: nature and actions. Endocr Rev 28:726-741.

Hampel H, Burger K, Teipel SJ, Bokde AL, Zetterberg H, Blennow K (2008) Core candidate neurochemical and imaging biomarkers of Alzheimer's disease. Alzheimers Dement 4:38-48.

Han X, Aenlle KK, Bean LA, Rani A, Semple-Rowland SL, Kumar A, Foster TC (2013) Role of estrogen receptor alpha and beta in preserving hippocampal function during aging. J Neurosci 33:2671-2683.

Hara Y, Waters EM, McEwen BS, Morrison JH (2015) Estrogen Effects on Cognitive and Synaptic Health Over the Lifecourse. Physiol Rev 95:785-807.

Hardy J, Selkoe DJ (2002) The amyloid hypothesis of Alzheimer's disease: progress and problems on the road to therapeutics. Science 297:353-356.

Hart SA, Snyder MA, Smejkalova T, Woolley CS (2007) Estrogen mobilizes a subset of estrogen receptor-alpha-immunoreactive vesicles in inhibitory presynaptic boutons in hippocampal CA1. J Neurosci 27:2102-2111. 
Hartz AM, Zhong Y, Wolf A, LeVine H, III, Miller DS, Bauer B (2016) Abeta40 Reduces P-Glycoprotein at the Blood-Brain Barrier through the Ubiquitin-Proteasome Pathway. J Neurosci 36:1930-1941.

Harwood DT, Handelsman DJ (2009) Development and validation of a sensitive liquid chromatography-tandem mass spectrometry assay to simultaneously measure androgens and estrogens in serum without derivatization. Clin Chim Acta 409:78-84.

Hasegawa Y, Hojo Y, Kojima H, Ikeda M, Hotta K, Sato R, Ooishi Y, Yoshiya M, Chung BC, Yamazaki T, Kawato S (2015) Estradiol rapidly modulates synaptic plasticity of hippocampal neurons: Involvement of kinase networks. Brain Res 1621:147-161.

Hattori C, Asai M, Onishi H, Sasagawa N, Hashimoto Y, Saido TC, Maruyama K, Mizutani S, Ishiura S (2006) BACE1 interacts with lipid raft proteins. J Neurosci Res 84:912-917.

Henderson VW (2009) Estrogens, episodic memory, and Alzheimer's disease: a critical update. Semin Reprod Med 27:283-293.

Henderson VW (2010) Action of estrogens in the aging brain: dementia and cognitive aging. Biochim Biophys Acta 1800:1077-1083.

Henderson VW, Brinton RD (2010) Menopause and mitochondria: windows into estrogen effects on Alzheimer's disease risk and therapy. Prog Brain Res 182:77-96.

Henderson VW, Guthrie JR, Dennerstein L (2003) Serum lipids and memory in a population based cohort of middle age women. J Neurol Neurosurg Psychiatry 74:15301535.

Herrick SP, Waters EM, Drake CT, McEwen BS, Milner TA (2006) Extranuclear estrogen receptor beta immunoreactivity is on doublecortin-containing cells in the adult and neonatal rat dentate gyrus. Brain Res 1121:46-58.

Heverin M, Maioli S, Pham T, Mateos L, Camporesi E, Ali Z, Winblad B, CedazoMinguez A, Bjorkhem I (2015) 27-hydroxycholesterol mediates negative effects of dietary cholesterol on cognition in mice. Behav Brain Res 278:356-359.

Heverin M, Bogdanovic N, Lutjohann D, Bayer T, Pikuleva I, Bretillon L, Diczfalusy U, Winblad B, Bjorkhem I (2004) Changes in the levels of cerebral and extracerebral sterols in the brain of patients with Alzheimer's disease. Journal of Lipid Research 45:186-193.

Heverin M, Meaney S, Lutjohann D, Diczfalusy U, Wahren J, Bjorkhem I (2005) Crossing the barrier: net flux of 27-hydroxycholesterol into the human brain. Journal of Lipid Research 46:1047-1052.

Holtzman DM, Bales KR, Tenkova T, Fagan AM, Parsadanian M, Sartorius LJ, Mackey B, Olney J, McKeel D, Wozniak D, Paul SM (2000) Apolipoprotein E isoform-dependent 
amyloid deposition and neuritic degeneration in a mouse model of Alzheimer's disease. Proc Natl Acad Sci U S A 97:2892-2897.

Hu XY, Qin S, Lu YP, Ravid R, Swaab DF, Zhou JN (2003) Decreased estrogen receptor-alpha expression in hippocampal neurons in relation to hyperphosphorylated tau in Alzheimer patients. Acta Neuropathol 106:213-220.

Hughes TM, Kuller LH, Lopez OL, Becker JT, Evans RW, Sutton-Tyrrell K, Rosano C (2012) Markers of Cholesterol Metabolism in the Brain Show Stronger Associations with Cerebrovascular Disease than Alzheimer's Disease. Journal of Alzheimer's Disease 30:53-61.

Hughes TM, Rosano C, Evans RW, Kuller LH (2013) Brain Cholesterol Metabolism, Oxysterols, and Dementia. Journal of Alzheimer's Disease 33:891-911.

Hurley AC, Wells N (1999) Past, present, and future directions for Alzheimer research. Alzheimer Dis Assoc Disord 13 Suppl 1:S6-10.

Inagaki T, Frankfurt M, Luine V (2012) Estrogen-induced memory enhancements are blocked by acute bisphenol $A$ in adult female rats: role of dendritic spines.

Endocrinology 153:3357-3367.

Irvine K, Laws KR, Gale TM, Kondel TK (2012) Greater cognitive deterioration in women than men with Alzheimer's disease: a meta analysis. J Clin Exp Neuropsychol 34:989-998.

Irwin RW, Yao J, To J, Hamilton RT, Cadenas E, Brinton RD (2012) Selective oestrogen receptor modulators differentially potentiate brain mitochondrial function. $\mathrm{J}$ Neuroendocrinol 24:236-248.

Ishikawa T, Yuhanna IS, Umetani J, Lee WR, Korach KS, Shaul PW, Umetani M (2013) LXRbeta/estrogen receptor-alpha signaling in lipid rafts preserves endothelial integrity. $J$ Clin Invest 123:3488-3497.

Jarvik L, Greenson H (1987) About a peculiar disease of the cerebral cortex. By Alois Alzheimer, 1907. Alzheimer Dis Assoc Disord 1:3-8.

Jaya Prasanthi RP, Schommer E, Thomasson S, Thompson A, Feist G, Ghribi O (2008) Regulation of beta-amyloid levels in the brain of cholesterol-fed rabbit, a model system for sporadic Alzheimer's disease. Mech Ageing Dev 129:649-655.

Jiang Q, Lee CY, Mandrekar S, Wilkinson B, Cramer P, Zelcer N, Mann K, Lamb B, Willson TM, Collins JL, Richardson JC, Smith JD, Comery TA, Riddell D, Holtzman DM, Tontonoz P, Landreth GE (2008) ApoE promotes the proteolytic degradation of Abeta. Neuron 58:681-693.

Johnstone EM, Chaney MO, Norris FH, Pascual R, Little SP (1991) Conservation of the sequence of the Alzheimer's disease amyloid peptide in dog, polar bear and five other 
mammals by cross-species polymerase chain reaction analysis. Brain Res Mol Brain Res 10:299-305.

Johri A, Beal MF (2012) Mitochondrial dysfunction in neurodegenerative diseases. J Pharmacol Exp Ther 342:619-630.

Jones ME, Thorburn AW, Britt KL, Hewitt KN, Wreford NG, Proietto J, Oz OK, Leury BJ, Robertson KM, Yao S, Simpson ER (2000) Aromatase-deficient (ArKO) mice have a phenotype of increased adiposity. Proc Natl Acad Sci U S A 97:12735-12740.

Joosten H, van Eersel ME, Gansevoort RT, Bilo HJ, Slaets JP, Izaks GJ (2013) Cardiovascular risk profile and cognitive function in young, middle-aged, and elderly subjects. Stroke 44:1543-1549.

Kalmijn S, Launer Lenore J., Ott Alewijn, Witteman J.C.M., Hofman A., Breteler M.M.B. (1997) Dietary fat intake and the risk of incident dementia in the Rotterdam Study. Ann Neurol 42:776-782.

Kay D, BEAMISH P, ROTH M (1964) Old age mental disorders in New Castle upon tyne. I. A study of prevelance. Br J Psychiatry 110:146-158.

Kelly JF, Bienias JL, Shah A, Meeke KA, Schneider JA, Soriano E, Bennett DA (2008) Levels of estrogen receptors alpha and beta in frontal cortex of patients with Alzheimer's disease: relationship to Mini-Mental State Examination scores. Curr Alzheimer Res 5:45-51.

Kivipelto M, Helkala EL, Hanninen T, Laakso MP, Hallikainen M, Alhainen K, Soininen $\mathrm{H}$, Tuomilehto J, Nissinen A (2001a) Midlife vascular risk factors and late-life mild cognitive impairment: A population-based study. Neurology 56:1683-1689.

Kivipelto M, Helkala EL, Laakso MP, Hanninen T, Hallikainen M, Alhainen K, livonen S, Mannermaa A, Tuomilehto J, Nissinen A, Soininen H (2002) Apolipoprotein E epsilon4 allele, elevated midlife total cholesterol level, and high midlife systolic blood pressure are independent risk factors for late-life Alzheimer disease. Ann Intern Med 137:149155.

Kivipelto M, Helkala EL, Laakso MP, Hanninen T, Hallikainen M, Alhainen K, Soininen $\mathrm{H}$, Tuomilehto J, Nissinen A (2001b) Midlife vascular risk factors and Alzheimer's disease in later life: longitudinal, population based study. BMJ 322:1447-1451.

Kojro E, Gimpl G, Lammich S, Marz W, Fahrenholz F (2001) Low cholesterol stimulates the nonamyloidogenic pathway by its effect on the alpha -secretase ADAM 10. Proc Natl Acad Sci U S A 98:5815-5820.

Kostiainen R, Kauppila TJ (2009) Effect of eluent on the ionization process in liquid chromatography-mass spectrometry. J Chromatogr A 1216:685-699. 
Launer LJ, White LR, Petrovitch H, Ross GW, Curb JD (2001) Cholesterol and neuropathologic markers of AD: a population-based autopsy study. Neurology 57:14471452.

Lebesgue D, Chevaleyre V, Zukin RS, Etgen AM (2009) Estradiol rescues neurons from global ischemia-induced cell death: multiple cellular pathways of neuroprotection. Steroids 74:555-561.

Ledoux VA, Smejkalova T, May RM, Cooke BM, Woolley CS (2009) Estradiol facilitates the release of neuropeptide $Y$ to suppress hippocampus-dependent seizures. J Neurosci 29:1457-1468.

Lee SJ, Campomanes CR, Sikat PT, Greenfield AT, Allen PB, McEwen BS (2004) Estrogen induces phosphorylation of cyclic AMP response element binding (pCREB) in primary hippocampal cells in a time-dependent manner. Neuroscience 124:549-560.

Lemieux SK, Smith-Bell CA, Wells JR, Ezerioha NM, Carpenter JS, Sparks DL, Schreurs BG (2010) Neurovascular changes measured by time-of-flight MR angiography in cholesterol-fed rabbits with cortical amyloid beta-peptide accumulation. $\mathrm{J}$ Magn Reson Imaging 32:306-314.

Leoni V, Masterman T, Patel P, Meaney S, Diczfalusy U, Bjorkhem I (2003) Side chain oxidized oxysterols in cerebrospinal fluid and the integrity of blood-brain and bloodcerebrospinal fluid barriers. J Lipid Res 44:793-799.

Leoni V, Caccia C (2011) Oxysterols as biomarkers in neurodegenerative diseases. Chemistry and Physics of Lipids 164:515-524.

Levin ER (2005) Integration of the extranuclear and nuclear actions of estrogen. Mol Endocrinol 19:1951-1959.

Li L, Cao D, Kim H, Lester R, Fukuchi K (2006) Simvastatin enhances learning and memory independent of amyloid load in mice. Ann Neurol 60:729-739.

Liang K, Yang L, Yin C, Xiao Z, Zhang J, Liu Y, Huang J (2010) Estrogen stimulates degradation of beta-amyloid peptide by up-regulating neprilysin. J Biol Chem 285:935942.

Lifshitz J, Friberg H, Neumar RW, Raghupathi R, Welsh FA, Janmey P, Saatman KE, Wieloch T, Grady MS, McIntosh TK (2003) Structural and functional damage sustained by mitochondria after traumatic brain injury in the rat: evidence for differentially sensitive populations in the cortex and hippocampus. J Cereb Blood Flow Metab 23:219-231.

Lin MS, Chen LY, Wang SSS, Chang Y, Chen WY (2008) Examining the levels of ganglioside and cholesterol in cell membrane on attenuation the cytotoxicity of betaamyloid peptide. Colloids and Surfaces B: Biointerfaces 65:172-177. 
Liu F, Day M, Muniz LC, Bitran D, Arias R, Revilla-Sanchez R, Grauer S, Zhang G, Kelley C, Pulito V, Sung A, Mervis RF, Navarra R, Hirst WD, Reinhart PH, Marquis KL, Moss SJ, Pangalos MN, Brandon NJ (2008) Activation of estrogen receptor-[beta] regulates hippocampal synaptic plasticity and improves memory. Nat Neurosci 11:334343.

Lu YP, Zeng M, Swaab DF, Ravid R, Zhou JN (2004) Colocalization and alteration of estrogen receptor-alpha and -beta in the hippocampus in Alzheimer's disease. Hum Pathol 35:275-280.

Luchsinger JA, Small S, Biessels GJ (2011) Should we target insulin resistance to prevent dementia due to Alzheimer disease? Arch Neurol 68:17-18.

Luchsinger J, Gustafson D (2009) Adiposity and Alzheimer's disease. Curr Opin Clin Nutr Metab Care 12:15-21.

Lutjohann D, Breuer O, Ahlborg G, Nennesmo I, Siden A, Diczfalusy U, Bjorkhem I (1996) Cholesterol homeostasis in human brain: evidence for an age-dependent flux of 24S-hydroxycholesterol from the brain into the circulation. Proc Natl Acad Sci U S A 93:9799-9804.

Lutjohann D, Papassotiropoulos A, Bjorkhem I, Locatelli S, Bagli M, Oehring RD, Schlegel U, Jessen F, Rao ML, von BK, Heun R (2000) Plasma 24S-hydroxycholesterol (cerebrosterol) is increased in Alzheimer and vascular demented patients. J Lipid Res 41:195-198.

Lutjohann D, Stroick M, Bertsch T, Kuhl S, Lindenthal B, Thelen K, Andersson U, Bjorkhem I, Bergmann KK, Fassbender K (2004) High doses of simvastatin, pravastatin, and cholesterol reduce brain cholesterol synthesis in guinea pigs. Steroids 69:431-438.

Luu W, Sharpe LJ, Capell-Hattam I, Gelissen IC, Brown AJ (2016) Oxysterols: Old Tale, New Twists. Annu Rev Pharmacol Toxicol 56:447-467.

Luzzi S, Vella L, Bartolini M, Provinciali L, Silvestrini M (2010) Atherosclerosis in the Evolution of Alzheimer's Disease: Can Treatment Reduce Cognitive Decline? Journal of Alzheimer's Disease 20:893-901.

MacLennan AH, Henderson VW, Paine BJ, Mathias J, Ramsay EN, Ryan P, Stocks NP, Taylor AW (2006) Hormone therapy, timing of initiation, and cognition in women aged older than 60 years: the REMEMBER pilot study. Menopause 13:28-36.

MacLusky NJ, Luine VN, Hajszan T, Leranth C (2005) The 17alpha and 17beta isomers of estradiol both induce rapid spine synapse formation in the CA1 hippocampal subfield of ovariectomized female rats. Endocrinology 146:287-293.

Madani R, Poirier R, Wolfer DP, Welzl H, Groscurth P, Lipp HP, Lu B, El MM, Mercken M, Nitsch RM, Mohajeri MH (2006) Lack of neprilysin suffices to generate murine 
amyloid-like deposits in the brain and behavioral deficit in vivo. J Neurosci Res 84:18711878.

Maki PM, Dennerstein L, Clark M, Guthrie J, LaMontagne P, Fornelli D, Little D, Henderson VW, Resnick SM (2011) Perimenopausal use of hormone therapy is associated with enhanced memory and hippocampal function later in life. Brain Res 1379:232-243.

Maki PM, Resnick SM (2000) Longitudinal effects of estrogen replacement therapy on PET cerebral blood flow and cognition. Neurobiol Aging 21:373-383.

Mannella P, Brinton RD (2006) Estrogen receptor protein interaction with phosphatidylinositol 3-kinase leads to activation of phosphorylated Akt and extracellular signal-regulated kinase $1 / 2$ in the same population of cortical neurons: a unified mechanism of estrogen action. J Neurosci 26:9439-9447.

Manrique C, Lastra G, Habibi J, Mugerfeld I, Garro M, Sowers JR (2012) Loss of Estrogen Receptor alpha Signaling Leads to Insulin Resistance and Obesity in Young and Adult Female Mice. Cardiorenal Med 2:200-210.

Mantha SV, Prasad M, Kalra J, Prasad K (1993) Antioxidant enzymes in hypercholesterolemia and effects of vitamin E in rabbits. Atherosclerosis 101:135-144.

Marin R, Guerra B, Hernandez-Jimenez JG, Kang XL, Fraser JD, Lopez FJ, Alonso R (2003) Estradiol prevents amyloid-beta peptide-induced cell death in a cholinergic cell line via modulation of a classical estrogen receptor. Neuroscience 121:917-926.

Marquer C, Devauges V, Cossec JC, Liot G, Lecart S, Saudou F, Duyckaerts C, Leveque-Fort S, Potier MC (2011) Local cholesterol increase triggers amyloid precursor protein-Bace1 clustering in lipid rafts and rapid endocytosis. FASEB J 25:1295-1305.

Martins RN, Harper CG, Stokes GB, Masters CL (1986) Increased cerebral glucose-6phosphate dehydrogenase activity in Alzheimer's disease may reflect oxidative stress. J Neurochem 46:1042-1045.

Marwarha G, Ghribi O (2015) Does the oxysterol 27-hydroxycholesterol underlie Alzheimer's disease-Parkinson's disease overlap? Exp Gerontol 68:13-18.

Mateos L, Ismail MA, Gil-Bea FJ, Leoni V, Winblad B, Bjorkhem I, Cedazo-Minguez A (2011a) Upregulation of brain renin angiotensin system by 27-hydroxycholesterol in Alzheimer's disease. J Alzheimers Dis 24:669-679.

Mateos L, Ismail MA, Gil-Bea FJ, Schule R, Schols L, Heverin M, Folkesson R, Bjorkhem I, Cedazo-Minguez A (2011b) Side chain-oxidized oxysterols regulate the brain renin-angiotensin system through a liver $\mathrm{X}$ receptor-dependent mechanism. J Biol Chem 286:25574-25585. 
Matsuyama S, Teraoka R, Mori H, Tomiyama T (2007) Inverse correlation between amyloid precursor protein and synaptic plasticity in transgenic mice. Neuroreport 18:1083-1087.

Maulik M, Westaway D, Jhamandas JH, Kar S (2013) Role of Cholesterol in APP Metabolism and Its Significance in AlzheimerГÇÖs Disease Pathogenesis. Mol Neurobiol 47:37-63.

McEwen B (2002) Estrogen actions throughout the brain. Recent Prog Horm Res 57:357-384.

McEwen BS, Akama KT, Spencer-Segal JL, Milner TA, Waters EM (2012) Estrogen effects on the brain: actions beyond the hypothalamus via novel mechanisms. Behav Neurosci 126:4-16.

McEwen BS, Gould E, Orchinik M, Weiland NG, Woolley CS (1995) Oestrogens and the structural and functional plasticity of neurons: implications for memory, ageing and neurodegenerative processes. Ciba Found Symp 191:52-66.

McEwen BS, Milner TA (2007) Hippocampal formation: shedding light on the influence of sex and stress on the brain. Brain Res Rev 55:343-355.

Mecocci P, MacGarvey U, Beal MF (1994) Oxidative damage to mitochondrial DNA is increased in Alzheimer's disease. Ann Neurol 36:747-751.

Mendelsohn ME, Karas RH (1999) The protective effects of estrogen on the cardiovascular system. N Engl J Med 340:1801-1811.

Merlo S, Sortino MA (2012) Estrogen activates matrix metalloproteinases-2 and -9 to increase beta amyloid degradation. Mol Cell Neurosci 49:423-429.

Merlo S, Spampinato SF, Capani F, Sortino MA (2016) Early beta-Amyloid-induced Synaptic Dysfunction Is Counteracted by Estrogen in Organotypic Hippocampal Cultures. Curr Alzheimer Res 13:631-640.

Milner TA, Ayoola K, Drake CT, Herrick SP, Tabori NE, McEwen BS, Warrier S, Alves SE (2005) Ultrastructural localization of estrogen receptor beta immunoreactivity in the rat hippocampal formation. J Comp Neurol 491:81-95.

Minino AM, Murphy SL, Xu J, Kochanek KD (2011) Deaths: final data for 2008. Natl Vital Stat Rep 59:1-126.

Mitra SW, Hoskin E, Yudkovitz J, Pear L, Wilkinson HA, Hayashi S, Pfaff DW, Ogawa S, Rohrer SP, Schaeffer JM, McEwen BS, Alves SE (2003) Immunolocalization of estrogen receptor beta in the mouse brain: comparison with estrogen receptor alpha. Endocrinology 144:2055-2067. 
Mitterling KL, Spencer JL, Dziedzic N, Shenoy S, McCarthy K, Waters EM, McEwen BS, Milner TA (2010) Cellular and subcellular localization of estrogen and progestin receptor immunoreactivities in the mouse hippocampus. J Comp Neurol 518:2729-2743.

Morris JC, Roe CM, Xiong C, Fagan AM, Goate AM, Holtzman DM, Mintun MA (2010) APOE predicts amyloid-beta but not tau Alzheimer pathology in cognitively normal aging. Ann Neurol 67:122-131.

Mosconi L, Pupi A, De Leon MJ (2008) Brain glucose hypometabolism and oxidative stress in preclinical Alzheimer's disease. Ann N Y Acad Sci 1147:180-195.

Moyer JR, Jr., Deyo RA, Disterhoft JF (1990) Hippocampectomy disrupts trace eyeblink conditioning in rabbits. Behav Neurosci 104:243-252.

Mufson EJ, Mahady L, Waters D, Counts SE, Perez SE, DeKosky ST, Ginsberg SD, Ikonomovic MD, Scheff SW, Binder LI (2015) Hippocampal plasticity during the progression of Alzheimer's disease. Neuroscience 309:51-67.

Mukai $\mathrm{H}$, Tsurugizawa T, Murakami G, Kominami S, Ishii H, Ogiue-Ikeda M, Takata N, Tanabe N, Furukawa A, Hojo Y, Ooishi Y, Morrison JH, Janssen WG, Rose JA, Chambon P, Kato S, Izumi S, Yamazaki T, Kimoto T, Kawato S (2007) Rapid modulation of long-term depression and spinogenesis via synaptic estrogen receptors in hippocampal principal neurons. J Neurochem 100:950-967.

Mukherjee A, Song E, Kihiko-Ehmann M, Goodman JP, Jr., Pyrek JS, Estus S, Hersh LB (2000) Insulysin hydrolyzes amyloid beta peptides to products that are neither neurotoxic nor deposit on amyloid plaques. J Neurosci 20:8745-8749.

Murakami G, Hojo Y, Ogiue-lkeda M, Mukai H, Chambon P, Nakajima K, Ooishi Y, Kimoto T, Kawato $S$ (2015) Estrogen receptor KO mice study on rapid modulation of spines and long-term depression in the hippocampus. Brain Res 1621:133-146.

Murphy E, Steenbergen C (2007) Gender-based differences in mechanisms of protection in myocardial ischemia-reperfusion injury. Cardiovasc Res 75:478-486.

Naaz A, Zakroczymski M, Heine P, Taylor J, Saunders P, Lubahn D, Cooke PS (2002) Effect of ovariectomy on adipose tissue of mice in the absence of estrogen receptor alpha (ERalpha): a potential role for estrogen receptor beta (ERbeta). Horm Metab Res 34:758-763.

Nelson ER, DuSell CD, Wang X, Howe MK, Evans G, Michalek RD, Umetani M, Rathmell JC, Khosla S, Gesty-Palmer D, McDonnell DP (2011) The oxysterol, 27hydroxycholesterol, links cholesterol metabolism to bone homeostasis through its actions on the estrogen and liver X receptors. Endocrinology 152:4691-4705.

Nelson ER, Wardell SE, Jasper JS, Park S, Suchindran S, Howe MK, Carver NJ, Pillai RV, Sullivan PM, Sondhi V, Umetani M, Geradts J, McDonnell DP (2013) 27 - 
Hydroxycholesterol links hypercholesterolemia and breast cancer pathophysiology. Science 342:1094-1098.

Nilsen J, Chen S, Irwin R, Iwamoto S, Brinton R (2006) Estrogen protects neuronal cells from amyloid beta-induced apoptosis via regulation of mitochondrial proteins and function. BMC Neuroscience 7:74.

Nilsson S, Makela S, Treuter E, Tujague M, Thomsen J, Andersson G, Enmark E, Pettersson K, Warner M, Gustafsson JA (2001) Mechanisms of estrogen action. Physiol Rev 81:1535-1565.

Nord LC, Sundqvist J, Andersson E, Fried G (2010) Analysis of oestrogen regulation of alpha-, beta- and gamma-secretase gene and protein expression in cultured human neuronal and glial cells. Neurodegener Dis 7:349-364.

Notkola IL, Sulkava R, Pekkanen J, Erkinjuntti T, Ehnholm C, Kivinen P, Tuomilehto J, Nissinen A (1998) Serum total cholesterol, apolipoprotein E epsilon 4 allele, and Alzheimer's disease. Neuroepidemiology 17:14-20.

O'Neill RA, et al. (2006) Isoelectric focusing technology quantifies protein signaling in 25 cells. Proc Natl Acad Sci U S A 103:16153-16158.

Oberlander JG, Woolley CS (2016) 17beta-Estradiol Acutely Potentiates Glutamatergic Synaptic Transmission in the Hippocampus through Distinct Mechanisms in Males and Females. J Neurosci 36:2677-2690.

Ong WY, Tanaka K, Dawe GS, Ittner LM, Farooqui AA (2013) Slow Excitotoxicity in Alzheimer's Disease. Journal of Alzheimer's Disease 35:643-668.

Padurariu M, Ciobica A, Mavroudis I, Fotiou D, Baloyannis S (2012) Hippocampal neuronal loss in the CA1 and CA3 areas of Alzheimer's disease patients. Psychiatr Danub 24:152-158.

Panza F, Frisardi V, Capurso C, Imbimbo BP, Vendemiale G, Santamato A, D'Onofrio G, Seripa D, Sancarlo D, Pilotto A, Solfrizzi V (2010) Metabolic syndrome and cognitive impairment: current epidemiology and possible underlying mechanisms. J Alzheimers Dis 21:691-724.

Pappolla MA, Bryant-Thomas TK, Herbert D, Pacheco J, Fabra GM, Manjon M, Girones X, Henry TL, Matsubara E, Zambon D, Wolozin B, Sano M, Cruz-Sanchez FF, Thal LJ, Petanceska SS, Refolo LM (2003) Mild hypercholesterolemia is an early risk factor for the development of Alzheimer amyloid pathology. Neurology 61:199-205.

Peters A, Folger Sethares C (2014) The fine structure of the aging brain.

Pfrieger FW (2003) Cholesterol homeostasis and function in neurons of the central nervous system. Cell Mol Life Sci 60:1158-1171. 
Phan A, Gabor CS, Favaro KJ, Kaschack S, Armstrong JN, MacLusky NJ, Choleris E (2012) Low doses of 17beta-estradiol rapidly improve learning and increase hippocampal dendritic spines. Neuropsychopharmacology 37:2299-2309.

Phan A, Lancaster KE, Armstrong JN, MacLusky NJ, Choleris E (2011) Rapid effects of estrogen receptor alpha and beta selective agonists on learning and dendritic spines in female mice. Endocrinology 152:1492-1502.

Phinney AL, Calhoun ME, Wolfer DP, Lipp HP, Zheng H, Jucker M (1999) No hippocampal neuron or synaptic bouton loss in learning-impaired aged beta-amyloid precursor protein-null mice. Neuroscience 90:1207-1216.

Porayette P, Gallego MJ, Kaltcheva MM, Bowen RL, Vadakkadath MS, Atwood CS (2009) Differential processing of amyloid-beta precursor protein directs human embryonic stem cell proliferation and differentiation into neuronal precursor cells. J Biol Chem 284:23806-23817.

Posse de Chaves E (2012) Reciprocal regulation of cholesterol and beta amyloid at the subcellular level in AlzheimerГÇÖs disease. Can J Physiol Pharmacol 90:753-764.

Prasad K, Kalra J (1993) Oxygen free radicals and hypercholesterolemic atherosclerosis: effect of vitamin E. Am Heart J 125:958-973.

Prasanthi JR, Dasari B, Marwarha G, Larson T, Chen X, Geiger JD, Ghribi O (2010) Caffeine protects against oxidative stress and Alzheimer's disease-like pathology in rabbit hippocampus induced by cholesterol-enriched diet. Free Radic Biol Med 49:12121220.

Priller C, Bauer T, Mitteregger G, Krebs B, Kretzschmar HA, Herms J (2006) Synapse formation and function is modulated by the amyloid precursor protein. $J$ Neurosci 26:7212-7221.

Puglielli L, Konopka G, Pack-Chung E, Ingano LA, Berezovska O, Hyman BT, Chang TY, Tanzi RE, Kovacs DM (2001) Acyl-coenzyme A: cholesterol acyltransferase modulates the generation of the amyloid beta-peptide. Nat Cell Biol 3:905-912.

Qu J, Liu W, Huang C, Xu C, Du G, Gu A, Wang X (2014) Estrogen receptors are involved in polychlorinated biphenyl-induced apoptosis on mouse spermatocyte GC-2 cell line. Toxicol In Vitro 28:373-380.

Radhakrishnan A, Ikeda Y, Kwon HJ, Brown MS, Goldstein JL (2007) Sterol-regulated transport of SREBPs from endoplasmic reticulum to Golgi: oxysterols block transport by binding to Insig. Proc Natl Acad Sci U S A 104:6511-6518.

Rasgon NL, Geist CL, Kenna HA, Wroolie TE, Williams KE, Silverman DH (2014a) Prospective randomized trial to assess effects of continuing hormone therapy on cerebral function in postmenopausal women at risk for dementia. PLoS ONE 9:e89095. 
Rasgon NL, Kenna HA, Wroolie TE, Williams KE, DeMuth BN, Silverman DH (2014b) Insulin resistance and medial prefrontal gyrus metabolism in women receiving hormone therapy. Psychiatry Res 223:28-36.

Reddy PH (2009) Amyloid beta, mitochondrial structural and functional dynamics in Alzheimer's disease. Experimental Neurology 218:286-292.

Regitz-Zagrosek V, Seeland U (2012) Sex and gender differences in clinical medicine. Handb Exp Pharmacol3-22.

Reiman EM, Chen K, Liu X, Bandy D, Yu M, Lee W, Ayutyanont N, Keppler J, Reeder SA, Langbaum JB, Alexander GE, Klunk WE, Mathis CA, Price JC, Aizenstein HJ, DeKosky ST, Caselli RJ (2009) Fibrillar amyloid-beta burden in cognitively normal people at 3 levels of genetic risk for Alzheimer's disease. Proc Natl Acad Sci U S A 106:6820-6825.

Repa JJ, Turley SD, Lobaccaro JA, Medina J, Li L, Lustig K, Shan B, Heyman RA, Dietschy JM, Mangelsdorf DJ (2000) Regulation of absorption and ABC1-mediated efflux of cholesterol by RXR heterodimers. Science 289:1524-1529.

Resnick SM, Maki PM, Rapp SR, Espeland MA, Brunner R, Coker LH, Granek IA, Hogan P, Ockene JK, Shumaker SA (2006) Effects of combination estrogen plus progestin hormone treatment on cognition and affect. J Clin Endocrinol Metab 91:18021810.

Rettberg JR, Yao J, Brinton RD (2014) Estrogen: a master regulator of bioenergetic systems in the brain and body. Front Neuroendocrinol 35:8-30.

Rhodes ME, Frye CA (2006) ERbeta-selective SERMs produce mnemonic-enhancing effects in the inhibitory avoidance and water maze tasks. Neurobiol Learn Mem 85:183191.

Richner M, Bach G, West MJ (2009) Over expression of amyloid beta-protein reduces the number of neurons in the striatum of APPswe/PS1DeltaE9. Brain Res 1266:87-92.

Riedel BC, Thompson PM, Brinton RD (2016) Age, APOE and sex: Triad of risk of Alzheimer's disease. J Steroid Biochem Mol Biol 160:134-147.

Rissman EF, Heck AL, Leonard JE, Shupnik MA, Gustafsson JA (2002) Disruption of estrogen receptor beta gene impairs spatial learning in female mice. Proc Natl Acad Sci U S A 99:3996-4001.

Rocca WA, Bower JH, Maraganore DM, Ahlskog JE, Grossardt BR, de AM, Melton LJ, III (2007) Increased risk of cognitive impairment or dementia in women who underwent oophorectomy before menopause. Neurology 69:1074-1083. 
Rocca WA, Bower JH, Maraganore DM, Ahlskog JE, Grossardt BR, de AM, Melton LJ, III (2008) Increased risk of parkinsonism in women who underwent oophorectomy before menopause. Neurology 70:200-209.

Rocca WA, Grossardt BR, Shuster LT (2011) Oophorectomy, menopause, estrogen treatment, and cognitive aging: clinical evidence for a window of opportunity. Brain Res 1379:188-198.

Rune GM, Frotscher M (2005) Neurosteroid synthesis in the hippocampus: role in synaptic plasticity. Neuroscience 136:833-842.

Russell DW, Halford RW, Ramirez DM, Shah R, Kotti T (2009) Cholesterol 24hydroxylase: an enzyme of cholesterol turnover in the brain. Annu Rev Biochem 78:1017-1040.

Salloway S, Gur T, Berzin T, Tavares R, Zipser B, Correia S, Hovanesian V, Fallon J, Kuo-Leblanc V, Glass D, Hulette C, Rosenberg C, Vitek M, Stopa E (2002) Effect of APOE genotype on microvascular basement membrane in Alzheimer's disease. J Neurol Sci 203-204:183-187.

Sano M, Bell KL, Galasko D, Galvin JE, Thomas RG, van Dyck CH, Aisen PS (2011) A randomized, double-blind, placebo-controlled trial of simvastatin to treat Alzheimer disease. Neurology 77:556-563.

Santilli F, Bucciarelli L, Noto D, Cefalu AB, Davi V, Ferrante E, Pettinella C, Averna MR, Ciabattoni G, Davi G (2007) Decreased plasma soluble RAGE in patients with hypercholesterolemia: effects of statins. Free Radic Biol Med 43:1255-1262.

Savaskan E, Olivieri G, Meier F, Ravid R, Muller-Spahn F (2001) Hippocampal estrogen beta-receptor immunoreactivity is increased in Alzheimer's disease. Brain Res 908:113119.

Scharfman HE, MacLusky NJ (2006a) Estrogen and brain-derived neurotrophic factor (BDNF) in hippocampus: complexity of steroid hormone-growth factor interactions in the adult CNS. Front Neuroendocrinol 27:415-435.

Scharfman HE, MacLusky NJ (2006b) The influence of gonadal hormones on neuronal excitability, seizures, and epilepsy in the female. Epilepsia 47:1423-1440.

Scharfman HE, Mercurio TC, Goodman JH, Wilson MA, MacLusky NJ (2003) Hippocampal excitability increases during the estrous cycle in the rat: a potential role for brain-derived neurotrophic factor. J Neurosci 23:11641-11652.

Scheff SW, Ansari MA, Mufson EJ (2016) Oxidative stress and hippocampal synaptic protein levels in elderly cognitively intact individuals with Alzheimer's disease pathology. Neurobiol Aging 42:1-12. 
Scheff SW, Price DA, Ansari MA, Roberts KN, Schmitt FA, Ikonomovic MD, Mufson EJ (2015) Synaptic change in the posterior cingulate gyrus in the progression of Alzheimer's disease. J Alzheimers Dis 43:1073-1090.

Scheff SW, Price DA, Schmitt FA, DeKosky ST, Mufson EJ (2007) Synaptic alterations in CA1 in mild Alzheimer disease and mild cognitive impairment. Neurology 68:15011508.

Scheff SW, Price DA, Schmitt FA, Mufson EJ (2006) Hippocampal synaptic loss in early Alzheimer's disease and mild cognitive impairment. Neurobiology of Aging 27:13721384.

Schioth HB, Craft S, Brooks SJ, Frey WH, Benedict C (2012a) Brain insulin signaling and Alzheimer's disease: current evidence and future directions. Mol Neurobiol 46:4-10.

Schioth HB, Frey WH, Brooks SJ, Benedict C (2012b) Insulin to treat Alzheimer's disease: just follow your nose? Expert Rev Clin Pharmacol 5:17-20.

Schmued LC, Stowers CC, Scallet AC, Xu L (2005) Fluoro-Jade C results in ultra high resolution and contrast labeling of degenerating neurons. Brain Res 1035:24-31.

Schneider JA, Arvanitakis Z, Bang W, Bennett DA (2007) Mixed brain pathologies account for most dementia cases in community-dwelling older persons. Neurology 69:2197-2204.

Schneider JA, Arvanitakis Z, Leurgans SE, Bennett DA (2009) The neuropathology of probable Alzheimer disease and mild cognitive impairment. Ann Neurol 66:200-208.

Schreurs BG (2003) Classical conditioning and modification of the rabbit's (Oryctolagus cuniculus) unconditioned nictitating membrane response. Behav Cogn Neurosci Rev 2:83-96.

Schreurs BG (2013) Cholesterol and Copper Affect Learning and Memory in the Rabbit. Int J Alzheimers Dis 2013:518780.

Schreurs BG, Smith-Bell CA, Darwish DS, Stankovic G, Sparks DL (2007a) Classical conditioning of the rabbit's nictitating membrane response is a function of the duration of dietary cholesterol. Nutr Neurosci 10:159-168.

Schreurs BG, Smith-Bell CA, Darwish DS, Stankovic G, Sparks DL (2007b) High dietary cholesterol facilitates classical conditioning of the rabbit's nictitating membrane response. Nutr Neurosci 10:31-43.

Schreurs BG, Smith-Bell CA, Lemieux SK (2013a) Dietary cholesterol increases ventricular volume and narrows cerebrovascular diameter in a rabbit model of Alzheimer's disease. Neuroscience 254:61-69. 
Schreurs BG, Smith-Bell CA, Wang D, Burhans LB (2013b) Dietary cholesterol degrades rabbit long term memory for discrimination learning but facilitates acquisition of discrimination reversal. Neurobiology of Learning and Memory 106:238-245.

Schreurs BG, Sparks DL (2015) Dietary high cholesterol and trace metals in the drinking water increase levels of $A B C A 1$ in the rabbit hippocampus and temporal cortex. J Alzheimers Dis 49:201-209.

Schreurs BG, Wang D, Smith-Bell CA, Burhans LB, Bell R, Gonzalez-Joekes J (2012) Dietary Cholesterol Concentration and Duration Degrade Long-Term Memory of Classical Conditioning of the Rabbit's Nictitating Membrane Response. Int J Alzheimers Dis 2012:732634.

Selkoe DJ (2001) Clearing the brain's amyloid cobwebs. Neuron 32:177-180.

Serneels L, et al. (2009) gamma-Secretase heterogeneity in the Aph1 subunit: relevance for Alzheimer's disease. Science 324:639-642.

Sherrington R, et al. (1996) Alzheimer's disease associated with mutations in presenilin 2 is rare and variably penetrant. Hum Mol Genet 5:985-988.

Sherrington R, et al. (1995) Cloning of a gene bearing missense mutations in earlyonset familial Alzheimer's disease. Nature 375:754-760.

Sherwin BB (2009) Estrogen therapy: is time of initiation critical for neuroprotection? Nat Rev Endocrinol 5:620-627.

Sherwin BB, Chertkow H, Schipper H, Nasreddine Z (2011) A randomized controlled trial of estrogen treatment in men with mild cognitive impairment. Neurobiol Aging 32:1808-1817.

Shumaker SA, Legault C, Kuller L, Rapp SR, Thal L, Lane DS, Fillit H, Stefanick ML, Hendrix SL, Lewis CE, Masaki K, Coker LH (2004) Conjugated equine estrogens and incidence of probable dementia and mild cognitive impairment in postmenopausal women: Women's Health Initiative Memory Study. JAMA 291:2947-2958.

Sierra A, Gottfried-Blackmore A, Milner TA, McEwen BS, Bulloch K (2008) Steroid hormone receptor expression and function in microglia. Glia 56:659-674.

Simpkins JW, Yang SH, Sarkar SN, Pearce V (2008) Estrogen actions on mitochondria-physiological and pathological implications. Mol Cell Endocrinol 290:51-59.

Simpkins JW, Yi KD, Yang SH, Dykens JA (2010) Mitochondrial mechanisms of estrogen neuroprotection. Biochimica et Biophysica Acta (BBA) - General Subjects 1800:1113-1120. 
Singh-Manoux A, Kivimaki M, Glymour MM, Elbaz A, Berr C, Ebmeier KP, Ferrie JE, Dugravot A (2012) Timing of onset of cognitive decline: results from Whitehall II prospective cohort study. BMJ 344:d7622.

Smith CC, McMahon LL (2006) Estradiol-induced increase in the magnitude of longterm potentiation is prevented by blocking NR2B-containing receptors. J Neurosci 26:8517-8522.

Solomon A, Kareholt I, Ngandu T, Wolozin B, Macdonald SW, Winblad B, Nissinen A, Tuomilehto J, Soininen H, Kivipelto M (2009a) Serum total cholesterol, statins and cognition in non-demented elderly. Neurobiol Aging 30:1006-1009.

Solomon A, Kivipelto M, Wolozin B, Zhou J, Whitmer RA (2009b) Midlife serum cholesterol and increased risk of Alzheimer's and vascular dementia three decades later. Dement Geriatr Cogn Disord 28:75-80.

Solomon PR, Solomon SD, Schaaf EV, Perry HE (1983) Altered activity in the hippocampus is more detrimental to classical conditioning than removing the structure. Science 220:329-331.

Spampinato SF, Merlo S, Molinaro G, Battaglia G, Bruno V, Nicoletti F, Sortino MA (2012a) Dual effect of 17beta-estradiol on NMDA-induced neuronal death: involvement of metabotropic glutamate receptor 1. Endocrinology 153:5940-5948.

Spampinato SF, Molinaro G, Merlo S, lacovelli L, Caraci F, Battaglia G, Nicoletti F, Bruno V, Sortino MA (2012b) Estrogen receptors and type 1 metabotropic glutamate receptors are interdependent in protecting cortical neurons against beta-amyloid toxicity. Mol Pharmacol 81:12-20.

Sparks DL (1997) Dietary cholesterol induces Alzheimer-like beta-amyloid immunoreactivity in rabbit brain. Nutrition, metabolism and Cardiovascular Diseases 7:255-266.

Sparks DL (2008) The early and ongoing experience with the cholesterol-fed rabbit as a model of Alzheimer's disease: the old, the new and the pilot. J Alzheimers Dis 15:641656.

Sparks DL, Hunsaker JC, Scheff SW, Kryscio RJ, Henson JL, Markesbery WR (1990b) Cortical senile plaques in coronary artery disease, aging and Alzheimer's disease. Neurobiol Aging 11.

Sparks DL, Hunsaker JC, III, Scheff SW, Kryscio RJ, Henson JL, Markesbery WR (1990a) Cortical senile plaques in coronary artery disease, aging and Alzheimer's disease. Neurobiol Aging 11:601-607.

Sparks DL, Martins R, Martin T (2002) Cholesterol and cognition: rationale for the AD cholesterol-lowering treatment trial and sex-related Differences in beta-amyloid 
accumulation in the brains of spontaneously hypercholesterolemic Watanabe rabbits. Ann N Y Acad Sci 977:356-366.

Sparks DL, Scheff SW, Hunsaker JC, III, Liu H, Landers T, Gross DR (1994) Induction of Alzheimer-like beta-amyloid immunoreactivity in the brains of rabbits with dietary cholesterol. Exp Neurol 126:88-94.

Sparks DL, Schreurs BG (2003) Trace amounts of copper in water induce beta-amyloid plaques and learning deficits in a rabbit model of Alzheimer's disease. Proc Natl Acad Sci U S A 100:11065-11069.

Spencer JL, Waters EM, Milner TA, McEwen BS (2008a) Estrous cycle regulates activation of hippocampal Akt, LIM kinase, and neurotrophin receptors in C57BL/6 mice. Neuroscience 155:1106-1119.

Spencer JL, Waters EM, Romeo RD, Wood GE, Milner TA, McEwen BS (2008c) Uncovering the mechanisms of estrogen effects on hippocampal function. Front Neuroendocrinol 29:219-237.

Spencer JL, Waters EM, Romeo RD, Wood GE, Milner TA, McEwen BS (2008b) Uncovering the mechanisms of estrogen effects on hippocampal function. Front Neuroendocrinol 29:219-237.

Srivastava DP, Woolfrey KM, Jones KA, Shum CY, Lash LL, Swanson GT, Penzes P (2008) Rapid enhancement of two-step wiring plasticity by estrogen and NMDA receptor activity. Proc Natl Acad Sci U S A 105:14650-14655.

Srivastava DP, Woolfrey KM, Liu F, Brandon NJ, Penzes P (2010) Estrogen receptor ss activity modulates synaptic signaling and structure. J Neurosci 30:13454-13460.

Srivastava DP, Woolfrey KM, Penzes P (2013) Insights into rapid modulation of neuroplasticity by brain estrogens. Pharmacol Rev 65:1318-1350.

St George-Hyslop P, et al. (1992) Genetic evidence for a novel familial Alzheimer's disease locus on chromosome 14. Nat Genet 2:330-334.

St George-Hyslop PH, Tanzi RE, Polinsky RJ, Haines JL, Nee L, Watkins PC, Myers $\mathrm{RH}$, Feldman RG, Pollen D, Drachman D, . (1987) The genetic defect causing familial Alzheimer's disease maps on chromosome 21. Science 235:885-890.

Stavros JB (2013) Alterations of Mitochondria and Golgi Apparatus Are Related to Synaptic Pathology in Alzheimer's Disease.

Strassnig M, Ganguli M (2005) About a peculiar disease of the cerebral cortex: Alzheimer's original case revisited. Psychiatry (Edgmont ) 2:30-33.

Szymczak S, Kalita K, Jaworski J, Mioduszewska B, Savonenko A, Markowska A, Merchenthaler I, Kaczmarek L (2006) Increased estrogen receptor beta expression 
correlates with decreased spine formation in the rat hippocampus. Hippocampus 16:453-463.

Tabatadze N, Sato SM, Woolley CS (2014) Quantitative analysis of long-form aromatase mRNA in the male and female rat brain. PLoS ONE 9:e100628.

Tanzi RE, Bertram L (2005) Twenty years of the Alzheimer's disease amyloid hypothesis: a genetic perspective. Cell 120:545-555.

Terry RD, Masliah E, Salmon DP, Butters N, DeTeresa R, Hill R, Hansen LA, Katzman $R$ (1991) Physical basis of cognitive alterations in Alzheimer's disease: synapse loss is the major correlate of cognitive impairment. Ann Neurol 30:572-580.

Tomicek NJ, Lancaster TS, Korzick DH (2011) Increased estrogen receptor beta in adipose tissue is associated with increased intracellular and reduced circulating adiponectin protein levels in aged female rats. Gend Med 8:325-333.

Tuscher JJ, Luine V, Frankfurt M, Frick KM (2016) Estradiol-Mediated Spine Changes in the Dorsal Hippocampus and Medial Prefrontal Cortex of Ovariectomized Female Mice Depend on ERK and mTOR Activation in the Dorsal Hippocampus. J Neurosci 36:14831489.

Umeda T, Tomiyama T, Kitajima E, Idomoto T, Nomura S, Lambert MP, Klein WL, Mori $H$ (2012) Hypercholesterolemia accelerates intraneuronal accumulation of Amyloid beta oligomers resulting in memory impairment in Alzheimer's disease model mice. Life Sciences 91:1169-1176.

Umetani M, Domoto H, Gormley AK, Yuhanna IS, Cummins CL, Javitt NB, Korach KS, Shaul PW, Mangelsdorf DJ (2007) 27-Hydroxycholesterol is an endogenous SERM that inhibits the cardiovascular effects of estrogen. Nat Med 13:1185-1192.

Umetani M, Ghosh P, Ishikawa T, Umetani J, Ahmed M, Mineo C, Shaul PW (2014) The cholesterol metabolite 27-hydroxycholesterol promotes atherosclerosis via proinflammatory processes mediated by estrogen receptor alpha. Cell Metab 20:172182.

Umetani M, Shaul PW (2011) 27-Hydroxycholesterol: the first identified endogenous SERM. Trends Endocrinol Metab 22:130-135.

Ungar L, Altmann A, Greicius MD (2014) Apolipoprotein E, gender, and Alzheimer's disease: an overlooked, but potent and promising interaction. Brain Imaging Behav 8:262-273.

Vagelatos NT, Eslick GD (2013) Type 2 diabetes as a risk factor for Alzheimer's disease: the confounders, interactions, and neuropathology associated with this relationship. Epidemiol Rev 35:152-160. 
Van BC, Backhovens H, Cruts M, De WG, Bruyland M, Cras P, Martin JJ (1992) Mapping of a gene predisposing to early-onset Alzheimer's disease to chromosome 14q24.3. Nat Genet 2:335-339.

Vasudevan N, Kow LM, Pfaff DW (2001) Early membrane estrogenic effects required for full expression of slower genomic actions in a nerve cell line. Proc Natl Acad Sci U S A 98:12267-12271.

Vasudevan N, Pfaff DW (2007) Membrane-initiated actions of estrogens in neuroendocrinology: emerging principles. Endocr Rev 28:1-19.

Vasudevan N, Pfaff DW (2008) Non-genomic actions of estrogens and their interaction with genomic actions in the brain. Front Neuroendocrinol 29:238-257.

Vekrellis K, Ye Z, Qiu WQ, Walsh D, Hartley D, Chesneau V, Rosner MR, Selkoe DJ (2000) Neurons regulate extracellular levels of amyloid beta-protein via proteolysis by insulin-degrading enzyme. J Neurosci 20:1657-1665.

Verghese J, Kuslansky G, Katz MJ, Sliwinski M, Crystal HA, Buschke H, Lipton RB (2000) Cognitive performance in surgically menopausal women on estrogen. Neurology $55: 872-874$.

Viswanathan A, Rocca WA, Tzourio C (2009) Vascular risk factors and dementia: how to move forward? Neurology 72:368-374.

Wagner OI, Lifshitz J, Janmey PA, Linden M, McIntosh TK, Leterrier JF (2003)

Mechanisms of mitochondria-neurofilament interactions. J Neurosci 23:9046-9058.

Wallace DC (2005) A mitochondrial paradigm of metabolic and degenerative diseases, aging, and cancer: a dawn for evolutionary medicine. Annu Rev Genet 39:359-407.

Wang D, Schreurs BG (2010) Dietary cholesterol modulates the excitability of rabbit hippocampal CA1 pyramidal neurons. Neurosci Lett 479:327-331.

Wang JM, Irwin RW, Brinton RD (2006) Activation of estrogen receptor alpha increases and estrogen receptor beta decreases apolipoprotein $E$ expression in hippocampus in vitro and in vivo. Proc Natl Acad Sci U S A 103:16983-16988.

Waters EM, Mitterling K, Spencer JL, Mazid S, McEwen BS, Milner TA (2009) Estrogen receptor alpha and beta specific agonists regulate expression of synaptic proteins in rat hippocampus. Brain Res 1290:1-11.

Waters EM, Yildirim M, Janssen WG, Lou WY, McEwen BS, Morrison JH, Milner TA (2011) Estrogen and aging affect the synaptic distribution of estrogen receptor betaimmunoreactivity in the CA1 region of female rat hippocampus. Brain Res 1379:86-97. 
West MJ, Bach G, Soderman A, Jensen JL (2009) Synaptic contact number and size in stratum radiatum CA1 of APP/PS1DeltaE9 transgenic mice. Neurobiol Aging 30:17561776.

West R, Beeri MS, Schmeidler J, Hannigan CM, Angelo G, Grossman HT, Rosendorff C, Silverman JM (2008) Better memory functioning associated with higher total and lowdensity lipoprotein cholesterol levels in very elderly subjects without the apolipoprotein e4 allele. Am J Geriatr Psychiatry 16:781-785.

Whitmer RA, Gunderson EP, Barrett-Connor E, Quesenberry CP, Jr., Yaffe K (2005) Obesity in middle age and future risk of dementia: a 27 year longitudinal population based study. BMJ 330:1360.

Whitmer RA, Quesenberry CP, Zhou J, Yaffe K (2011) Timing of Hormone Therapy and Dementia: The Critical Window Theory Re-visited. Ann Neurol 69:163-169.

Williams JW, Plassman BL, Burke J, Benjamin S (2010) Preventing Alzheimer's disease and cognitive decline. Evid Rep Technol Assess (Full Rep)1-727.

Winter JN, Jefferson LS, Kimball SR (2011) ERK and Akt signaling pathways function through parallel mechanisms to promote mTORC1 signaling. Am J Physiol Cell Physiol 300:C1172-C1180.

Woodruff-Pak DS, Agelan A, Del Valle L (2007) A Rabbit Model of Alzheimer's Disease: Valid at Neuropathological, Cognitive, and Therapeutic Levels. Journal of Alzheimer's Disease 11:371-383.

Woolley CS (1999a) Effects of estrogen in the CNS. Curr Opin Neurobiol 9:349-354.

Woolley CS (1999b) Electrophysiological and cellular effects of estrogen on neuronal function. Crit Rev Neurobiol 13:1-20.

Woolley CS (2007) Acute effects of estrogen on neuronal physiology. Annu Rev Pharmacol Toxicol 47:657-680.

Woolley CS, McEwen BS (1992) Estradiol mediates fluctuation in hippocampal synapse density during the estrous cycle in the adult rat. J Neurosci 12:2549-2554.

Woolley CS, Weiland NG, McEwen BS, Schwartzkroin PA (1997) Estradiol increases the sensitivity of hippocampal CA1 pyramidal cells to NMDA receptor-mediated synaptic input: correlation with dendritic spine density. J Neurosci 17:1848-1859.

Wu Q, Ishikawa T, Sirianni R, Tang H, McDonald JG, Yuhanna IS, Thompson B, Girard L, Mineo C, Brekken RA, Umetani M, Euhus DM, Xie Y, Shaul PW (2013) 27Hydroxycholesterol promotes cell-autonomous, ER-positive breast cancer growth. Cell Rep 5:637-645. 
Yan SD, Zhu H, Zhu A, Golabek A, Du H, Roher A, Yu J, Soto C, Schmidt AM, Stern D, Kindy M (2000) Receptor-dependent cell stress and amyloid accumulation in systemic amyloidosis. Nat Med 6:643-651.

Yang SH, Liu R, Perez EJ, Wen Y, Stevens SM, Jr., Valencia T, Brun-Zinkernagel AM, Prokai L, Will Y, Dykens J, Koulen P, Simpkins JW (2004) Mitochondrial localization of estrogen receptor beta. Proc Natl Acad Sci U S A 101:4130-4135.

Yang SH, Sarkar SN, Liu R, Perez EJ, Wang X, Wen Y, Yan LJ, Simpkins JW (2009) Estrogen receptor beta as a mitochondrial vulnerability factor. J Biol Chem 284:95409548.

Yao J, Irwin R, Chen S, Hamilton R, Cadenas E, Brinton RD (2012) Ovarian hormone loss induces bioenergetic deficits and mitochondrial beta-amyloid. Neurobiol Aging 33:1507-1521.

Yao J, Irwin RW, Zhao L, Nilsen J, Hamilton RT, Brinton RD (2009) Mitochondrial bioenergetic deficit precedes Alzheimer's pathology in female mouse model of Alzheimer's disease. Proc Natl Acad Sci U S A 106:14670-14675.

Yao J, Brinton RD (2012) Estrogen Regulation of Mitochondrial Bioenergetics: Implications for Prevention of Alzheimer's Disease. In: Advances in Pharmacology Current State of Alzheimer's Disease Research and Therapeutics (Elias KMaM, ed), pp 327-371. Academic Press.

Yasojima K, Akiyama H, McGeer EG, McGeer PL (2001) Reduced neprilysin in high plaque areas of Alzheimer brain: a possible relationship to deficient degradation of betaamyloid peptide. Neurosci Lett 297:97-100.

Yue X, Lu M, Lancaster T, Cao P, Honda SI, Staufenbiel M, Harada N, Zhong Z, Shen Y, Li R (2005) Brain estrogen deficiency accelerates Amyloid beta plaque formation in an Alzheimer's disease animal model. Proceedings of the National Academy of Sciences of the United States of America 102:19198-19203.

Yuen GS, McEwen BS, Akama KT (2011) LIM kinase mediates estrogen action on the actin depolymerization factor Cofilin. Brain Res 1379:44-52.

Zambon D, Quintana M, Mata P, Alonso R, Benavent J, Cruz-Sanchez F, Gich J, Pocovi M, Civeira F, Capurro S, Bachman D, Sambamurti K, Nicholas J, Pappolla MA (2010) Higher incidence of mild cognitive impairment in familial hypercholesterolemia. Am J Med 123:267-274.

Zatta P, Zambenedetti P, Stella MP, Licastro F (2002) Astrocytosis, microgliosis, metallothionein-I-II and amyloid expression in high cholesterol-fed rabbits. J Alzheimers Dis 4:1-9. 
Zhang DD, Yu HL, Ma WW, Liu QR, Han J, Wang H, Xiao R (2015) 27-

Hydroxycholesterol contributes to disruptive effects on learning and memory by

modulating cholesterol metabolism in the rat brain. Neuroscience 300:163-173.

Zhang QG, Han D, Wang RM, Dong Y, Yang F, Vadlamudi RK, Brann DW (2011) C terminus of Hsc70-interacting protein (CHIP)-mediated degradation of hippocampal estrogen receptor-alpha and the critical period hypothesis of estrogen neuroprotection. Proc Natl Acad Sci U S A 108:E617-E624.

Zhao L, Mao Z, Woody SK, Brinton RD (2016) Sex differences in metabolic aging of the brain: insights into female susceptibility to Alzheimer's disease. Neurobiol Aging 42:6979.

Zhao L, Yao J, Mao Z, Chen S, Wang Y, Brinton RD (2011) 17beta-Estradiol regulates insulin-degrading enzyme expression via an ERbeta/PI3-K pathway in hippocampus: relevance to Alzheimer's prevention. Neurobiol Aging 32:1949-1963.

Zhao L, Mao Z, Chen S, Schneider LS, Brinton RD (2013) Early Intervention with an Estrogen Receptor beta-Selective Phytoestrogenic Formulation Prolongs Survival, Improves Spatial Recognition Memory, and Slows Progression of Amyloid Pathology in a Female Mouse Model of Alzheimer's Disease. J Alzheimers Dis 37:403-419.

Zheng H, Xu H, Uljon SN, Gross R, Hardy K, Gaynor J, Lafrancois J, Simpkins J, Refolo LM, Petanceska S, Wang R, Duff K (2002) Modulation of A(beta) peptides by estrogen in mouse models. J Neurochem 80:191-196.

Zhu L, Brown WC, Cai Q, Krust A, Chambon P, McGuinness OP, Stafford JM (2013) Estrogen treatment after ovariectomy protects against fatty liver and may improve pathway-selective insulin resistance. Diabetes 62:424-434.

Zipser BD, Johanson CE, Gonzalez L, Berzin TM, Tavares R, Hulette CM, Vitek MP, Hovanesian V, Stopa EG (2007) Microvascular injury and blood-brain barrier leakage in Alzheimer's disease. Neurobiol Aging 28:977-986.

Znamensky V, Akama KT, McEwen BS, Milner TA (2003) Estrogen levels regulate the subcellular distribution of phosphorylated Akt in hippocampal CA1 dendrites. J Neurosci 23:2340-2347.

Zuliani G, Donnorso MP, Bosi C, Passaro A, Dalla NE, Zurlo A, Bonetti F, Mozzi AF, Cortese C (2011) Plasma 24S-hydroxycholesterol levels in elderly subjects with late onset Alzheimer's disease or vascular dementia: a case-control study. BMC Neurol $11: 121$. 